\title{
AN ANALYSIS OF THE IMPACT OF BIRTHING PRACTICES ON LONG-TERM HEALTH AND REPRODUCTIVE OUTCOMES FROM THE 1970 BRITISH COHORT STUDY: INSIGHTS FROM EVOLUTIONARY THEORY
}

\author{
By \\ Elizabeth Turner
}

\author{
A thesis \\ submitted in partial fulfillment \\ of the requirements for the degree of \\ Master of Arts in Anthropology \\ Boise State University
}

August 2018 
(C) 2018

Elizabeth Turner

ALL RIGHTS RESERVED 


\title{
DEFENSE COMMITTEE AND FINAL READING APPROVALS
}

\author{
of the thesis submitted by
}

\author{
Elizabeth Turner
}

Thesis Title: An Analysis of the Impact of Birthing Practices on Long-Term Health and Reproductive Outcomes from the 1970 British Cohort Study: Insights from Evolutionary Theory

Date of Final Oral Examination: 30 April 2018

The following individuals read and discussed the thesis submitted by student Elizabeth Turner, and they evaluated her presentation and response to questions during the final oral examination. They found that the student passed the final oral examination.

John P. Ziker, Ph.D.

Chair, Supervisory Committee

Kristin Snopkowski, Ph.D. Member, Supervisory Committee

Robert Graff, Ph.D.

Member, Supervisory Committee

The final reading approval of the thesis was granted by John P. Ziker, Ph.D., Chair of the Supervisory Committee. The thesis was approved by the Graduate College. 


\section{DEDICATION}

This thesis is dedicated to my husband, who has provided me with unending patience, encouragement, and for being my sounding board and rock, even when miles away. I also dedicate this work to my mother for her ceaseless support, confidence, and kindness during my lengthy dedication to academic pursuits. 


\section{ACKNOWLEDGEMENTS}

A sincere thank you to my committee members, Dr. John Ziker, Dr. Kristin Snopkowski, and Dr. Robert Graff, for taking time out of their busy schedules to offer their expertise and guidance. Particularly, I would like to convey my appreciation to my advisor and committee chair, Dr. John Ziker, for the direction, feedback, and support he has provided throughout the various stages of my research and my graduate studies. I would also like convey my gratitude to Dr. Kristin Snopkowski for her statistical guidance and expertise, as well as her unending encouragement. Additionally, I would like to acknowledge the UK Data Service and Data Archive for access to the data for the 1970 British Cohort Study. Final thanks go to my family and friends for their love and understanding through this process. Without the support of so many individuals, this thesis would not have been possible. 


\begin{abstract}
A wealth of research has been amassed and continues to grow through efforts to understand the complex nature of the relationship between the colonization and development of the human gut microbiota, its influence on the development of the immune system, and its role in both health and disease. Since previous research has demonstrated early life conditions can influence the colonization and development of the human gut microbiota, it is critical to understand how circumstances around the birthing process affect long-term outcomes beginning at this crucial stage in our development. Using the 1970 British Cohort Study, this thesis examines the relationship between birthing conditions and the outcomes of overall health, mental health, and reproduction using the evolutionary framework of life history theory through backwards stepwise regression analyses. Results indicated being born at home or use of maternal pain relief during labor resulted in a lower occurrence of infections and childhood diseases. As well, being born at home, having an assisted vaginal delivery, or use of maternal pain relief during labor resulted in a decrease in the likelihood of respiratory issues. Contrary to expectation, elective cesarean delivery predicted a lower likelihood of developing respiratory issues in this birth cohort and requires future research. Use of maternal anesthetics during labor resulted in a greater occurrence of digestive issues. Interestingly, being born at home with a medical practitioner and being born in a medical facility with a medical practitioner both correlated with an earlier age of menarche. Being born at home


was also found to correlate with a greater likelihood of a cohort member having a greater number of offspring themselves. Surprisingly, birthing conditions did not predict the likelihood of a cohort member developing depression in this study. From the results, there appears to be a connection between conditions that present an early life stress and negative health outcomes as well as an earlier age of menarche. These results are consistent with predictions from life history theory. The results also suggest that a reduction of stress for the birthing mother could present a reduction in early life stress for a fetus leading to a lower occurrence of immune dysfunction that translates to a decreased likelihood of respiratory issues and infections and childhood diseases. Additionally, the results for the reproduction outcome suggest that conditions representative of early life stress or extrinsic risk, whether that risk be increased exposure to pathogens or due to a more difficult birth, lead to an earlier age of menarche. While other research has concluded that cesarean section is detrimental for long-term health outcomes of the fetus, my findings demonstrate complex and multi-faceted relationships between early life conditions and long-term outcomes. By approaching future studies looking at birthing conditions and their relationship with long-term outcomes from a holistic perspective, a more comprehensive understanding of the role birthing conditions and surrounding circumstances have on overall health, mental health, and reproduction outcomes can be achieved. 
TABLE OF CONTENTS

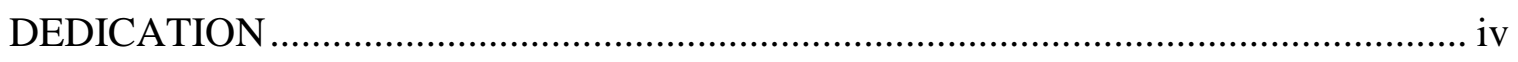

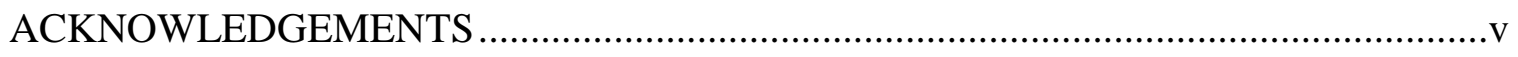

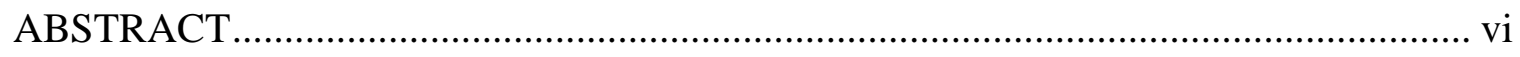

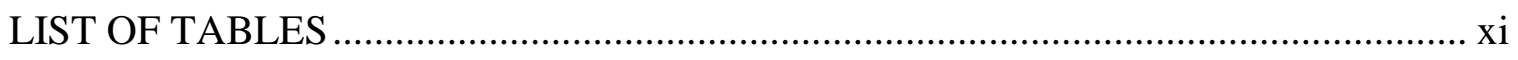

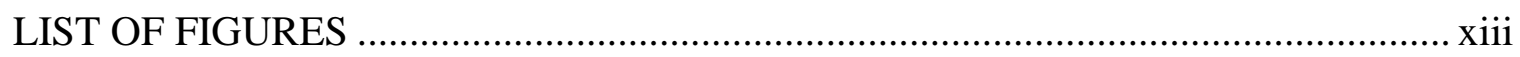

CHAPTER ONE: INTRODUCTION AND BACKGROUND ..........................................

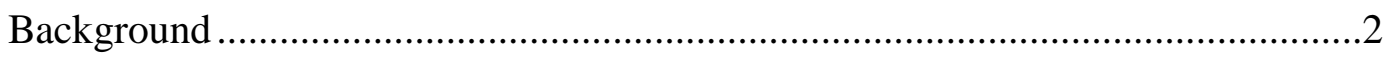

The Human Gut Microbiota: Development and Function ............................2

Connections between the Human Gut Microbiota, Overall Health, and Mental Health........................................................................................

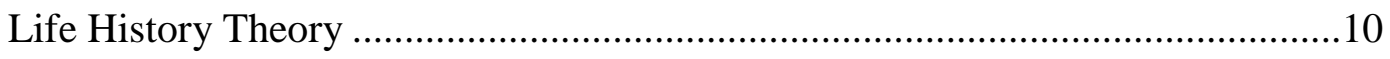

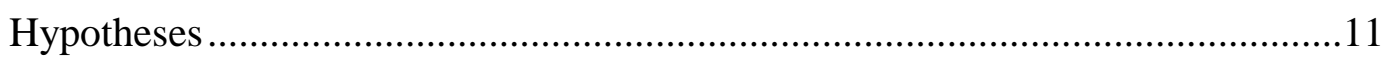

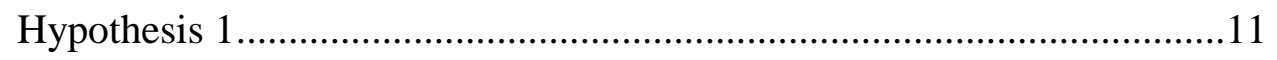

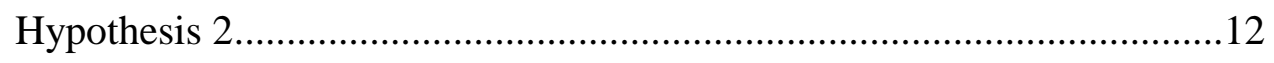

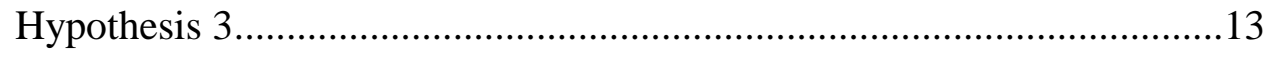

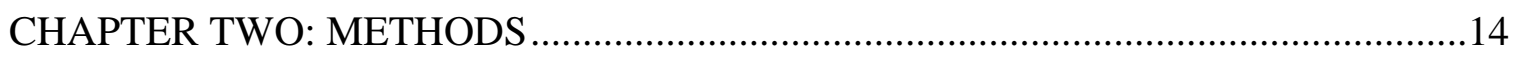

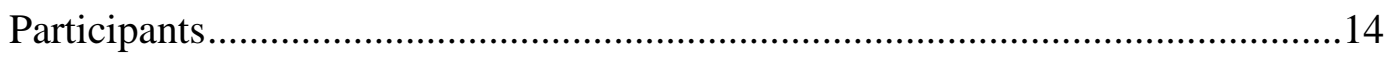

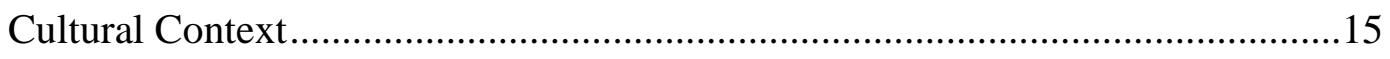

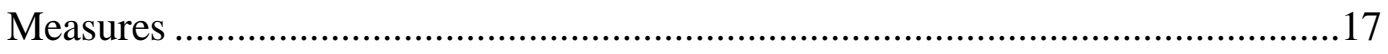

viii 
Independent Variables

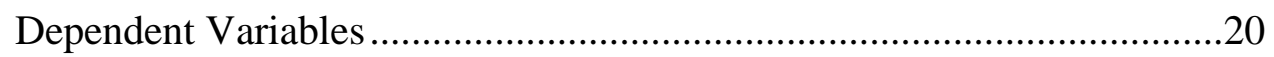

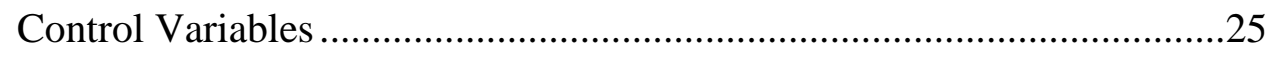

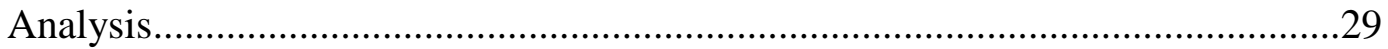

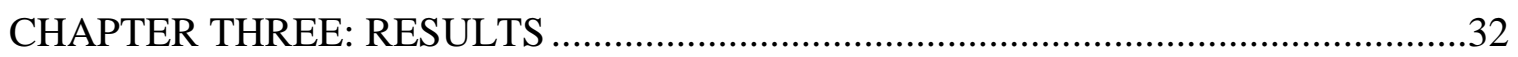

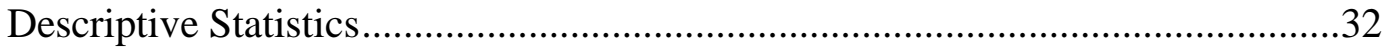

Descriptive Statistics Table...........................................................................

Overall Health Outcome - Hypothesis 1 ..............................................................37

Outcome 1A - Infections and Childhood Diseases ………………….........38

Outcome 1B - Allergy, Skin, and Joint Issues ..........................................40

Outcome 1C - Respiratory Issues ...........................................................42

Outcome 1D - Digestive Issues ...............................................................45

Reproduction Outcome - Hypothesis 2 ..........................................................48

Outcome 2A - Age of Menarche ……………………………..................48

Outcome 2B - Total number of offspring ...............................................51

Mental Health Outcome - Hypothesis 3 …………….........................................54

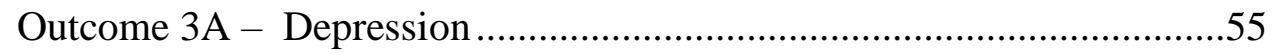

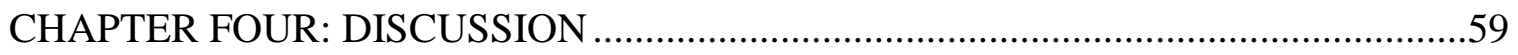

Overall Health Outcome - Hypothesis 1 ............................................................59

Outcome 1A - Infections and Childhood Diseases ....................................60

Outcome 1B - Allergies, Skin, and Joint Issues ........................................63

Outcome 1C - Respiratory Issues ...........................................................67 
Outcome 1D - Digestive Issues ....................................................74

Overall Health Outcome Conclusion ....................................................76

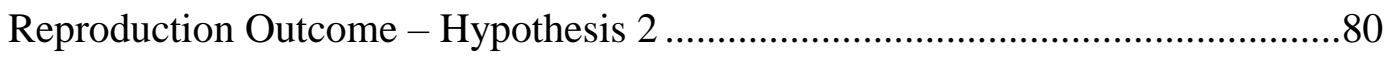

Outcome 2B -Total Number of Offspring .........................................81

Outcome 2A -Age of Menarche ..................................................... 85

Reproduction Outcome Conclusion.....................................................89

Mental Health Outcome - Hypothesis 3 .......................................................91

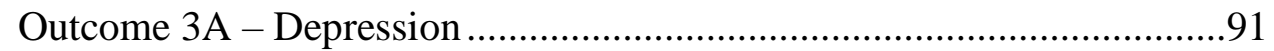

Mental Health Outcome Conclusion .................................................93

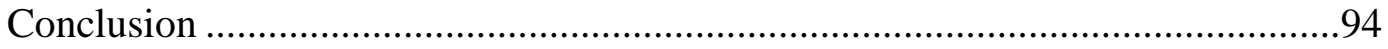

Limitations \& Future Research .......................................................96

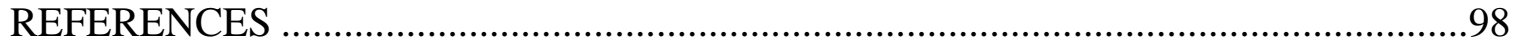

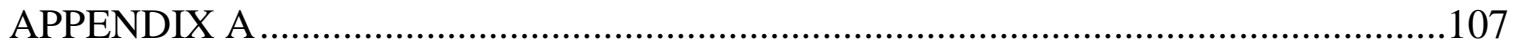




\section{LIST OF TABLES}

Table 1. Independent variables defining the birthing conditions included in analysis.

Table 2. The dependent variables for each of the outcomes included in analysis .. 24

Table 3. Control variables included in backwards stepwise regression to determine best model. 25

Table 4. Final models with their independent and dependent variables and the type of regression analysis performed. 30

Table 5. Descriptive statistics for independent, dependent, and control variables included in models. 34

Table 6. Outcome 1A linear regression statistical results for the dependent variable infections \& childhood diseases. 39

Table 7: $\quad$ Outcome 1B logistic regression statistical results for the dependent variable allergy, skin, and joint issues .

Table 8. Outcome 1C linear regression statistical results for the dependent variable respiratory issues. 44

Table 9: $\quad$ Outcome 1D logistic regression statistical results for the dependent variable digestive issues. 46

Table 10. Outcome 2A linear regression statistical results for the dependent variable age of menarche 49

Table 11. Outcome 2B linear regression statistical results for the dependent variable total number of offspring ..... 53

Table 12. Outcome 3A logistic regression statistical results for the dependent variable depression 56

Table A.1 Collinearity Statistics of Outcome 1A Infections and Childhood Diseases

Table A.2 Durbin-Watson for Independent Errors of Outcome 1A Infections and Childhood Diseases 109 
Table A.3 Linearity of the logit of Outcome 1B Allergy, Skin, and Joint Issues.... 113

Table A.4 Collinearity Statistics of Outcome 1B Allergy, Skin, and Joint Issues .. 114

Table A.5 Collinearity Statistics of Outcome 1C Respiratory Issues ..................... 115

Table A.6 Durbin-Watson for Independent Errors of Outcome 1C Respiratory Issues 116

Table A.7 Linearity of the logit of Outcome 1D Digestive Issues ....................... 120

Table A.8 Collinearity Statistics of Outcome 1D Digestive Issues ....................... 121

Table A.9 Collinearity Statistics of Outcome 2A Age of Menarche ...................... 122

Table A.10 Durbin-Watson for Independent Errors of Outcome 2A Age of Menarche

Table A.11 Collinearity Statistics of Outcome 2B Total Number of Offspring ........ 127

Table A.12 Durbin-Watson for Independent Errors of Outcome 2B Total Number of Offspring .............................................................................. 128

Table A.13 Linearity of the Logit of Outcome 3A Depression ............................... 132

Table A.14 Collinearity Statistics of Outcome 3A Depression .............................. 133 


\section{LIST OF FIGURES}

Figure 1. The recoded variable categories of place \& attendant at delivery for Outcome 2A plotted against persons per room ratio. ................................. 51

Figure A.1 Distribution of Residuals of Outcome 1A Infections and Childhood

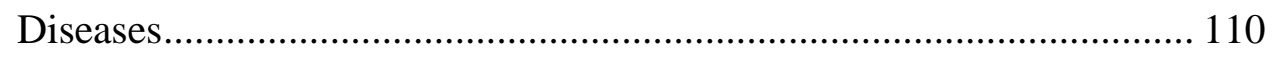

Figure A.2 P-P Plot of Outcome 1A Infections and Childhood Diseases.................. 111

Figure A.3 Plot of Outcome 1A Infections and Childhood Diseases........................ 112

Figure A.4 Distribution of Residuals of Outcome 1C Respiratory Issues ................ 117

Figure A.5 P-P Plot of Outcome 1C Respiratory Issues ......................................... 118

Figure A.6 Plot of Outcome 1C Respiratory Issues ............................................... 119

Figure A.7 Distribution of Residuals of Outcome 2A Age of Menarche ................. 124

Figure A.8 P-P Plot of Outcome 2A Age of Menarche ……................................... 125

Figure A.9 Plot of Outcome 2A Age of Menarche ……....................................... 126

Figure A.10 Normal Distribution of Outcome 2B Total Number of Offspring.......... 129

Figure A.11 P-P Plot of 2B Total Number of Offspring ........................................ 130

Figure A.12 Plot of Outcome 2B Total Number of Offspring ……........................... 131 


\section{CHAPTER ONE: INTRODUCTION AND BACKGROUND}

A growing body of research has enlightened our understanding of the dynamic, symbiotic community of microorganisms housed in our digestive tract, demonstrating strong connections between the composition of the human gut microbiota and its relationship to our health and the occurrence of disease. This research has drawn our attention to the likely importance of the initial inoculation of microbes at birth that lay the foundation for the establishment of our gut microbial composition and subsequent development of the immune system. Since early life influences can impact the colonization and development of the human gut microbiota, it is crucial to understand how birthing conditions impact health and disease.

Expanding interest in our microbiome has become a rich area of research, and what has come to be most understood about our microbiota is how complex the interactions and relationships are between the various species and their host, as well as the complexity of the roles of the microbiota in modulating health or disease (Conrad and Vlassov 2015, Kåhrström, Pariente, and Weiss 2016). While we continue to gain a deeper understanding of various aspects of the human gut microbiota, we are now in a position in which we can take a broader perspective that considers a combination of variables and how their concurrence can influence the colonization and development of the gut microbiota and long-term health. This thesis serves to expand the scope of this area of research, drawing on the vast body of research that has been and continues to be amassed while investigating the relationships between different variables to obtain a 
comprehensive perspective of how early life influences impact long-term health beginning at a crucial stage in our development. To do so, I examine how circumstances around the birthing process impact overall health using the 1970 British Cohort Study. Additionally, I investigate how digestive health mediates the relationship between the birthing process and mental health, as well as the relationship between the birthing process and future reproduction using the evolutionary theoretical framework of life history theory.

\section{Background}

\section{The Human Gut Microbiota: Development and Function}

The human gut microbiota, a complex population of microorganisms that line our digestive tract, has co-evolved with the human body and provides several important benefits including its role in a number of physiological processes (Guarner and Malagelada 2003; Foster, Rinaman, and Cryan 2017). According to the Human Microbiome Project, although only accounting for between $1 \%$ to $3 \%$ of our body mass, microorganisms are essential for maintaining our health as they perform a variety of important functions within the body (National Intitute of Health 2015). The primary functions of the human gut microbiota include metabolism of nutrients, synthesis of vitamins, aiding in the development of the immune system, and providing protection against invading pathogens (Guarner and Malagelada 2003).

In addition to its role in metabolism and vitamin synthesis and absorption, an important function of the gut microbiota is the development and regulation of the immune system. The main barrier between the immune system of the host and the external environment is the intestinal mucosa (Guarner and Malagelada 2003). The gut 
contains the largest number of immunocompetent cells in the body, and it is the interaction at this mucosal layer, between the host cells and gut bacteria, that helps the body develop a properly functioning, or competent, immune system. The colonization of microbes in the digestive track play an important role in this development as exposure to gut microbes results in an increase in the production of white blood cells that are involved in the immune system's response to invading pathogens. Therefore, the interaction between the host's digestive tract and its microbial community at an early age are essential for the development of a healthy immune system.

The gut microbiota is also involved in the body's protection against pathogens. The gut microbiota performs a protective function in the gut such that it aids in the resistance of colonization by invading pathogens or opportunistic bacteria (Guarner and Malagelada 2003). Mechanisms have evolved in order for the gut's native bacteria to outcompete invaders (Kamada et al. 2013). These mechanisms include the ability of the gut bacteria to produce toxins that prevent the colonization of other bacteria, along with the ability to out-compete invaders for limited nutrient resources. Gut bacteria are also able to alter the conditions of the host's digestive tract, including altering the $\mathrm{pH}$, making the environment inhospitable to invading pathogens. The ability of the microbiota to resist invading pathogens or other microbes is referred to as the barrier effect, and it is able to provide this barrier effect because there is a natural equilibrium which exists under normal conditions in the microbial community occupying our digestive tract (Guarner and Malagelada 2003). This protective function can become compromised when the natural equilibrium of our digestive system is disturbed, such as through the use of antibiotics. The gut microbiota is also involved with fighting off microbes that cause 
disease through its production of anti-inflammatory compounds (National Intitute of Health 2015). It is through these functions that this community of microorganisms play a vital role in our health and development. Therefore, understanding the contributing factors to the colonization of the gut microbiota is crucial because of its potential for significant, long term impacts on health (Azad et al. 2013).

Because of the increasing interest in understanding how our gut microbiota impacts health, research initiatives have targeted various factors related to the health, development, and impacts of this microbial composition. Research has targeted the mode through which initial inoculation of the gut microbes occur, connections between the composition of the gut microbiota and several diseases, as well as more recent research drawing connections between the composition of the gut microbiota and mental health. Early development of the gut microbiota is largely influenced by key factors that shape its normal composition and ability to perform its natural functions in the body (Jandhyala, Talukdar, and Subramanyam 2015). These principal factors include method of delivery, early infant diet, and exposure to antibiotics. Studies have shown that these factors, which shape the early development of the gut microbial composition, significantly influence the development of a healthy immune response, and this early development appears to be closely correlated to disease susceptibility (Fujimura et al. 2010).

While the uterus is not a sterile environment as it was once thought to be, it has been determined that the method of delivery during childbirth plays a substantial role in the initial acquisition of bacteria that will colonize the infant microbiota (Rautava et al. 2012; Azad et al. 2013). Babies receive an important inoculation of maternal microbes in passage through the birth canal during vaginal delivery, and studies have shown that 
cesarean delivery disrupts the colonization of the infant microbiota by preventing contact with maternal microbes in the birth canal (Azad et al. 2013). Rather than having an initial intestinal colonization pattern that resembles the bacteria taxa found in the birth canal, infants delivered by cesarean section were found to have initial colonization resembling the maternal skin microbiota (Dominguez-Bello et al. 2010). According to DominguezBello et al. (2010), the lack of exposure to vaginal bacteria in cesarean section delivered infants may, in part, provide an explanation for the increased susceptibility to particular pathogens compared to infants born by vaginal delivery. For these reasons, method of delivery has come under increasing scrutiny in recent years and sparked debate regarding the potential long-term impacts of practices such as cesarean section in the face of rising rates of elective cesarean deliveries worldwide.

Another principal means by which humans acquire bacteria that will shape the normal composition of the gut microbiota is through the early infant diet. Substantial differences have been observed in the microbial composition between infants who are breastfed compared to those who are formula-fed, with breastfed infants being exposed to over 700 species of bacteria found in the maternal milk microbiota (Jandhyala, Talukdar, and Subramanyam 2015; Rodríguez et al. 2015). Breastmilk is also known to contain beneficial complex oligosaccharides that function as a prebiotic and selectively promote the growth of certain types of bacteria which may be associated with increased digestive health (Albenberg and $\mathrm{Wu} 2014$ ). The gut microbiota will continue to be influenced through exposure to microbes from food and environmental sources and will come to a sort of equilibrium around the age of two to three years in which the microbiota profile 
will generally resemble that of an adult (Conrad and Vlassov 2015; Lozupone et al. 2012).

The third predominant factor that influences the early development of the microbiota is exposure to antibiotics. The early colonization of the gut microbiota is sensitive and susceptible to disturbances from external factors and antibiotic exposure can have a significant and lasting impact (Gibson, Crofts, and Dantas 2015). Exposure to antibiotics disrupts the normal composition of the microbiota by eliminating not only infectious pathogens but the beneficial bacteria as well (Jandhyala, Talukdar, and Subramanyam 2015). This poses an issue because, along with trying to restore the microbial composition of the gut from the antibiotic-induced disruption, microbes in the present environment along with opportunistic infections influence the re-colonization that will then differ from that of the original or developing microbiome. The factors influencing the initial colonization of the microbiota early in life are important to understand because it is relevant to the final composition of the gut microbiota in adults, and a well-established and maintained gut microbiota could result in a decrease in disease-risk across the lifespan (Guarner and Malagelada 2003; Rodríguez et al. 2015). According to Rodriquez, "[o]nce established, the composition of the gut microbiota is relatively stable throughout adult life, but can be altered as a result of bacterial infections, antibiotic treatment, lifestyle, surgical, and a long-term change in diet," and "[s]hifts in this complex microbial system have been reported to increase the risk of disease" (Rodríguez et al. 2015, 1). While the adult gut microbiota generally returns to its initial state after a period of time following a perturbation, significant alterations to the gut microbiota induced through, for instance, antibiotic disruption can persist from months to 
years and has the potential to shift gut flora composition to an alternative stable state (Francino 2015, Dethlefsen and Relman 2011). While antibiotic use is a critical factor in both the development and maintenance of the gut microbiota, due to the lack of available data in the 1970 British Cohort Study, antibiotic use was excluded as a variable in this study.

An additional variable that has a notable impact on the gut microbiota is the effect of stress and its ability to modify the composition and development of the gut microbiota. Research has demonstrated that exposure to stress can lead to changes in both the composition and diversity of the gut microbiota and that these stress-induced changes in the gut flora can have profound impacts on the immune response (Bailey et al. 2011). Stress can also increase gut permeability and allow bacteria to cross the intestine mucosal layer, activating an immune response and leading to alterations in the hypothalamic pituitary adrenal (HPA) axis which is responsible for the body's complex stress response system (Dinan and Cryan 2012). Research targeted at understanding the effects of maternal prenatal stress has demonstrated strong correlations with infant gut microbiota colonization pattern and health (Zijlmans et al. 2015). Research conducted on monkeys found that moderate maternal prenatal stress alters infant gut microbial profile and concentrations which could lead to enhanced susceptibility to infection (Bailey, Lubach, and Coe 2004). From this, it is evident that stress has a measurable effect on not only the composition and diversity of the gut microbiota but also that maternal prenatal stress has the potential to influence early programming of the human immune system and response to stress beginning in-utero. 
Connections between the Human Gut Microbiota, Overall Health, and Mental Health

Interactions between the human digestive tract and its microbiota have been shown to have important impacts on human health and the development of disease. Studies have demonstrated a correlation between deviations in an individual's gut microbiota from that of a healthy microbial composition, also referred to as a state of gut dysbiosis, and the occurrence of various disease states (Conrad and Vlassov 2015). Marked differences have been demonstrated between the microbial composition in healthy individuals and those with occurrences of, for example, intestinal related diseases (Kamada et al. 2013). Evidence also suggest that the occurrence of allergic diseases are associated with imbalances in the microbial composition of the digestive system (Melli et al. 2015). Studies looking at the association between allergies and gut microbiota have been investigating the initial development of the gut microbial system in infants and whether the surrounding factors that influence the initial colonization of the infant microbiota can predict the development of future allergies (Kozyrskyj 2015). Rodríguez et al. (2015) reports that additional links have been explored between gut dysbiosis and the development of asthma, obesity, diabetes mellitus type 2, and celiac disease. As well, cancer, autoimmune disorders such as rheumatoid arthritis, diabetes mellitus type 1, and multiple sclerosis, malnutrition, metabolic syndrome, cardiovascular disease, irritable bowel syndrome, and inflammatory bowel diseases such as Crohn's disease and ulcerative colitis have also been studied in conjunction with imbalances in the gut microbiota (Conrad and Vlassov 2015; Wu and Wu 2012; Miyake et al. 2015; Lozupone et al. 2012; Wang et al. 2017). In 2012, over 25 diseases, syndromes, or functional anomalies were thought to be linked with the composition of the gut microbiota (de Vos 
and de Vos 2012). As of 2015, that number has doubled and continues to grow, with the National Institute of Health (2015) asserting that an increasing number of studies are demonstrating that alterations or imbalances in our microbiome are being linked with continuously more disease states. With the growing number of connections demonstrated between gut composition and various diseases, directing our attention to factors impacting the foundation and development of the gut microbiota gains increasing importance.

Lastly, an emerging area of research explores the relationship between the human gut microbiota and mental health. The composition of the gut microbiota is an influential contributing factor to the complex communication network between the brain and gut, deemed the gut-brain axis (Moloney et al. 2014). The gut microbiota has, in fact, been referred to as "a key regulator of the gut-brain axis" (Foster, Rinaman, and Cryan 2017, 125). These gut-brain signaling pathways include the immune, endocrine, autonomic, and enteric nervous systems (Lach et al. 2018). The central role of the gut-brain axis in various mental health disorders is beginning to emerge, and these findings are of increasing importance with the World Health Organization finding depressive disorders to be the primary cause of global disability (Lopez and Murray 1998). Along with depression, other mental health disorders that are being linked to dysregulation of the gutbrain axis include mood disorders and stress-related psychiatric symptoms such as anxiety (Dinan and Cryan 2013). These conditions are also found to have a high comorbidity with gastrointestinal disorders, further demonstrating the link between the gut microbiota and mental health disorders via the gut microbiota-brain axis. 


\section{Life History Theory}

It is the goal of this thesis to examine the relationships between birthing practices, overall health, mental health, and future reproduction using life history theory. Natural selection should favor optimal trade-offs in the allocation of limited resources among competing demands in such a way that maximizes survival and reproduction (McDade 2003). Life history theory is an evolutionary theoretical framework for understanding this allocation of resources across somatic maintenance, growth, and reproduction that results in different life history trajectories according to relevant developmental and ecological conditions (Ellis et al. 2009). Since fitness cannot be simultaneously maximized across all three competing biological functions due to energetic constraints from limited resources, resource allocations are prioritized in various trade-offs. These trade-offs influence life history trajectories including whether to continue investing in growth versus investing in reproduction. A higher level of extrinsic risk influencing mortality earlier in life is associated with a faster life history trajectory, such that early life stress has been shown to influence the trade-offs between somatic effort and reproduction resulting in a faster life history trajectory with an earlier onset of reproduction (Nettle 2014; Hackman and Hruschka 2013; Walker et al. 2006). Disruptions to the initial inoculation and development of the immune system could result in damage to the soma, in which case modern technological birthing conditions, such as cesarean delivery, could be considered a form of early life stress.

While the initial colonization of the gut microbiota and its impact on the development of the immune system are critically important to survival, because the immune system comprises the body's defense system against invading pathogens and 
disease, this defense system can be energetically costly both to maintain and to utilize in the form of an immune response (McKean et al. 2008). The consequences are also costly if the immune system processes are misdirected such as in the case of autoimmunity (McDade 2003). Therefore, with increased negative detriments on health requiring a higher cost for immune system processes, either a slower life history trajectory with increased investment in immune system processes or a faster life history trajectory with resource expenditures diverted towards reproduction earlier could be advantageous. A trade-off favoring a faster life history trajectory could result in an earlier age of menarche, representing an increase in extrinsic risk. An earlier age of menarche could then potentially result in an increase in total number of offspring due to the trade-off between offspring quantity-quality and parental investment (Lawson 2011).

\section{Hypotheses}

To address my research question, what are the impacts of birthing conditions on (1) overall health, (2) mental health, and (3) future reproduction, I developed the following hypotheses:

\section{Hypothesis 1}

If modern technological birthing conditions influence the development of the immune system via the gut microbiota, then I expect to see higher rates of immune dysfunction. Modern technological birthing conditions might include a medical facility as the place of delivery, medical practitioner as a birthing attendant, and/or an assisted vaginal delivery or cesarean-section as the method of delivery.

(A) Infections and childhood diseases 
Prediction: If modern technological birthing conditions are a form of early life stress, then I predict I will find a correlation between technological birthing conditions and a higher rate of infections and childhood diseases. * Infections and childhood diseases may include measles, mumps, pertussis, German measles, glandular fever, chicken pox, meningitis, recurrent sore throat, recurrent ear infection, and pneumonia.

*Prediction also applies to Hypothesis 1 B-D with their respective outcomes.

(B) Allergy, skin, and joint issues

Allergy, skin, and joint issues may include allergies, allergy rhinitis, hay fever, eczema, other skin issues, arthritis, rheumatism or fibrosis, and joint or back pain.

(C) Respiratory issues

Respiratory issues may include asthma, wheezing, bronchitis, respiratory disease, and bronchiolitis or wheezy bronchitis.

(D) Digestive issues

Digestive issues may include recurrent stomach or abdominal issues, ulcer, gallstones, irritable bowel syndrome, ulcerative colitis, and Crohn's disease.

\section{$\underline{\text { Hypothesis } 2}$}

If there is a relationship between birthing conditions and future reproduction, then, in the presence of adequate nutrition, with increased detriments on health, I would expect to see life history speed up, such that there is:

(A) Earlier age of menarche

(B) Increase in total number of offspring** 
**Due to the unclear nature of capturing an accurate number of total pregnancies from the dataset, total number of genetically related offspring was used as a proxy in this study.

\section{Hypothesis 3}

If birthing conditions are linked to the development of the gut microbiota and there is a connection between digestive health and mental health, then I expect to see digestive health mediate the relationship between birthing conditions and depression. 


\section{CHAPTER TWO: METHODS}

In this chapter, I will be discussing the methods used to address my research question. I also include information on the dataset used in my analysis and the cultural context of the birth cohort. I discuss the independent, dependent, and control variables included in this study, as well as the statistical analyses performed on the models.

\section{Participants}

Through the UK Data Service, I obtained data for the 1970 British Cohort Study (1970 BCS) (Chamberlain and Chamberlain 2016). The 1970 BCS is a birth cohort study that includes 17,000 participants who were born in a single week in 1970 in England, Scotland, and Wales that were then traced longitudinally across eight sweeps, or surveys, at different ages, with the most recent sweep included in this study conducted in 2012 (Sullivan 2017). The 1970 BCS collected participant information on a wide array of variables including health, social and physical development, education, and economic circumstances from birth through adulthood. The dataset contains detailed information about participants' birth including information regarding the location, attendant, means of delivery, and use of interventions. Therefore, the 1970 BCS dataset provided the opportunity to examine links between participants' birthing conditions, defined as the circumstances surrounding the birthing process, and their overall health, reproduction, and mental health. 


\section{Cultural Context}

The historical context of the cohort study is 1970 Great Britain under the PostWar Consensus. High levels of social spending characterized the period, and the eventual budget cutbacks to the National Health Service had not yet taken place at the time of the participants' birth (Chantrill 2016). However, the United Kingdom experienced an economic crisis in 1974 resulting in eventual healthcare budget cuts beginning in the cohort's childhood (Kent-Smith 2017; Roberts 2016). The National Health Service is a system of universal health care in the United Kingdom providing universal healthcare and mental healthcare to all residents of the country free of charge (The Equality Trust 2017). The availability of free healthcare through the National Health Service was expected to ameliorate some of the class-based differences in overall health.

At the time of the cohort's birth in 1970, the dependence on coal and oil as energy sources heavily impacted air quality (National Statistics 2016). Over the course of the decade, coal use began to diminish with the rising use of alternative energy sources (Department for Business, Energy 2013). However, the combination of poor air quality and healthcare budget cuts likely negatively impacted the overall health of the birth cohort. From this, respiratory issues were expected to occur at a greater frequency.

Since the 1970s, emissions from major air pollutants substantially decreased in the United Kingdom. For instance, carbon monoxide emissions, which reduces blood capacity to carry oxygen around the body, decreased by $77 \%$ from 1970 to 2009 due to improved engine efficiency in the combustion of fuels (Randall 2001). The Control of Pollution Act enacted in 1974 sought to regulate composition of motor fuels (History of Air Pollution in the UK 2000). From 1971 to 2009, the mortality rate for diseases of the 
circulatory system decreased $70 \%$ in males and $71 \%$ in females (Sweet 2011). For the same time span, the mortality rate for respiratory diseases decreased over $60 \%$ in males and 39\% in females. As well, smoking among adults reportedly encompassed $45 \%$ of the population in 1972, with $51 \%$ of men and $41 \%$ of women who smoked (Office for National Statistics 2013). Comparatively, in 2011, smoking among adults decreased to $20 \%$ of the population.

The average life expectancy from birth in the United Kingdom is among the top $15 \%$ in the world with a population average life expectancy of 80.7 years (Central Intelligence Agency 2017). While life expectancy in the United Kingdom is on the rise, due to the improvement in life expectancy exceeding that of healthy life expectancy, the proportion of life spent in good health has declined (Office for National Statistics 2015). Non-communicable diseases, such as cardiovascular disease, respiratory disease, diabetes, cancer, digestive issues, and mental health conditions, are responsible for $86 \%$ of all deaths before the age of 75 annually (British Heart Foundation 2017). National guidelines for weekly alcohol intake are exceeded by a quarter of adults in the United Kingdom (British Heart Foundation 2017). According to the Global Burden of Disease study conducted in 2013, depression is the predominant global mental health problem and nearly half of adults in the United Kingdom believe they have had a diagnosable mental health problem in their lifetime, yet only a third have received a formal diagnosis (Mental Health Foundation 2016).

During the twentieth century, there was a notable transition in the birthing location and method of delivery in the United Kingdom. In 1927, giving birth at home was the norm in the United Kingdom, with only $15 \%$ of births occurring at medical 
facilities (Nove, Berrington, and Matthews 2008). In 1955, we see a marked decrease to only $33.4 \%$ of births taking place at home. The shift away from giving birth at home to giving birth in institutions continued between 1963 to 1974, with home births dropping from $30 \%$ to $4.2 \%$, respectively (Nove, Berrington, and Matthews 2008). With the increasing rates of deliveries occurring in medical facilities, the rates of cesarean deliveries were similarly on the rise. In 2001, more than 1 in 5 births in the United Kingdom were delivered by cesarean section, a substantial increase from $4 \%$ in the 1970 s to $21.5 \%$ (Dobson 2001). These statistics provide evidence towards an increasing medicalized approach to childbirth in the United Kingdom and with this transition a new set of variables are introduced into the equation of circumstances defining birthing conditions that could have important impacts on aspects of health, reproduction, and mental health outcomes.

\section{Measures}

\section{$\underline{\text { Independent Variables }}$}

To investigate the potential long-term health impacts of birthing conditions, the independent variables in this analysis included: (1) place of delivery, (2) birthing attendant, (3) how labor started, (4) means by which labor was induced, (5) method of delivery, (6) pain relief methods, and (7) use of anesthetics. By looking at who attended a cohort member's birth and where the birth took place, how birth began, delivery method, and interventions used to facilitate childbirth, I was able to define the conditions surrounding the birth of the cohort member to gain a larger perspective of potentially influential conditions and their impact on long-term outcomes. I have included all of these variables, however, since this is an exploratory analysis, I have no a priori 
predictions for the variables of maternal pain relief during labor and use of maternal anesthetics.

To prepare the dataset for statistical analysis, I transformed the data by recoding several variables and combining similar categories. The dataset included several variables with various types of birthing attendants, specified by occupation, and I collapsed these into a single binary variable for birthing attendant with the categories of midwife and medical practitioner; see Table 1 below for details regarding the recategorization of birthing attendant. I recoded the variable for pain relief during labor by combining three variables, including pain relief analgesics, pain relief drugs, and other pain relief methods, into a binary variable to denote the use of pain relief during labor. For the variables representing use of anesthetics during labor, I combined and recoded these into a binary variable. While the variables for how labor began and labor induction means were initially included as separate variables in the analysis, since these variables encompass similar information, I recoded them into a single variable representing whether labor began spontaneously or was induced and, if the latter, by what means of induction; the new variable is, hence forth, referred to as "labor induction means". Finally, due to concerns regarding the inclusion of two variables reflecting similar information about cesarean delivery, since those deliveries that began as a cesarean section also had an outcome of cesarean delivery, and its subsequent impact on the models, I collapsed the variables for method of delivery and labor induction means into a single variable. This new variable accounts for whether labor began spontaneously or was induced and its delivery method outcome. For details about the recoding of independent variables and how those variables were regrouped, see Table 1 (below). 
Table 1. Independent variables defining the birthing conditions included in analysis. Variables are organized by independent variable (left), variables utilized to create composite variable (right), and, if applicable, how variables were regrouped (center)

\begin{tabular}{|c|c|c|}
\hline $\begin{array}{l}\text { Independent } \\
\text { variables }\end{array}$ & $\begin{array}{l}\text { Categories within } \\
\text { variable }\end{array}$ & Variables collapsed into single variable \\
\hline \multirow[b]{2}{*}{ Place of Delivery } & At home & \\
\hline & $\begin{array}{l}\text { Medical } \\
\text { Facility }\end{array}$ & \\
\hline \multirow{7}{*}{ Birthing Attendant } & Midwife & $\begin{array}{l}\text { Delivery undertaken by } \\
\text { Domiciliary-Midwife } \\
\text { Delivery undertaken by Hospital } \\
\text { Midwife } \\
\text { Delivery undertaken by Pupil } \\
\text { Midwife }\end{array}$ \\
\hline & \multirow[t]{6}{*}{$\begin{array}{l}\text { Medical } \\
\text { Practitioner }\end{array}$} & $\begin{array}{l}\text { Delivery undertaken by Consult } \\
\text { Obstetrician }\end{array}$ \\
\hline & & Delivery undertaken by Registrar \\
\hline & & $\begin{array}{l}\text { Delivery undertaken by House } \\
\text { Officer }\end{array}$ \\
\hline & & Delivery undertaken by GP \\
\hline & & $\begin{array}{l}\text { Delivery undertaken by Medical } \\
\text { Student }\end{array}$ \\
\hline & & $\begin{array}{l}\text { Delivery undertaken by Hosp. } \\
\text { Doctor/Other }\end{array}$ \\
\hline $\begin{array}{l}\text { Method of } \\
\text { Delivery }\end{array}$ & $\begin{array}{l}\text { - Vaginal unassisted } \\
\text { delivery } \\
\text { - Vaginal assisted } \\
\text { delivery } \\
\text { - Labor induction } \\
\text { was spontaneous but } \\
\text { resulted in cesarean } \\
\text { delivery } \\
\text { - Labor started as } \\
\text { and resulted in } \\
\text { cesarean delivery }\end{array}$ & $\begin{array}{l}\text { How Labor Started } \\
\text { Labor Induction Means } \\
\text { Method of Delivery }\end{array}$ \\
\hline \multirow{3}{*}{$\begin{array}{l}\text { Pain Relief During } \\
\text { Labor }\end{array}$} & \multirow{3}{*}{ Binary (Y/N) } & $\begin{array}{l}\text { Pain relief during labor - } \\
\text { Analgesics }\end{array}$ \\
\hline & & Pain relief during labor - Drugs \\
\hline & & $\begin{array}{l}\text { Pain relief during labor - Other } \\
\text { methods }\end{array}$ \\
\hline \multirow{4}{*}{$\begin{array}{l}\text { Anesthetics during } \\
\text { labor }\end{array}$} & \multirow{4}{*}{ Binary $(\mathrm{Y} / \mathrm{N})$} & Anesthetics during labor (general) \\
\hline & & Anesthetics during labor (epidural) \\
\hline & & Anesthetics during labor (local) \\
\hline & & Anesthetics during labor (other) \\
\hline
\end{tabular}




\section{Dependent Variables}

The three outcomes assessed in this analysis included: (1) overall health, (2) reproduction, and (3) mental health. The outcome of overall health consisted of four categories: (1A) infections and childhood diseases; (1B) allergy, skin, and joint health; (1C) respiratory health; and (1D) digestive health. Next, the dependent variable for the reproduction outcome was (2A) age at menarche and (2B) total number of offspring. Lastly, the dependent variable for the mental health outcome was (3A) depression. The dependent variables were chosen based on their connections to each of the three outcomes. For the outcome of overall health, I included the four categories of variables, as previously outlined, as representative of overall health due to evidence from research of their underlying connections between birthing conditions and related health outcomes. Through the inoculation of gut microbes, the birthing conditions, particularly method of delivery, is linked with the development of the gut microbiota, which subsequently impacts the development of the immune system (Jandhyala, Talukdar, and Subramanyam 2015). Disruptions to the initial inoculation of healthy gut microbes can be correlated with higher rates of immune dysfunction as well as the development of digestive health issues (Guarner and Malagelada 2003; Conrad and Vlassov 2015). Research also indicates respiratory health issues occur at higher rates in infants born under birthing conditions involving cesarean delivery (Petrou and Khan 2013). By combining these four categories of variables, a measure of overall health was obtained, which allowed me to address my first hypothesis, namely, if modern technological birthing conditions influence the development of the immune system, then I expect to see higher a likelihood of health issues in all four outcome categories representative of overall health. For the 
reproduction outcome, due to theoretical trade-offs in life history theory with early life stress influencing trade-offs between somatic effort and reproduction resulting in a faster life history trajectory and an earlier onset of reproduction, I included the outcome variables of age of menarche and total number of offspring. By including these variables as measures of reproduction, this allowed me to address my second hypothesis, which proposed that, if the relationship between birthing conditions and future reproduction is mediated by health, then, with increased detriments on health, in the presence of adequate nutrition, I expected to see a faster life history with an earlier age of menarche and, due to an increase in the total number of potential reproductive years from an earlier age of menarche, an increase in total number of offspring. For the mental health outcome, due to connections between the gut microbiota and mental health through the pathway of the gut-brain axis, I included depression as a representative of mental health status. Including the variable depression allowed me to address my third hypothesis, which proposed that if there is a link between birthing conditions and the development of the gut microbiota and there is a connection between digestive health and mental health, then I expected to see digestive health mediate the relationship between birthing conditions and depression. Specifically, I expected to see a correlation between a greater number of digestive issues and an increase in the occurrence of depression. By including these variables, I was able to assess the relationships between the independent variables and the outcomes of overall health, reproduction, and mental health.

To determine the dependent variables included in the outcome for overall health, I reviewed the eight available survey sweeps, and those variables related to the health of the cohort member were included in the creation of a composite measure for each (1A) 
infections and childhood diseases, (1B) allergy, skin, and joint issues, (1C) respiratory issues, and (1D) digestive issues. I grouped variables representing recurrent infections and childhood diseases together as an indication of the cohort members' susceptibility to infections and diseases. Secondly, I grouped variables related to allergy, skin, and joint health together as an indication of the functioning of the cohort members' immune system as it relates to these specific issues. Since allergies, skin issues, joint issues, and the inflammatory response within the body all share a potential causal link with immune and autoimmune responses, I grouped these variables together to create a single composite variable related to overall immune function. While joint issues can result from excessive wear or strain on a joint, it is not possible to separate the causal nature of joint issues reported by cohort members. Likewise, it is not possible to determine the causal nature of reported skin issues and whether these reported issues were the result of an underlying inflammatory allergic response or due to other environmental cause such as contact dermatitis. Therefore, I included all variables related to joint and skin issues within this study in the composite allergy, skin, and joint issues variable. Thirdly, I grouped variables related to the health of the respiratory system together to create a single composite respiratory health variable to allow for the ability to explore how birthing conditions impact the development of respiratory issues in cohort members. Lastly, I grouped variables related to the health and development of the digestive system together, creating a single composite digestive health variable, to understand how birthing conditions impact the development and health of the digestive system.

To create these composite variables, first, I recoded longitudinal variables of similar health ailments, i.e. measles at 2 years old, measles at 5 years old, and measles at 
10 years old, into a single variable representative of a cohort member ever having said ailment. For each general health outcome category, I then created a composite measure as the proportion of reported ailments on a scale between 0 and 1 , with higher proportions representing a greater number of health ailments within each respective category. See Table 2 below for outcome variables and those variables included to create a composite measure, if applicable.

For the digestive health composite variable, the frequencies were bimodal, with cohort members generally having more digestive issues or generally having less digestive issues. Therefore, I created a binary digestive health composite variable to distinguish between those having less than $50 \%$ of the reported issues and those having greater than or equal to $50 \%$ of the reported digestive issues. As well, for the allergy, skin, and joint health composite variable, cohort members generally reported having more of these issues or they did not report having these issues. Therefore, I created a binary allergy, skin, and joint health composite variable representing whether cohort members had none of the reported issues or reported having allergy, skin, and joint issues.

Due to concerns with the model with respiratory issues as the dependent variable, I controlled for the total number of responses and excluded those with a response count less than $80 \%$. This was done to control for the potential overestimation of respiratory issues for cohort members missing response data for a large proportion of the issues included in the composite variable. For example, data on only one or two of the five categories included in the respiratory composite variable existed for a number of cohort members. Therefore, the proportions for these cohort members would be overestimated as having a greater proportion of respiratory issues. This issue is unique to the respiratory 
health variable where, for a majority of cohort members, data existed either for one or two of the variables or for all of the variables included in the respiratory composite variable.

Table 2. The dependent variables for each of the outcomes included in analysis. Variables are organized by outcome category (left), outcome composite measure (center), and variables, if any, used to create composite measure (right). *Variable represents total number of genetic offspring ever had at 42 years old, which is the most recent available survey year.

\begin{tabular}{|c|c|c|}
\hline $\begin{array}{l}\text { Outcome } \\
\text { Category }\end{array}$ & Outcome Measure & $\begin{array}{l}\text { Variables collapsed into composite } \\
\text { measure, if created }\end{array}$ \\
\hline \multirow[t]{5}{*}{$\begin{array}{l}\text { Overall } \\
\text { Health } \\
\text { Outcome }\end{array}$} & $\begin{array}{l}\text { (1A) Infections \& } \\
\text { childhood diseases }\end{array}$ & $\begin{array}{l}\text { Measles } \\
\text { Mumps } \\
\text { Pertussis } \\
\text { German Measles } \\
\text { Glandular Fever (Mononucleosis) } \\
\text { Chicken Pox } \\
\text { Meningitis } \\
\text { Recurrent sore throat/ear infection } \\
\text { Pneumonia }\end{array}$ \\
\hline & $\begin{array}{l}\text { (1B) Allergy, skin, } \\
\text { joint issues }\end{array}$ & $\begin{array}{l}\text { Allergies (allergies, allergy rhinitis, hay } \\
\text { fever, etc.) } \\
\text { Eczema/other skin issues } \\
\text { Arthritis } \\
\text { Rheumatism/fibrosis } \\
\text { Joint/back pain }\end{array}$ \\
\hline & (1C) Respiratory issues & $\begin{array}{l}\text { Asthma } \\
\text { Wheezing } \\
\text { Bronchitis } \\
\text { Respiratory Disease } \\
\text { Bronchiolitis/wheezy bronchitis }\end{array}$ \\
\hline & (1D) Digestive issues & $\begin{array}{l}\text { Recurrent stomach/abdominal issues } \\
\text { Ulcer } \\
\text { Gallstones } \\
\text { Irritable Bowel Syndrome } \\
\text { Ulcerative Colitis } \\
\text { Crohn's Disease }\end{array}$ \\
\hline & (2A) Age of menarche & \\
\hline
\end{tabular}




\begin{tabular}{|l|l|l|}
\cline { 2 - 3 } $\begin{array}{l}\text { Reproduction } \\
\text { Outcome }\end{array}$ & $\begin{array}{l}\text { (2B) Total number of } \\
\text { offspring* }\end{array}$ & \\
\hline $\begin{array}{l}\text { Mental } \\
\text { Health }\end{array}$ & (3A) Depression, ever & Depression at age 16 \\
Outcome & Depression at age 26 \\
\end{tabular}

\section{Control Variables}

To determine the best model, all control variables were included in a backwards stepwise regression analysis against each of the dependent variables. I then controlled for those variables that had a significant effect across all models. The control variables included in the analysis are listed in Table 3 (below). Several control variables were excluded due to their substantial limitations on the number of valid cases included in the analysis. By excluding these variables, denoted by an asterisk in Table 3, I was able to maximize the number of cases included in the final model. As well, the category of triplets was excluded from the multiplicity variable since the category was constant or had missing correlations and was removed by SPSS from the analysis.

Table 3. Control variables included in backwards stepwise regression to determine best model. Those variables that had a statistically significant impact were included in the final model. *Inclusion of variable drops sample size too significantly to be included in final model. + Variable is only included in model for total number of offspring but excluded in other models because it did not have a significant effect across all other models.

\begin{tabular}{|l|c|}
\hline Control Variables & $\begin{array}{c}\text { Variables } \\
\text { included in } \\
\text { final model }\end{array}$ \\
\hline Multiplicity & $\mathrm{Y}$ \\
\hline Sex of the baby & $\mathrm{Y}$ \\
\hline Ethnic group of cohort member & $\mathrm{Y}$ \\
\hline $\begin{array}{l}\text { Number of children older than } \\
\text { child }\end{array}$ & $\mathrm{Y}$ \\
\hline $\begin{array}{l}\text { Mother's age at completion of } \\
\text { education }\end{array}$ & $\mathrm{Y}$ \\
\hline $\begin{array}{l}\text { Father's age at completion of } \\
\text { education }\end{array}$ & $\mathrm{N}$ \\
\hline Social class of father in 1970 & $\mathrm{N}$ \\
\hline
\end{tabular}




\begin{tabular}{|l|l|}
\hline Mother working status & $\mathrm{Y}^{\dagger}$ \\
\hline Cohort member father presence & $\mathrm{N}^{*}$ \\
\hline Persons per room ratio & $\mathrm{Y}$ \\
\hline Type of accommodation & $\mathrm{N}$ \\
\hline Present parental marital status & $\mathrm{Y}$ \\
\hline $\begin{array}{l}\text { Premarital conception of cohort } \\
\text { member }\end{array}$ & $\mathrm{Y}$ \\
\hline $\begin{array}{l}\text { Cohort member mother's age at } \\
\text { delivery }\end{array}$ & $\mathrm{N}^{*}$ \\
\hline $\begin{array}{l}\text { Cohort member mother's alcohol } \\
\text { consumption during early } \\
\text { pregnancy }\end{array}$ & $\mathrm{N}^{*}$ \\
\hline $\begin{array}{l}\text { Cohort member mother's alcohol } \\
\text { consumption during Late } \\
\text { pregnancy }\end{array}$ & $\mathrm{Y}^{*}$ \\
\hline $\begin{array}{l}\text { Cohort member mother's } \\
\text { smoking habits during pregnancy }\end{array}$ & $\mathrm{N}^{*}$ \\
\hline $\begin{array}{l}\text { Cohort member's alcohol } \\
\text { consumption, max. ever }\end{array}$ & $\mathrm{N}^{*}$ \\
\hline $\begin{array}{l}\text { Cohort member's smoking status } \\
\text { Breastfeeding of cohort member, } \\
\text { length of time }\end{array}$ & $\mathrm{Y}$ \\
\hline
\end{tabular}

Multiplicity Since multi-fetal births are negatively associated with infant health, I included multiplicity as a control variable. Multi-fetal births are considered high-risk and contribute to higher rates of childhood mortality (Hong 2006). Multi-fetal births are associated with greater rates of pre-term births and low birthweight, with pre-term neonates at an increased risk for health and developmental problems as well as accounting for roughly $70 \%$ of perinatal mortality (Blondel et al. 2002).

Sex \& ethnicity I included sex of baby to control for the potential influence of biological sex on the dependent variables. As well, I included ethnicity to control for the potential influence of ethnicity and associated genetic and cultural variation on the variables of interest. 
Maternal age at delivery There has been a demographic shift with a larger proportion of women delaying childbearing until later in their reproductive years (Balasch and Gratacós 2011). In 2014, the mean age of mothers in the United Kingdom at first birth was 28.5 years (Central Intelligence Agency 2017). With advanced maternal age, there is a greater risk of negative pregnancy consequences including obstetric and perinatal outcomes (Blomberg, Tyrberg, and Kjølhede 2014). As well, adverse perinatal and neonatal outcomes are also associated with young maternal age at birth (Demirci et al. 2016, Kang et al. 2015). To account for this, I controlled for maternal age at delivery. Number of children older than cohort member With increasing number of older siblings, financial support and parental investment is distributed across a greater number of children (Downey 1995). Children with a greater number of siblings have a higher likelihood of living in more crowded accommodations (Hart and Smith 2003). As well, having more siblings will likely increase the probability of exposure to pathogens and therefore increase disease risk. Combined with greater exposure to early infections and potential access to a lower quality diet, the number of siblings can have a significant impact on childhood quality and health (Hart and Smith 2003). Because of its potential impacts on child development and health outcomes, I controlled for number of older siblings.

Socioeconomic measures Research has demonstrated the association between socioeconomic status and a range of health outcomes in children (Bradley and Corwyn 2002). To account for this, father's social class, mother's working status, persons per room ratio, type of accommodation, and parent educational achievement were utilized to control for the influence of socioeconomic status. Regarding the use of father's social 
class in 1970, I initially included both mother's social class and father's social class in 1970 in this analysis and the data looked like what was to be expected: women tended to marry within their social class or to that of a higher social class. Father's social class was included, instead of mother's social class, since a large percentage of women (27\%) were coded as 'housewife' under mother's social class in 1970. Thus, I included father's social class as a control in this study to retain a greater portion of valid cases. However, from the variable for mother's social class in 1970, I created a new variable to account for mother's working status. As noted in Table 3, mother's working status was included in the model for the reproduction outcome of total number of offspring. This variable was excluded from the other models since it did not have a significant effect across those models.

For parent educational achievement, a causal link has been established between a mother's educational attainment and child mortality such that child mortality decreases as mother's educational attainment increases (Gakidou et al. 2010). Therefore, mother's age at completion of education was included as a control. As well, father's age at completion of education was also included to account for the influence of father's educational attainment on the outcome variables.

Father presence, marital status, and premarital conception Initially, I included cohort member father presence as a control to account for the influence of father presence on child health (Lawson et al. 2017). However, due to limitations on the total number of valid cases, I removed this variable from the initial analysis. Parental marital status and whether cohort member was conceived premaritally were also included to account for the influence of potential parental investment on child health. 
Smoking and alcohol consumption Due to the known negative health impacts of alcohol consumption and smoking, I controlled for smoking status and alcohol use of both cohort member and mothers' use during pregnancy of cohort member. As previously noted, due to limitations on the total number of valid cases, I excluded the variables for cohort member's alcohol consumption and smoking, as well as cohort member's mother's alcohol consumption during pregnancy, from the initial analysis.

Breastfeeding The benefits of breastfeeding have been well-documented and established, particularly towards the reduction of morbidity and mortality in childhood due to infectious diseases (Horta and Victora 2013). Because of this, it is important to account for the effects of breastfeeding on the health of the cohort member and was therefore included as a control variable.

\section{Analysis}

To explore the predictors of the birthing conditions on the outcomes, I preformed backwards stepwise regression analyses using SPSS v.24. These models predict whether the place of delivery, birthing attendant, method of delivery, use of pain relief during labor, and anesthetic use during the birth of the cohort member impact the overall health, reproduction, and mental health outcomes of the cohort member. Seven models were constructed to test my predictions, and these are outlined in Table 4 below including the type of regression analyses performed. To determine whether the independent variables were significant predictors on the outcome variables, I performed a backwards stepwise analysis for each of the models, which systematically excluded the least significant independent variable from a given model in a stepwise procedure until all remaining independent variables were statistically significant at $\mathrm{p} \leq .10$. As previously mentioned, 
all controls were held constant across the models, except for the model for Outcome 2B with the dependent variable of total number of offspring which also included the control variable of the cohort member's mother's working status. For list of control variables, see Table 3, as previously discussed.

Table 4. Final models with their independent and dependent variables and the type of regression analysis performed. *No independent variables were significant in the model at $p \leq .10$. $\dagger$ Independent variable was recoded to include place of delivery and attendant at delivery into a single variable.

\begin{tabular}{|c|c|c|c|c|}
\hline Model & $\begin{array}{l}\text { Statistical } \\
\text { Model }\end{array}$ & $\begin{array}{l}\text { Outcome } \\
\text { Category }\end{array}$ & $\begin{array}{l}\text { Independent } \\
\text { Variable(s) }\end{array}$ & $\begin{array}{l}\text { Dependent } \\
\text { Variable }\end{array}$ \\
\hline Outcome 1A & $\begin{array}{l}\text { Linear } \\
\text { Regression }\end{array}$ & Health & $\begin{array}{l}\text { Place of } \\
\text { delivery } \\
\text { Pain relief }\end{array}$ & $\begin{array}{l}\text { Infections and } \\
\text { childhood } \\
\text { diseases } \\
\text { (composite } \\
\text { measure) } \\
\end{array}$ \\
\hline Outcome $1 \mathrm{~B}^{*}$ & $\begin{array}{l}\text { Logistic } \\
\text { Regression }\end{array}$ & Health & - & $\begin{array}{l}\text { Allergy, skin, } \\
\text { and joint issues } \\
\text { (composite } \\
\text { measure) }\end{array}$ \\
\hline Outcome 1C & $\begin{array}{l}\text { Linear } \\
\text { Regression }\end{array}$ & Health & $\begin{array}{l}\text { Place of } \\
\text { delivery } \\
\text { Method of } \\
\text { delivery } \\
\text { Pain relief }\end{array}$ & $\begin{array}{l}\text { Respiratory } \\
\text { issues } \\
\text { (composite } \\
\text { measure) }\end{array}$ \\
\hline Outcome 1D & $\begin{array}{l}\text { Logistic } \\
\text { Regression }\end{array}$ & Health & $\begin{array}{l}\text { Anesthetic use } \\
\text { during labor }\end{array}$ & $\begin{array}{l}\text { Digestive } \\
\text { issues } \\
\text { (composite } \\
\text { measure) } \\
\end{array}$ \\
\hline Outcome $2 \mathrm{~A}$ & $\begin{array}{l}\text { Linear } \\
\text { Regression }\end{array}$ & Reproduction & $\begin{array}{l}\text { Place \& } \\
\text { attendant at } \\
\text { delivery }^{\dagger}\end{array}$ & $\begin{array}{l}\text { Age of } \\
\text { menarche }\end{array}$ \\
\hline Outcome 2B & $\begin{array}{l}\text { Linear } \\
\text { Regression }\end{array}$ & Reproduction & $\begin{array}{l}\text { Place of } \\
\text { delivery }\end{array}$ & $\begin{array}{l}\text { Total number } \\
\text { of offspring }\end{array}$ \\
\hline Outcome $3 \mathrm{~A}^{*}$ & $\begin{array}{l}\text { Logistic } \\
\text { Regression }\end{array}$ & Mental Health & - & Depression \\
\hline
\end{tabular}

In looking at the model for Outcome 2A with the dependent variable of age of menarche, a difference was observed in the beta and p-value for the socioeconomic status 
control variable of persons per room ratio between the first model, which only included the controls, and the second model, which also included the dependent variables. The change in values suggested part of the variance explained by persons per room ratio was also being explained by the inclusion of the dependent variables of place of delivery and birthing attendant. Therefore, I recoded the independent variables of place of delivery and birthing attendant into a single variable to include an interaction in the model. This allowed for a better understanding of how socioeconomic status could influence the location and birthing attendant at the delivery of the cohort member.

To conclude, in this section I discussed three outcomes with a total of seven dependent variables, control variables looking at potential influencial factors from ethnicity to length of breastfeeding, and independent variables defining birthing conditions, which are relevant to theoretical factors involving the impact of early life stress on overall health, reproduction, and mental health outcomes. I used backwards stepwise regression analyses to identify significant variables relevant to my research questions and life history theory. 


\section{CHAPTER THREE: RESULTS}

In this chapter, I will look at the best reduced model for each of the dependent variables across the three outcomes of (1) overall health, (2) reproduction, and (3) mental health. For the overall health outcome, the composite measures include: (1A) infections and childhood diseases; (1B) allergy, skin, and joint issues; (1C) respiratory issues; and (1D) digestive issues. For the reproduction outcome, the dependent variables include (2A) age of menarche and (2B) total number of offspring. For the mental health outcome, this includes the dependent variable of (3A) depression.

\section{Descriptive Statistics}

Table 5 below shows the overall descriptive statistics for the variables included in this study which is comprised of 17,196 cohort members from the 1970 British Cohort Study. Of these individuals, 53\% of cohort members reported allergy, skin, or joint issues by age 42 , whereas $47 \%$ did not report any of these issues. A small proportion of cohort members, or $11.5 \%$, also reported experiencing at least half of the six categories of digestive issues included in this measure, whereas $88.5 \%$ experienced few digestive issues. Similarly, $81 \%$ of cohort members reported never experiencing depression, compared to $19 \%$ of cohort members who reported having depression at some point in their lifetime. Cohort members reported having an average of 2 out of the 9 infections and childhood diseases included in the composite measure, or an average of $22 \%$ of these illnesses. For respiratory issues, cohort members reported having an average of 1.5 out of the 5 respiratory issues included in the composite measure, or an average of $29 \%$ of these 
respiratory issues. For the female cohort members, age of menarche was reported as having occurred between the ages of 10 and 16, with the mean age of menarche at 12 years and 8 months of age. Total number of genetic offspring for cohort members ranged between 0 and 10 offspring with the mean number of offspring being 1.7. For details regarding the creation of composite measures, see Table 2 in Methods section.

For the dependent variables, $87 \%$ of cohort members were born in a medical facility and $13 \%$ were born at home. Approximately $76 \%$ of cohort members had a midwife attend their birth, whereas $24 \%$ were born in the attendance of a medical practitioner. A large portion, or $85 \%$, of cohort members were born by unassisted vaginal delivery, compared to $10 \%$ born through assisted vaginal delivery, $3 \%$ of births that began as spontaneous but resulted in an emergency cesarean delivery, and $1.5 \%$ of births that began as a cesarean delivery. Mothers of cohort members received some sort of pain relief during labor in $92 \%$ of cohort members' births and the remaining $8 \%$ whose mothers received no form of pain relief during labor. Anesthetics were used in $26 \%$ of births, whereas $74 \%$ did not utilize any form of anesthetics during the birth of the cohort member.

Cohort members included in this study were $98 \%$ single births, with $2 \%$ twin births, and one set of triplets. Just over half, or $52 \%$, of these individuals are male and $48 \%$ female, and $77 \%$ of these individuals identified their ethnicity as United Kingdom with almost $4 \%$ identifying as some other ethnicity. The remaining $19 \%$ did not report ethnicity. Cohort members were born to mothers who were on average roughly 26 years old and had an average of one older sibling. A great majority, or 94\%, of cohort members' parents were married at the time of the cohort member's birth. While only $6 \%$ 
of cohort members' parents were single at the time of the birth of the cohort member, $8 \%$ of cohort members were conceived premaritally. The average age of completion of education for the mothers of cohort members was just under 16 years old, which is the age at which compulsory education in the United Kingdom ends (Education System in the UK 2017). The average persons per room ratio during the childhood of the cohort member is .90 persons per room with a range from .07 to 6 persons per room. At the time of the cohort member's birth, $67 \%$ of the cohort members' mothers worked. In looking at the smoking habits of the cohort members' mothers during pregnancy, $46 \%$ smoked during pregnancy, $12 \%$ ceased smoking pre-pregnancy, and $42 \%$ were non-smokers. Regarding breastfeeding, $11 \%$ of cohort members were breastfed greater than three months, $26 \%$ were breastfed less than three months, while $63 \%$ were never breastfed. $\underline{\text { Descriptive Statistics Table }}$

Table 5. Descriptive statistics for independent, dependent, and control variables included in models.

\begin{tabular}{|c|c|c|c|c|c|}
\hline Outcome & Variable & & & & \\
\hline & Dependent variables & Mean & $\mathrm{SD}$ & Range & $n$ \\
\hline Overall Health & $\begin{array}{l}\text { (1A) Infections \& } \\
\text { childhood diseases }\end{array}$ & 0.2208 & 0.1897 & $0-1$ & 16026 \\
\hline Overall Health & (1C) Respiratory issues & 0.2921 & 0.2334 & $0-1$ & 9844 \\
\hline Reproduction & (2A) Age of menarche & 12.698 & 1.301 & $10-16$ & 3350 \\
\hline Reproduction & $\begin{array}{l}(2 \mathrm{~B}) \text { Total number of } \\
\text { offspring }\end{array}$ & 1.7 & 1.256 & $0-10$ & 9678 \\
\hline \multirow{3}{*}{ Overall Health } & & $n$ & $\%$ & Total & \\
\hline & $\begin{array}{l}\text { (1B) Allergy, skin, and } \\
\text { joint issues }\end{array}$ & & & 14505 & \\
\hline & $\begin{array}{l}\text { Cohort member } \\
\text { reported no allergy, } \\
\text { skin, or joint issues }\end{array}$ & 6826 & 47.1 & & \\
\hline
\end{tabular}




\begin{tabular}{|c|c|c|c|c|}
\hline \multirow{4}{*}{ Overall Health } & $\begin{array}{l}\text { Cohort member had } \\
\text { allergy, skin, or } \\
\text { joint issues }\end{array}$ & 7679 & 52.9 & \\
\hline & (1D) Digestive issues & & & 15985 \\
\hline & $\begin{array}{l}<50 \% \text { digestive } \\
\text { issues }\end{array}$ & 14141 & 88.5 & \\
\hline & $\begin{array}{l}\geq 50 \% \text { digestive } \\
\text { issues }\end{array}$ & 1844 & 11.5 & \\
\hline \multirow[t]{19}{*}{ Mental Health } & (3A) Depression & & & 12706 \\
\hline & $\begin{array}{l}\text { Cohort member } \\
\text { reported never } \\
\text { having depression }\end{array}$ & 10334 & 81.3 & \\
\hline & $\begin{array}{l}\text { Cohort member } \\
\text { reported having } \\
\text { depression }\end{array}$ & 2372 & 18.7 & \\
\hline & Independent variables & $n$ & $\%$ & Total \\
\hline & Place of delivery & & & 17195 \\
\hline & At home & 2215 & 12.9 & \\
\hline & Medical facility & 14980 & 87.1 & \\
\hline & Birthing attendant & & & 17050 \\
\hline & Midwife & 12904 & 75.7 & \\
\hline & $\begin{array}{l}\text { Medical } \\
\text { practitioner }\end{array}$ & 4146 & 24.3 & \\
\hline & Method of delivery & & & 17151 \\
\hline & $\begin{array}{l}\text { Vaginal unassisted } \\
\text { delivery }\end{array}$ & 14626 & 85.3 & \\
\hline & $\begin{array}{l}\text { Vaginal assisted } \\
\text { delivery }\end{array}$ & 1750 & 10.2 & \\
\hline & $\begin{array}{l}\text { Labor began } \\
\text { spontaneously but } \\
\text { resulted in cesarean } \\
\text { delivery }\end{array}$ & 511 & 3 & \\
\hline & $\begin{array}{l}\text { Labor started as and } \\
\text { resulted in cesarean } \\
\text { delivery }\end{array}$ & 264 & 1.5 & \\
\hline & Pain relief during labor & & & 16699 \\
\hline & No & 1278 & 7.7 & \\
\hline & Yes & 15421 & 92.3 & \\
\hline & Anesthetics during labor & & & 17196 \\
\hline
\end{tabular}




\begin{tabular}{|c|c|c|c|c|}
\hline No & 12673 & 73.7 & & \\
\hline Yes & 4523 & 26.3 & & \\
\hline Control variables & Mean & SD & Range & $n$ \\
\hline $\begin{array}{l}\text { Number of children older } \\
\text { than child }\end{array}$ & 1.06 & 1.158 & $0-10$ & 13121 \\
\hline $\begin{array}{l}\text { Mother's age at } \\
\text { completion of education }\end{array}$ & 15.77 & 4.06 & $0-97$ & 17049 \\
\hline Persons per room ratio & 0.8971 & 0.3304 & $.07-6$ & 12943 \\
\hline $\begin{array}{l}\text { Cohort member mother } \\
\text { age at delivery }\end{array}$ & 25.97 & 5.534 & $14-52$ & 17093 \\
\hline & $n$ & $\%$ & Total & \\
\hline Multiplicity & & & 17196 & \\
\hline Single & 16815 & 97.8 & & \\
\hline Twin & 378 & 2.2 & & \\
\hline Triplet & 3 & 0 & & \\
\hline Sex of the baby & & & 17185 & \\
\hline Male & 8906 & 51.8 & & \\
\hline Female & 8279 & 48.2 & & \\
\hline Cohort member ethnicity & & & 11615 & \\
\hline United Kingdom & 8957 & 77.1 & & \\
\hline Other ethnicity & 428 & 3.7 & & \\
\hline $\begin{array}{l}\text { Ethnicity not } \\
\text { reported }\end{array}$ & 2230 & 19.2 & & \\
\hline $\begin{array}{l}\text { Parent marital status at } \\
\text { time of cohort member's } \\
\text { birth }\end{array}$ & & & 17179 & \\
\hline Single & 1037 & 6 & & \\
\hline Married & 16142 & 94 & & \\
\hline Premarital conception & & & 16827 & \\
\hline No & 15432 & 91.7 & & \\
\hline Yes & 1395 & 8.3 & & \\
\hline $\begin{array}{l}\text { Cohort member mother's } \\
\text { smoking during } \\
\text { pregnancy }\end{array}$ & & & 17109 & \\
\hline Non-smoker & 7179 & 42 & & \\
\hline $\begin{array}{l}\text { Stopped smoking } \\
\text { pre-pregnancy }\end{array}$ & 2031 & 11.9 & & \\
\hline
\end{tabular}




\begin{tabular}{|l|lrrr|}
$\quad \begin{array}{l}\text { Smoked during } \\
\text { pregnancy }\end{array}$ & 7899 & 46.2 & \\
$\begin{array}{l}\text { Breastfeeding, length of } \\
\text { time }\end{array}$ & & & 12981 \\
$\quad$ Never breastfed & 8182 & 63 & \\
$\quad \begin{array}{l}\text { Breastfed <3 } \\
\text { months }\end{array}$ & 3387 & 26.1 & \\
$\quad \begin{array}{l}\text { Breastfed } \geq 3 \\
\text { months }\end{array}$ & 1412 & 10.9 & \\
$\begin{array}{l}\text { Mother's working status } \\
\text { at time of cohort member } \\
\text { birth } \quad\end{array}$ & & & \\
$\quad$ Not working & 5104 & 32.8 & \\
$\quad$ Working & 10476 & 67.2 & \\
\hline
\end{tabular}

\section{Overall Health Outcome - Hypothesis 1}

In this section, I looked at the best reduced models for the four composite variables of the overall health outcome, including (1A) infections and childhood diseases, (1B) allergy, skin, and joint issues, (1C) respiratory issues, and (1D) digestive issues. These composite measures are representative of overall health due to their underlying connections between birthing conditions and related health outcomes. Through analyzing the best reduced models for these composite measures, I was able to address Hypothesis 1:

If modern technological birthing conditions influence the development of the immune system via the gut microbiota, then I expect to see higher rates of immune dysfunction, including higher rates of (1A) infections and childhood diseases, (1B) allergy, skin, and joint issues, (1C) respiratory issues, and (1D) digestive issues. 


\section{Outcome 1A - Infections and Childhood Diseases}

\section{Control Variables}

For the control variable of ethnicity, other ethnicity was significant with a negative beta value $(\beta=-.037, p=.009)$. Ethnicity not reported was highly significant with a negative beta value $(\beta=-.026, \mathrm{p}<.001)$. The negative beta values for both other ethnicity and ethnicity not reported indicated negative correlations between having an ethnicity other than United Kingdom or not reporting one's ethnicity and having a lower risk of infections and childhood diseases. Mother's age at delivery was significant with a slightly negative beta value $(\beta=-.001, p=.042)$. Smoking during pregnancy of cohort member was highly significant with a positive beta value $(\beta=.021, \mathrm{p}<.001)$. Compared to those who were non-smokers, a cohort member born to a mother who smoked throughout her pregnancy had a higher likelihood of developing infections and childhood diseases. Breastfeeding between 0-3 months was significant and had a negative beta value ( $\beta=-$ $.009, \mathrm{p}=.042$ ). Compared to those who were never breastfed, cohort members who were breastfed between 0-3 months of age had a slightly lower likelihood of developing infections and childhood diseases. For the control variable of multiplicity, twin birth was significant at $\mathrm{p} \leq .10$ with a positive beta $(\beta=.023, \mathrm{p}=.067)$.

\section{Independent Variables}

For Outcome 1A, I looked at the impact of birthing conditions on the overall health outcome of infections and childhood diseases. Place of delivery was significant with a positive beta value $(\beta=.01, p=.068)$. The directionality of the beta value indicated a positive correlation between being born in a medical facility and the occurrence of 
developing infections and childhood diseases. Pain relief during labor was also significant with a negative beta value $(\beta=-.013, p=.062)$. This indicated a negative correlation between a cohort member's mother having received pain relief during labor and a decreased risk for the cohort member of developing infections and childhood diseases.

\section{Assumptions}

All assumptions of the linear regression model were met. See Appendix A for tests of assumptions.

Table 6. Outcome 1A linear regression statistical results for the dependent variable infections \& childhood diseases. Model $n=16026$. Model $R^{2}=0.013$.

\begin{tabular}{|llcccc|}
\hline Outcome 1A & & B & $\begin{array}{c}\text { Std. } \\
\text { Beta }\end{array}$ & $\begin{array}{c}\text { Std. } \\
\text { Error }\end{array}$ & Sig. \\
\hline Controls & (Constant) & 0.275 & & 0.020 & 0.000 \\
\hline Multiplicity* & Reference category: Single birth & & & & \\
& Twin birth & 0.023 & 0.020 & 0.013 & 0.067 \\
\hline & Sex of cohort member & 0.002 & 0.006 & 0.004 & 0.587 \\
\hline Ethnicity & $\begin{array}{l}\text { Reference category: United Kingdom } \\
\text { Other ethnicity }\end{array}$ & -0.037 & -0.028 & 0.014 & 0.009 \\
& Ethnicity not reported & -0.026 & -0.06 & 0.005 & 0.000 \\
\hline & Number of children older than child & 0.003 & 0.017 & 0.002 & 0.247 \\
\hline & $\begin{array}{l}\text { Mother's age at completion of } \\
\text { education }\end{array}$ & -0.001 & -0.016 & 0.001 & 0.155 \\
\hline & Persons per room ratio & 0.005 & 0.009 & 0.007 & 0.466 \\
\hline & Parent marital status at birth & -0.015 & -0.017 & 0.010 & 0.133 \\
\hline & Premarital conception & 0.006 & 0.011 & 0.007 & 0.352 \\
\hline & Mother's age at delivery & -0.001 & -0.026 & 0.000 & 0.042 \\
\hline $\begin{array}{l}\text { Cohort } \\
\text { member } \\
\text { mother's } \\
\text { smoking } \\
\text { status }\end{array}$ & $\begin{array}{l}\text { Reference category: Non-smoker } \\
\text { Stopped smoking pre-pregnancy }\end{array}$ & 0.005 & 0.010 & 0.006 & 0.360 \\
& Smoked during pregnancy & 0.021 & 0.063 & 0.004 & 0.000 \\
\hline
\end{tabular}




\begin{tabular}{|llllll|}
\hline \multirow{2}{*}{ Breastfeeding } & Reference category: Never Breastfed & & & & \\
& $\begin{array}{l}\text { Breastfed < 3 months } \\
\text { Breastfed } \geq 3 \text { months }\end{array}$ & -0.009 & -0.023 & 0.004 & 0.042 \\
& Independent Variables & -0.007 & -0.013 & 0.006 & 0.233 \\
\hline $\begin{array}{l}\text { Place of } \\
\text { delivery }\end{array}$ & $\begin{array}{l}\text { Reference category: At home } \\
\text { Medical facility }\end{array}$ & & & & \\
\hline & Pain relief during labor & -0.010 & 0.020 & 0.005 & 0.068 \\
\hline
\end{tabular}

Outcome 1B - Allergy, Skin, and Joint Issues

\section{Control Variables}

Sex of cohort member was highly significant and had an odds ratio greater than 1 $(\operatorname{Exp}(B)=1.367, p<.001)$, indicating that being male significantly increased the likelihood of having allergy, skin and joint issues by 1.37 times during one's lifetime. For Ethnicity, ethnicity not reported was significant and had an odds ratio greater than 1 $(\operatorname{Exp}(\mathrm{B})=1.151, \mathrm{p}=.020)$. This indicated that, compared to those who reported having an ethnicity of United Kingdom, the likelihood of having allergy, skin and joint issues increased by 1.15 times for those who did not report their ethnicity. Number of children older than child was highly significant with an odds ratio less than $1(\operatorname{Exp}(B)=.906$, $\mathrm{p}<.001$ ), indicating that, for every additional older sibling a cohort member had, the likelihood of having allergy, skin, or joint issues decreased by .91 times. Persons per room ratio was significant with an odds ratio less than $1(\operatorname{Exp}(B)=.783, \mathrm{p}=.005)$. This meant that, for every unit increase in people per room, the likelihood of having allergy, joint, or skin issues decreased by .78 times. Premarital conception was highly significant with an odds ratio less than $1(\operatorname{Exp}(B)=.726, \mathrm{p}<.001)$, indicating that being conceived before parents were married decreased the likelihood of developing allergy, skin, or joint issues by .73 times. Mother's age at delivery was significant with an odds ratio close to 1 $(\operatorname{Exp}(B)=1.009, p=.069)$. While mother's age at delivery was significant at the level of 
$\mathrm{p}<.10$, since the odds ratio is 1.01 , this indicated that, for each year older a cohort member's mother was at their delivery, the likelihood of developing allergy, skin, or joint issues slightly increased. Breastfeeding between 0-3 months was significant and had an odds ratio greater than $1(\operatorname{Exp}(\mathrm{B})=1.137, \mathrm{p}=.012)$. As well, breastfeeding at least 3 months or more was highly significant and had an odds ratio also greater than 1 $(\operatorname{Exp}(B)=1.491, \mathrm{p}<.001)$. Compared to those who were never breastfed, for cohort members who were breastfed between 0-3 months of age and those breastfed for a duration longer than 3 months of age, this increased the likelihood of having allergy, skin and joint issues by 1.1 times and 1.5 times, respectively.

\section{Independent Variables}

For Outcome 1B, I looked at the impact of birthing conditions on the overall health outcome of allergy, skin and joint issues. Since no independent variables were significant at $\mathrm{p}<.10$, no independent variables were retained in the reduced model.

\section{Assumptions}

The logistic regression model violated the assumption of linearity of the logit. See Appendix A for tests of assumptions.

Table 7: Outcome 1B logistic regression statistical results for the dependent variable allergy, skin, and joint issues. Model $n=14505$. Model Nagelkerke $R^{2}=$ 0.027.

\begin{tabular}{|llcccc|}
\hline Outcome 1B & B & $\begin{array}{c}\text { Std. } \\
\text { Error }\end{array}$ & Sig. & Exp(B) \\
\hline Controls & (Constant) & -0.233 & 0.233 & 0.318 & 0.792 \\
\hline & Multiplicity & -0.073 & 0.154 & 0.634 & 0.929 \\
\hline \multirow{2}{*}{ Ethnicity } & Sex of cohort member & 0.312 & 0.044 & $<0.001$ & 1.367 \\
& $\begin{array}{l}\text { Reference category: United } \\
\text { Kingdom } \\
\text { Other ethnicity }\end{array}$ & & & 0.039 & \\
& & -0.146 & 0.164 & 0.374 & 0.864
\end{tabular}




\begin{tabular}{|llcccc|} 
& Ethnicity not reported & 0.141 & 0.06 & 0.020 & 1.151 \\
\hline & $\begin{array}{l}\text { Number of children older than } \\
\text { child }\end{array}$ & -0.099 & 0.026 & $<0.001$ & 0.906 \\
\hline & $\begin{array}{l}\text { Mother's age at completion of } \\
\text { education }\end{array}$ & 0.012 & 0.008 & 0.133 & 1.012 \\
\hline & Persons per room ratio & -0.244 & 0.087 & 0.005 & 0.783 \\
\hline & Parent marital status at birth & 0.090 & 0.121 & 0.456 & 1.094 \\
\hline & Premarital conception & -0.320 & 0.084 & $<0.001$ & 0.726 \\
\hline & Mother's age at delivery & 0.009 & 0.005 & 0.069 & 1.009 \\
\hline $\begin{array}{l}\text { Cohort } \\
\text { member } \\
\text { mother's } \\
\text { smoking } \\
\text { status }\end{array}$ & $\begin{array}{l}\text { Reference category: Non-smoker } \\
\text { Stopped smoking pre-pregnancy }\end{array}$ & -0.039 & 0.069 & 0.571 & 0.961 \\
\hline Breastfeeding & $\begin{array}{l}\text { Smoked during pregnancy } \\
\text { Breastfed }\end{array}$ & -0.063 & 0.048 & 0.190 & 0.939 \\
\hline $\begin{array}{l}\text { Breastfed < 3 months } \\
\text { Breastfed } \geq 3 \text { months }\end{array}$ & 0.128 & 0.051 & 0.012 & 1.137 \\
& 0.400 & 0.074 & $<0.001$ & 1.491 \\
\hline
\end{tabular}

\section{Outcome 1C - Respiratory Issues}

\section{Control variables}

Sex of cohort member was highly significant and had a negative beta value ( $\beta=$ $.022, \mathrm{p}<.001)$, indicating that being female was positively correlated with an increased risk of having respiratory issues during one's lifetime. Number of children older than child was also significant with a positive beta value $(\beta=.008, p=.020)$. As well, mother's age at completion of education was significant and had a positive beta value $(\beta=.003$, $p=.006)$. Persons per room ratio was highly significant with a negative beta value $(\beta=-$ $.050, \mathrm{p}<.001)$, indicating an inverse relationship between wealth and likelihood of respiratory issues. Parent marital status at the time of the cohort member's birth was significant with a negative beta value $(\beta=-.034, \mathrm{p}=.037)$, which indicated those cohort members born to married parents were less likely to develop respiratory issues. In contrast, premarital conception was also significant with a negative beta value $(\beta=-.019$, 
$\mathrm{p}=.072$ ), indicating cohort members who were conceived before their parents were married were significantly less likely to develop respiratory issues. Mother's age at delivery was significant with a negative beta value $(\beta=-.001, \mathrm{p}=.051)$. Smoking during pregnancy of cohort member was significant with a positive beta value $(\beta=.016, p=.011)$. Compared to those who were non-smokers, a cohort member born to a mother who smoked throughout her pregnancy had a higher likelihood of developing respiratory issues.

\section{Independent variables}

For Outcome 1C, I looked at the impact of birthing conditions on the overall health outcome of respiratory issues. Place of delivery was significant with a positive beta value $(\beta=.022, \mathrm{p}=.008)$. The directionality of the beta value indicated a positive correlation between being born in a medical facility and the occurrence of developing respiratory issues. For method of delivery, compared to vaginal unassisted delivery, delivery that started and ended as a cesarean was significant and had a negative beta value ( $\beta=-.074, p=.004)$. As well, compared to vaginal unassisted delivery, vaginal assisted delivery was significant at the level of $\mathrm{p}<.10$ and had a negative beta value $(\beta=-$ $.018, \mathrm{p}=.056$ ). Pain relief during labor was also significant with a negative beta value $(\beta=-.030, p=.015)$. This indicated a negative correlation between a cohort member's mother having received pain relief during labor and a decreased risk for the cohort member of developing respiratory issues.

\section{Assumptions}

All assumptions of the linear regression model were met. See Appendix A for tests of assumptions. 
Table 8. Outcome 1C linear regression statistical results for the dependent variable respiratory issues. Model $n=9844$. Model $R^{2}=0.012$.

\begin{tabular}{|c|c|c|c|c|c|}
\hline \multicolumn{2}{|l|}{ Outcome 1C } & \multirow{3}{*}{$\begin{array}{c}\text { B } \\
0.373\end{array}$} & \multirow[t]{3}{*}{$\begin{array}{l}\text { Std. } \\
\text { Beta } \\
\end{array}$} & \multirow{3}{*}{$\begin{array}{c}\begin{array}{c}\text { Std. } \\
\text { Error }\end{array} \\
0.032\end{array}$} & \multirow{3}{*}{$\frac{\text { Sig. }}{0.000}$} \\
\hline & (Constant) & & & & \\
\hline \multicolumn{2}{|l|}{ Controls } & & & & \\
\hline \multirow[t]{3}{*}{ Multiplicity* } & $\begin{array}{l}\text { Reference category: Single } \\
\text { birth }\end{array}$ & & & & \\
\hline & Twin birth & 0.009 & 0.006 & 0.019 & 0.623 \\
\hline & Sex of cohort member & -0.022 & -0.046 & 0.006 & 0.000 \\
\hline \multirow[t]{9}{*}{ Ethnicity } & $\begin{array}{l}\text { Reference category: United } \\
\text { Kingdom }\end{array}$ & & & & \\
\hline & Other ethnicity & -0.019 & -0.01 & 0.022 & 0.404 \\
\hline & Ethnicity not reported & -0.012 & -0.018 & 0.008 & 0.135 \\
\hline & $\begin{array}{l}\text { Number of children older than } \\
\text { child }\end{array}$ & 0.008 & 0.037 & 0.004 & 0.020 \\
\hline & $\begin{array}{l}\text { Mother's age at completion of } \\
\text { education }\end{array}$ & 0.003 & 0.033 & 0.001 & 0.006 \\
\hline & Persons per room ratio & -0.05 & -0.061 & 0.012 & 0.000 \\
\hline & Parent marital status at birth & -0.034 & -0.025 & 0.016 & 0.037 \\
\hline & Premarital conception & -0.019 & -0.023 & 0.011 & 0.072 \\
\hline & Mother's age at delivery & -0.001 & -0.028 & 0.001 & 0.051 \\
\hline \multirow{3}{*}{$\begin{array}{l}\text { Cohort } \\
\text { member } \\
\text { mother's } \\
\text { smoking } \\
\text { status }\end{array}$} & $\begin{array}{l}\text { Reference category: Non- } \\
\text { smoker }\end{array}$ & & & & \\
\hline & $\begin{array}{l}\text { Stopped smoking pre- } \\
\text { pregnancy }\end{array}$ & -0.003 & -0.005 & 0.009 & 0.719 \\
\hline & Smoked during pregnancy & 0.016 & 0.033 & 0.006 & 0.011 \\
\hline \multirow[t]{3}{*}{ Breastfeeding } & $\begin{array}{l}\text { Reference category: Never } \\
\text { breastfed }\end{array}$ & & & & \\
\hline & Breastfed $<3$ months & 0.007 & 0.014 & 0.007 & 0.256 \\
\hline & Breastfed $\geq 3$ months & 0.013 & 0.018 & 0.009 & 0.150 \\
\hline \multicolumn{6}{|c|}{ Independent Variables } \\
\hline \multirow{2}{*}{$\begin{array}{l}\text { Place of } \\
\text { delivery }\end{array}$} & Reference category: At home & & & & \\
\hline & Medical facility & 0.022 & 0.033 & 0.008 & 0.008 \\
\hline \multirow[t]{5}{*}{$\begin{array}{l}\text { Method of } \\
\text { delivery }\end{array}$} & $\begin{array}{l}\text { Reference category: Vaginal } \\
\text { unassisted delivery }\end{array}$ & & & & \\
\hline & Vaginal assisted delivery & -0.018 & -0.024 & 0.009 & 0.056 \\
\hline & $\begin{array}{l}\text { Cesarean delivery - } \\
\text { spontaneous }\end{array}$ & -0.006 & -0.004 & 0.017 & 0.721 \\
\hline & Cesarean delivery - started as & -0.074 & -0.039 & 0.026 & 0.004 \\
\hline & Pain Relief during labor & -0.030 & -0.033 & 0.012 & 0.015 \\
\hline
\end{tabular}




\section{Outcome 1D - Digestive Issues}

\section{Control variables}

Sex of cohort member was highly significant with an odds ratio less than 1 $(\operatorname{Exp}(B)=.699, \mathrm{p}<.001)$. This indicated that being male decreased the likelihood of having digestive issues by .70 times. Ethnicity not reported was highly significant with an odds ratio greater than $1(\operatorname{Exp}(B)=1.428, \mathrm{p}<.001)$, indicating that, compared to those who reported having an ethnicity of United Kingdom, the likelihood of having digestive issues increased by 1.4 times for those who did not report their ethnicity. Number of children older than child was significant with an odds ratio greater than $1(\operatorname{Exp}(B)=1.123, p=.006)$, indicating that, for each additional older sibling a cohort member had, the likelihood of digestive issues increased by 1.1 times. Mother's age at delivery was significant with an odds ratio less than $1(\operatorname{Exp}(B)=.986, p=.084)$. While mother's age at delivery was significant at the level of $\mathrm{p}<.10$, since the odds ratio is .99 , this indicated that, for each year older a cohort member's mother was at their delivery, the likelihood of developing digestive issues decreased only slightly. Breastfeeding for a duration of at least 3 months or more was significant with an odds ratio less than $1(\operatorname{Exp}(B)=.690, \mathrm{p}=.006)$. This indicated that, compared to those who were never breastfed, for cohort members who were breastfed for a longer duration, their likelihood of developing digestive issues decreased by .69 times.

\section{Independent variables}

For Outcome 1D, I looked at the impact of birthing conditions on the overall health outcome of digestive issues. Anesthetic use during labor was significant with an odds ratio greater than $1(\operatorname{Exp}(\mathrm{B})=1.160, \mathrm{p}=.079)$, indicating that using anesthetics during 
birth of the cohort member increased the likelihood of the cohort member developing digestive issues by 1.2 times, and this was significant at the level of $\mathrm{p}<.10$.

\section{Assumptions}

The logistic regression model violated the assumption of linearity of the logit. See Appendix A for tests of assumptions.

Table 9: Outcome 1D logistic regression statistical results for the dependent variable digestive issues. Model $n=15985$. Model Nagelkerke $R^{2}=0.017$.

\begin{tabular}{|c|c|c|c|c|c|}
\hline Outcome 1D & & $\mathrm{B}$ & Std. Error & Sig. & $\operatorname{Exp}(B)$ \\
\hline & (Constant) & -1.544 & 0.430 & $<0.001$ & 0.214 \\
\hline Controls & & & & & \\
\hline & Multiplicity & -0.375 & 0.278 & 0.176 & 0.687 \\
\hline & Sex of cohort member & -0.359 & 0.073 & $<0.001$ & 0.699 \\
\hline Ethnicity & Reference category: United Kingdom & & & $<0.001$ & \\
\hline & Other ethnicity & 0.175 & 0.266 & 0.509 & 1.192 \\
\hline & Ethnicity not reported & 0.357 & 0.087 & 0.000 & 1.428 \\
\hline & Number of children older than child & 0.116 & 0.043 & 0.006 & 1.123 \\
\hline & $\begin{array}{l}\text { Mother's age at completion of } \\
\text { education }\end{array}$ & -0.019 & 0.019 & 0.309 & 0.981 \\
\hline & Persons per room ratio & -0.052 & 0.143 & 0.715 & 0.949 \\
\hline & Parent marital status at birth & -0.064 & 0.191 & 0.738 & 0.938 \\
\hline & Premarital conception & -0.038 & 0.139 & 0.782 & 0.962 \\
\hline & Mother's age at delivery & -0.014 & 0.008 & 0.084 & 0.986 \\
\hline Cohort & Reference category: Non-smoker & & & 0.238 & \\
\hline mother's & Stopped smoking pre-pregnancy & 0.175 & 0.113 & 0.120 & 1.191 \\
\hline $\begin{array}{l}\text { smoking } \\
\text { status }\end{array}$ & Smoked during pregnancy & 0.095 & 0.079 & 0.230 & 1.100 \\
\hline Breastfeeding & Reference category: Never breastfed & & & 0.014 & \\
\hline & Breastfed $<3$ months & 0.033 & 0.083 & 0.691 & 1.034 \\
\hline & Breastfed $\geq 3$ months & -0.372 & 0.136 & 0.006 & 0.690 \\
\hline Independent $V$ & ariables & & & & \\
\hline & Anesthetic use during labor & 0.148 & 0.084 & 0.079 & 1.160 \\
\hline
\end{tabular}

In summary, for the overall health outcome, the results of the dependent variables of Outcome 1A infections and childhood diseases and Outcome 1D digestive issues fell in the predicted direction, along with the results of the dependent variable Outcome 1C 
respiratory issues which generally fell into the predicted direction. The results for the dependent variable Outcome 1B allergy, skin, and joint issues was not predicted by any independent variables. The control variables that had an influence on the likelihood of having one of the overall health outcomes included sex of cohort member, ethnicity, mother's age at completion of education, number of children siblings, persons per room ratio, parent marital status, premarital conception, mother's age at delivery, smoking during pregnancy, breastfeeding time length, and multiplicity. For Outcome 1A, the independent variables that predicted an impact on the likelihood of having infections and childhood diseases were place of delivery and pain relief during labor. The impact of place of delivery was in the expected direction with those born in a medical facility having a greater likelihood of having infections and childhood diseases, while pain relief during delivery did not have the impact I expected since those whose mothers received pain relief during delivery had a lower likelihood of developing infections and childhood diseases. For Outcome 1B, no independent variables predicted the likelihood of having allergies, skin, and joint issues. For Outcome 1C, the independent variables that predicted an impact on the likelihood of having respiratory issues were place of delivery, method of delivery, and use of pain relief during labor. For method of delivery, compared to being born by a vaginal unassisted delivery, the categories that were significant included assisted vaginal delivery and elective cesarean delivery. The impact of place of delivery, assisted vaginal delivery, and use of pain relief during labor were in the expected direction with those who were born under technological birthing conditions were likely to develop respiratory issues. In contrast, elective cesarean did not have the impact I expected since those born by this method of delivery had a lower likelihood of 
developing respiratory issues. For Outcome 1D, the independent variable that predicted an impact on digestive issues was anesthetic use. The impact of anesthetic use was in the predicted direction since those whose mothers received anesthetics during their birth were more likely to develop digestive issues.

\section{Reproduction Outcome - Hypothesis 2}

In this section, I looked at the best reduced models for the reproduction outcome, including the dependent variables of (2A) age of menarche and (2B) total number of offspring. I included these variables as measures of reproduction for the outcome due to theoretical trade-offs in life history theory between early life stress and life history patterns. Including these variables allowed me to address Hypothesis 2:

If there is a relationship between birthing conditions and future reproduction, then, in the presence of adequate nutrition, with increased detriments on health, I expected to see a faster life history with an earlier age of menarche and an increase in total number of offspring.

\section{Outcome 2A - Age of Menarche}

\section{Control variables}

For the control variable of ethnicity, 'other ethnicity' was significant with a negative beta value $(\beta=-.290, p=.071)$, indicating a negative correlation between having an ethnicity other than United Kingdom and the age of onset of menarche.

\section{Independent variables}

For Outcome 2A, I looked at the impacts of birthing conditions on the reproduction outcome variable of age of menarche. For the variable place and attendant at delivery of the cohort member, having a medical practitioner at home was significant 
with a negative beta value $(\beta=-.605, p=.014)$. Compared to those cohort members who were delivered at a medical facility with a midwife, those who were born at home with a medical practitioner were more likely to have an earlier age of menarche. Those who were born at a medical facility with a medical practitioner was also significant and had a negative beta value $(\beta=-.102, p=.071)$. This indicated that, compared to those who were delivered at a medical facility with a midwife, those who were born at a medical facility with a medical practitioner had an earlier age of onset of menarche, although this was not as significant as the previous result for those born at home with a medical practitioner.

\section{Assumptions}

All assumptions of the linear regression model were met. See Appendix A for tests of assumptions.

Table 10. Outcome $2 \mathrm{~A}$ linear regression statistical results for the dependent variable age of menarche. Model $n=3350$. Model $R^{2}=0.008$.

\begin{tabular}{|c|c|c|c|c|c|}
\hline \multicolumn{2}{|l|}{ Outcome $2 \mathrm{~A}$} & B & $\begin{array}{l}\text { Std. } \\
\text { Beta }\end{array}$ & $\begin{array}{l}\text { Std. } \\
\text { Error }\end{array}$ & Sig. \\
\hline & (Constant) & 12.726 & 0.223 & & 0.000 \\
\hline \multicolumn{6}{|l|}{ Controls } \\
\hline \multirow[t]{2}{*}{ Multiplicity* } & Reference category: Single birth & & & & \\
\hline & Twin birth & -0.063 & 0.168 & -0.007 & 0.707 \\
\hline \multirow[t]{9}{*}{ Ethnicity } & Reference category: United Kingdom & & & & \\
\hline & Other ethnicity & -0.29 & 0.160 & -0.032 & 0.071 \\
\hline & Ethnicity not reported & -0.186 & 0.138 & -0.023 & 0.179 \\
\hline & Number of children older than child & 0.035 & 0.028 & 0.029 & 0.205 \\
\hline & $\begin{array}{l}\text { Mother's age at completion of } \\
\text { education }\end{array}$ & -0.005 & 0.007 & -0.012 & 0.503 \\
\hline & Persons per room ratio & 0.094 & 0.090 & 0.021 & 0.30 \\
\hline & Parent marital status at birth & 0.066 & 0.117 & 0.010 & 0.574 \\
\hline & Premarital conception & -0.03 & 0.088 & -0.006 & 0.732 \\
\hline & Mother's age at delivery & -0.001 & 0.005 & -0.004 & 0.851 \\
\hline \multirow{2}{*}{$\begin{array}{l}\text { Cohort } \\
\text { member } \\
\text { mother's }\end{array}$} & Reference category: Non-smoker & & & & \\
\hline & Stopped smoking pre-pregnancy & -0.11 & 0.071 & -0.028 & 0.122 \\
\hline
\end{tabular}




\begin{tabular}{|llcccc|}
$\begin{array}{l}\text { smoking } \\
\text { status }\end{array}$ & Smoked during pregnancy & -0.045 & 0.049 & -0.017 & 0.352 \\
\hline Breastfeeding & Reference category: Never breastfed & & & & \\
& Breastfed < 3 months & -0.084 & 0.053 & -0.029 & 0.110 \\
& Breastfed $\geq 3$ months & 0.094 & 0.070 & 0.024 & 0.183 \\
\hline Independent Variables & & & & \\
\hline Place and & Reference category: Midwife in medical facility & & & \\
attendant at & Medical practitioner at home & -0.605 & 0.246 & -0.043 & 0.014 \\
delivery & Midwife at home & -0.091 & 0.068 & -0.024 & 0.180 \\
& Medical practitioner at medical facility & -0.102 & 0.056 & -0.033 & 0.071 \\
\hline
\end{tabular}

As previously discussed in the Methods section, since a difference was observed in the beta and p-value for the socioeconomic status control variable of persons per room ratio between the first model, which included only the controls, and the second model, which also included the dependent variables, the independent variables of place of delivery and birthing attendant were recoded into a single variable to include an interaction. Significant results regarding these variables from the backwards stepwise linear regression were discussed in the previous paragraph. To better understand how socioeconomic status, as represented by persons per room ratio, may influence the location and birthing attendant at the delivery of the cohort member, persons per room ratio was graphed against each of the categories of location and attendant at birth; see Figure 1 below. From this, it was evident that the category of being born at a medical facility with a medical practitioner was significantly different from the other three categories as it relates to persons per room ratio at the $95 \%$ confidence interval, indicating a likely correlation between wealth and location and attendant at the delivery of a cohort member, where wealthier families were more likely to give birth in a medical facility under the care of a medical practitioner. 


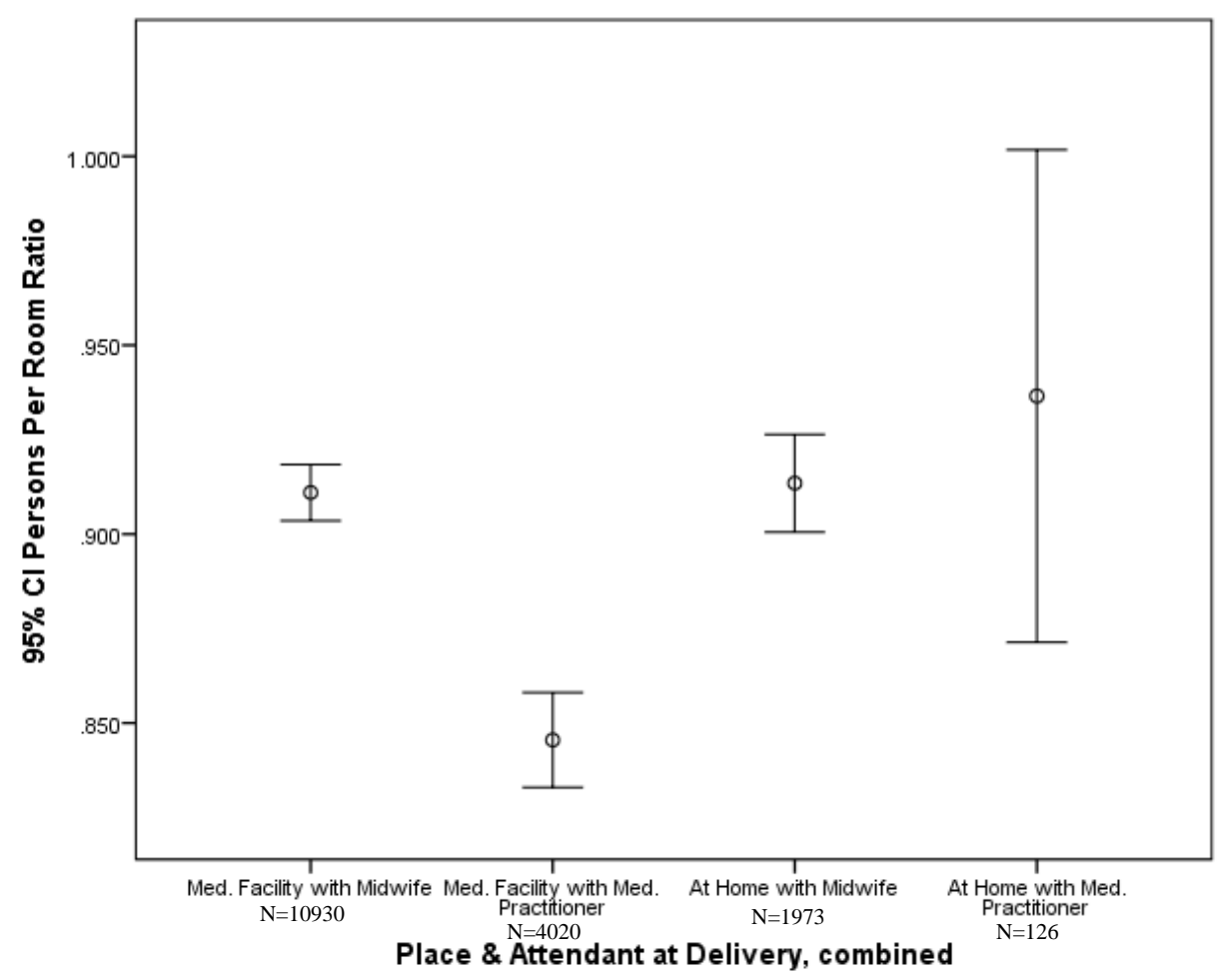

Figure 1. The recoded variable categories of place $\&$ attendant at delivery for Outcome 2A plotted against persons per room ratio. Error bars indicate 95\% confidence interval (CI).

\section{Outcome 2B - Total number of offspring}

\section{Control variables}

Sex of cohort member was highly significant and had a positive beta value ( $\beta=.172, p<.001)$, indicating that, compared to male cohort members, female cohort members had a significantly greater number of offspring. Number of children older than child was also significant with a positive beta value $(\beta=.106, p<.001)$. Persons per room ratio was highly significant with a positive beta value $(\beta=.316, \mathrm{p}<.001)$, indicating a correlation between lower wealth and a greater number of offspring. Mother's age at delivery was highly significant with a negative beta value $(\beta=-.028$, $\mathrm{p}<.001)$. Smoking during pregnancy of a cohort member was significant with a positive beta value $(\beta=.076$, $\mathrm{p}=.035$ ), indicating that, compared to those cohort members whose mothers were non- 
smokers, a cohort member born to a mother who smoked throughout her pregnancy was more likely to have a greater number of offspring. Breastfeeding for at least three months or more was significant and had a positive beta value $(\beta=.089, p=.087)$. Compared to those who were never breastfed, cohort members who were breastfed for a duration longer than three months had a greater likelihood of having more offspring. The working status of the cohort member's mother at the time of delivery was significant with a positive beta $(\beta=.091, \mathrm{p}=.022)$, indicating that those cohort members whose mothers worked had a great number of offspring themselves.

\section{Independent variables}

For Outcome 2B, I looked at the impacts of birthing conditions on the reproduction outcome of total number of offspring. Place of delivery was significant with a negative beta value $(\beta=-.146, p=.003)$. The directionality of the beta value indicated a correlation between being born at home and the likelihood of a cohort member having more offspring themselves.

\section{Assumptions}

All assumptions of the linear regression model were met. See Appendix A for tests of assumptions. 
Table 11. Outcome 2B linear regression statistical results for the dependent variable total number of offspring. $M o d e l ~ n=9678$. $M o d e l R^{2}=0.036$.

\begin{tabular}{|c|c|c|c|c|c|}
\hline \multicolumn{2}{|l|}{ Outcome 2B } & \multirow{3}{*}{$\frac{\mathrm{B}}{1.926}$} & \multirow[t]{2}{*}{$\begin{array}{l}\text { Std. } \\
\text { Beta }\end{array}$} & \multirow{3}{*}{$\begin{array}{c}\text { Std. } \\
\text { Error }\end{array}$} & \multirow{3}{*}{$\frac{\text { Sig. }}{0.000}$} \\
\hline & (Constant) & & & & \\
\hline \multicolumn{3}{|l|}{ Controls } & & & \\
\hline \multirow[t]{3}{*}{ Multiplicity* } & Reference category: Single birth & & & & \\
\hline & Twin birth & -0.077 & -0.009 & 0.120 & 0.521 \\
\hline & Sex of cohort member & 0.172 & 0.071 & 0.033 & 0.000 \\
\hline \multirow[t]{9}{*}{ Ethnicity } & Reference category: United Kingdom & & & & \\
\hline & Other ethnicity & 0.085 & 0.009 & 0.137 & 0.534 \\
\hline & Ethnicity not reported & 0.067 & 0.020 & 0.045 & 0.139 \\
\hline & Number of children older than child & 0.106 & 0.089 & 0.022 & 0.000 \\
\hline & $\begin{array}{l}\text { Mother's age at completion of } \\
\text { education }\end{array}$ & 0.005 & 0.008 & 0.008 & 0.577 \\
\hline & Persons per room ratio & 0.316 & 0.072 & 0.068 & 0.000 \\
\hline & Parent marital status at birth & -0.064 & -0.010 & 0.091 & 0.481 \\
\hline & Premarital conception & 0.051 & 0.012 & 0.065 & 0.429 \\
\hline & Mother's age at delivery & -0.028 & -0.122 & 0.004 & 0.000 \\
\hline \multirow{3}{*}{$\begin{array}{l}\text { Cohort } \\
\text { member } \\
\text { mother's } \\
\text { smoking } \\
\text { status } \\
\end{array}$} & Reference category: Non-smoker & & & & \\
\hline & Stopped smoking pre-pregnancy & 0.051 & 0.014 & 0.052 & 0.320 \\
\hline & Smoked during pregnancy & 0.076 & 0.031 & 0.036 & 0.035 \\
\hline \multirow[t]{4}{*}{ Breastfeeding } & Reference category: Never breastfed & & & & \\
\hline & Breastfed $<3$ months & -0.036 & -0.013 & 0.039 & 0.350 \\
\hline & Breastfed $\geq 3$ months & 0.089 & 0.025 & 0.052 & 0.087 \\
\hline & $\begin{array}{l}\text { Cohort member's mother working } \\
\text { status }\end{array}$ & 0.091 & 0.035 & 0.040 & 0.022 \\
\hline \multicolumn{6}{|c|}{ Independent Variables } \\
\hline \multirow{2}{*}{$\begin{array}{l}\text { Place of } \\
\text { delivery }\end{array}$} & Reference category: At home & & & & \\
\hline & Medical facility & -0.146 & -0.043 & 0.048 & 0.003 \\
\hline
\end{tabular}

In summary, for the reproduction outcome, the results of the dependent variable of Outcome 2A fell into the predicted direction, while the results of Outcome 2B did not fall in the predicted direction. The controls that had an influence on the reproductive outcomes included the ethnicity category of 'other', sex of cohort member, persons per room ratio, number of children older than child, mother's age at delivery, smoking during 
pregnancy of cohort member, breastfeeding for at least three months or more, and working status of cohort member's mother at the time of delivery. For Outcome 2A with the dependent variable of age of menarche, the independent variable that had an impact included place and attendant at delivery. Being born in a medical facility with a medical practitioner increased the likelihood of having an earlier age of menarche and was in the predicted direction, while being born at home with a medical practitioner also resulted in an earlier age of menarche which did not have the initial impact I was expecting. For Outcome 2B with the dependent variable of total number of offspring, the independent variable that had an impact included place of delivery. Those cohort members who were born at home were more likely to have more offspring themselves and this impact was in the predicted direction.

\section{Mental Health Outcome - Hypothesis 3}

In this section, I looked at the best reduced model for the mental health outcome of (3A) depression. I included the variable of depression as representative of mental health status due to connections drawn between the gut microbiota and mental health via the gut-brain axis. Including the variable depression allowed me to address Hypothesis 3:

If there is a link between birthing conditions and the development of the gut microbiota, and there is a connection between digestive health and mental health, then I expected to see digestive health mediate the relationship between birthing conditions and depression. Specifically, I expected to see a correlation between birthing conditions that resulted in a greater number of digestive issues and an increase in the occurrence of depression. 


\section{Outcome 3A - Depression}

\section{Control variables}

Sex of cohort member was highly significant with an odds ratio greater than 1 $(\operatorname{Exp}(B)=2.176, p<.001)$. This indicated that being male significantly increased the odds of having depression by 2.2 times. Parent marital status at birth was significant with an odds ratio less than $1(\operatorname{Exp}(\mathrm{B})=.761, \mathrm{p}=.083)$. This indicated that having parents who were married before a cohort member was born decreased the odds of having depression by .76 times. Premarital conception was significant and had an odds ratio greater than 1 $(\operatorname{Exp}(B)=1.122, p=.072)$, indicating that being conceived before parents were married increased the odds of developing depression by 1.1 times. Regarding the smoking status of the cohort member's mother during pregnancy, those who ceased smoking prepregnancy produced a significant result with an odds ratio greater than $1(\operatorname{Exp}(B)=1.247$, $\mathrm{p}=.016$ ). As well, smoking during pregnancy was also significant and had an odds ratio greater than $1(\operatorname{Exp}(B)=1.205, \mathrm{p}=.004)$. Compared to those whose mothers never smoked, for those whose mothers stopped smoking prior to pregnancy or smoked during their pregnancy with the cohort member, this increased the odds of those cohort members developing depression by 1.2 times.

\section{Independent variables}

For Outcome 3A, I looked at the impact of birthing conditions on the mental health outcome of depression. Since no independent variables were significant at $\mathrm{p}<.10$, no independent variables were retained in the reduced model. 


\section{Assumptions}

All assumptions of the logistic regression model were met. See Appendix A for tests of assumptions.

Table 12. Outcome 3A logistic regression statistical results for the dependent variable depression. Model $\mathbf{n}=12706$. Model Nagelkerke R2 = 0.04 .

\begin{tabular}{|c|c|c|c|c|c|}
\hline Outcome 3A & & B & $\begin{array}{l}\text { Std. } \\
\text { Error }\end{array}$ & Sig. & $\operatorname{Exp}(B)$ \\
\hline & (Constant) & -1.786 & 0.339 & $<0.001$ & 0.168 \\
\hline \multicolumn{6}{|l|}{ Controls } \\
\hline & Multiplicity & 0.031 & 0.208 & 0.882 & 1.031 \\
\hline & Sex of cohort member & 0.778 & 0.061 & $<0.001$ & 2.176 \\
\hline \multirow[t]{9}{*}{ Ethnicity } & Reference category: United Kingdom & & & 0.227 & \\
\hline & Other ethnicity & -0.386 & 0.256 & 0.132 & 0.680 \\
\hline & Ethnicity not reported & 0.061 & 0.081 & 0.45 & 1.063 \\
\hline & Number of children older than child & 0.041 & 0.035 & 0.242 & 1.042 \\
\hline & $\begin{array}{l}\text { Mother's age at completion of } \\
\text { education }\end{array}$ & -0.019 & 0.014 & 0.171 & 0.981 \\
\hline & Persons per room ratio & 0.061 & 0.118 & 0.605 & 1.063 \\
\hline & Parent marital status at birth & -0.273 & 0.158 & 0.083 & 0.761 \\
\hline & Premarital conception & 0.202 & 0.112 & 0.072 & 1.223 \\
\hline & Mother's age at delivery & 0.006 & 0.006 & 0.349 & 1.006 \\
\hline \multirow{3}{*}{$\begin{array}{l}\text { Cohort } \\
\text { member } \\
\text { mother's } \\
\text { smoking } \\
\text { status }\end{array}$} & Reference category: Non-smoker & & & 0.006 & \\
\hline & Stopped smoking pre-pregnancy & 0.221 & 0.092 & 0.016 & 1.247 \\
\hline & Smoked during pregnancy & 0.187 & 0.065 & 0.004 & 1.205 \\
\hline \multirow[t]{3}{*}{ Breastfeeding } & Reference category: Never breastfed & & & 0.487 & \\
\hline & Breastfed $<3$ months & 0.080 & 0.069 & 0.246 & 1.084 \\
\hline & Breastfed $\geq 3$ months & -0.002 & 0.098 & 0.985 & 0.998 \\
\hline
\end{tabular}

In summary, for the mental health outcome, no significant independent variables

were found at $\mathrm{p}<.10$, and therefore no birthing conditions predicted the dependent variable of depression. The control variables that had an influence on the likelihood of developing the mental health outcome of depression included sex of cohort member, parent marital status, premarital conception, maternal smoking before pregnancy, and maternal smoking during pregnancy. 
In conclusion, in this chapter I looked at whether birth conditions were associated with overall health, reproduction, and mental health outcomes. The overall health outcome included Outcome 1A infections and childhood diseases, Outcome 1B allergy, skin, and joint issues, Outcome 1C respiratory issues, and Outcome 1D digestive issues. For Outcome 1A, the independent variables that predicted an impact on the likelihood of having infections and childhood diseases were place of delivery and pain relief during labor. The impact of place of delivery was in the predicted direction, while pain relief during delivery did not have the impact I expected. For Outcome 1B, no independent variables predicted the likelihood of having allergies, skin, and joint issues. For Outcome 1C, the independent variables that predicted an impact on the likelihood of having respiratory issues were place of delivery, assisted vaginal delivery, elective cesarean delivery, and use of pain relief during labor. The impact of place of delivery, assisted vaginal delivery, and use of pain relief during labor were in the predicted direction, while elective cesarean did not have the impact I expected. For Outcome 1D, the independent variable that predicted an impact on digestive issues was anesthetic use, and the impact of anesthetic use was in the predicted direction. Next, the reproduction outcome included Outcome 2A age of menarche and Outcome 2B total number of offspring. For Outcome $2 \mathrm{~A}$ age of menarche, the independent variable that had an impact included place and attendant at delivery. The impact of being born in a medical facility with a medical practitioner was in the predicted direction, while being born at home with a medical practitioner did not have the initial impact I was expecting. For Outcome 2B total number of offspring, the independent variable that had an impact included place of delivery, and the impact of being born at home was in the predicted direction. Lastly, the mental health 
outcome included Outcome 3A depression. For Outcome 3A depression, no independent variables no independent variables predicted the likelihood of a cohort member having depression. 


\section{CHAPTER FOUR: DISCUSSION}

In this chapter, I will discuss the results of the best reduced model for each of the dependent variables across the three outcomes of (1) overall health, (2) reproduction, and (3) mental health. I conclude each section with a summary of my findings for that outcome and discuss whether the results met expectations for the corresponding hypothesis. For the overall health outcome, the dependent variables that were analyzed for Hypothesis 1 include (1A) infections and childhood diseases, (1B) allergy, skin, and joint issues, (1C) respiratory issues, and (1D) digestive issues. Next, for the reproduction outcome, the dependent variables that were analyzed for Hypothesis 2 include (2A) age of menarche and (2B) total number of offspring. Lastly, for the mental health outcome, the dependent variable that was analyzed for Hypothesis 3 includes (3A) depression. After discussing each of the three outcomes and their hypotheses, I conclude the chapter with a brief discussion of the implications from my research, its limitations, and suggestions for future research.

\section{Overall Health Outcome - Hypothesis 1}

In this section, I discuss the results from the best reduced models for the four composite variables of the overall health outcome in relation to Hypothesis 1. Hypothesis 1 stated that, if modern technological birthing conditions influence the development of the immune system via the gut microbiota, then I expected to see higher rates of immune dysfunction, including a higher likelihood of (1A) infections and childhood diseases, (1B) allergy, skin, and joint issues, (1C) respiratory issues, and (1D) digestive issues. In 
determining whether expectations for Hypothesis 1 were met, I address each outcome below with their respective predictions and results. I conclude this section with a discussion of the results from the overall health outcome and their relation to Hypothesis 1.

$\underline{\text { Outcome 1A - Infections and Childhood Diseases }}$

\section{Control Variables}

For Outcome 1A, the control variables that had a significant impact included the ethnicity categories of other ethnicity and ethnicity not reported, smoking during pregnancy, breastfeeding between 0-3 months of age, and the multiplicity of twin birth. For the control variable of ethnicity, both other ethnicity $(\beta=-.037, p=.009)$ and ethnicity not reported $(\beta=-.026, \mathrm{p}<.001)$ had significant impacts that indicated a negative correlation between having an ethnicity other than United Kingdom or not reporting one's ethnicity and having a lower risk of infections and childhood diseases. A plausible genetic factor is at play that potentially accounts for the differences observed across the categories of ethnicity that could be influencing the level of risk of infections and childhood diseases such that those of United Kingdom ethnicity have a greater genetically related risk of susceptibility to infections and childhood diseases compared to those cohort members of other ethnicities as well as those who did not report ethnicity. Unfortunately, no additional information was included in the study to account for the reason cohort members in the category of 'ethnicity not reported' chose not to report their ethnicity. For smoking during pregnancy of cohort member, as expected, this variable had a significant impact $(\beta=.021, \mathrm{p}<.001)$, indicating that a cohort member born to a mother who smoked during her pregnancy had a significantly higher likelihood of 
developing infections and childhood diseases. Smoking during pregnancy has been welldocumented to have significant negative impacts on development in-utero by the introduction of toxins from tobacco products and by decreasing oxygen supply to a growing fetus (CDC 2017). These conditions present an early life stress, which could impact the gut microbiota and development of the immune system as well as lead to poor fetal development, resulting in an increased risk of developing infections and childhood diseases. For the variable of breastfeeding, compared to those who were never breastfed, breastfeeding between 0-3 months $(\beta=-.009, \mathrm{p}=.042)$ had an impact such that being breastfed during the first three months of life resulted in a slightly lower likelihood of developing infections and childhood diseases. This impact was as expected since the benefits of breastfeeding are widely acknowledged in the literature in supporting the colonization of the gut microbiota and its influence on the development of the immune system (Rodríguez et al. 2015). According to the WHO, the benefits of breastfeeding reduce the potential for child morbidity and mortality specifically related to the development of infectious childhood diseases (Horta and Victora 2013). For the control variable of multiplicity, as expected, being been born a twin $(\beta=.023, p=.067)$ increased the likelihood of developing infections and childhood diseases. Multi-fetal births are considered high-risk and contribute to higher rates of childhood mortality (Hong 2006). Pre-term births and low birthweight due to competition for resources are associated with multi-fetal births with a greater risk for health and developmental problems (Blondel et al. 2002). These variables had a significant impact on the likelihood of a cohort member developing infections and childhood diseases and thus were controlled for in this model. 


\section{Independent Variables}

For Outcome 1A with the dependent variable of infections and childhood diseases, I predicted that, if modern technological birthing conditions are a form of early life stress, then I would find a correlation between technological birthing conditions and a higher rate of infections and childhood diseases. The independent variables that were significant in Outcome 1A included place of delivery and pain relief during labor. The impact of place of delivery $(\beta=.01, \mathrm{p}=.068)$ was as expected and indicated a correlation between being born in a medical facility and the slightly greater likelihood of developing infections and childhood diseases. There is a greater probability of being exposed to pathogenic bacteria and viruses present in a medical facility, and this exposure could have had an adverse effect on the development of the cohort members' gut microbiota as a neonate, as well as increasing exposure to contractible diseases, which could represent an early life stress on the cohort member. Results for pain relief during labor $(\beta=-.013$, $\mathrm{p}=.062$ ) were contrary to expectations and indicated an inverse relationship between a cohort member's mother having received pain relief during labor and a decreased risk for the cohort member of developing infections and childhood diseases. A potential explanation for this result is that there was a possible correlation between the stress and pain experienced during labor by the mother and the corresponding stress experienced by a fetus, such that a decrease in stress for the birthing mother could result in a decrease in stress for the cohort member during their birth. Conditions presenting an early life stress at birth could have important consequences on the development of a neonate's immune system and susceptibility to infections and childhood diseases. 
These results both support and do not support my prediction for Outcome 1A. While the impact of place of delivery supports my prediction that, if modern technological birthing conditions are a form of early life stress, then I would find a correlation between technological birthing conditions and a higher rate of infections and childhood diseases, the result for pain relief during labor contradicts expectations. Although it contradicted expectations and therefore does not support my prediction for Outcome 1A, the impact of pain relief during labor may in a way provide indirect support. While pain relief during labor would be considered a technological birthing condition, if stress for the birthing mother during labor is a form of early life stress for a fetus, then I would expect to find a correlation between pain relief during labor and a lower occurrence of infections and childhood diseases, of which is supported by my results.

Outcome 1B - Allergies, Skin, and Joint Issues

\section{Control Variables}

For Outcome 1B, the control variables that had a significant impact included sex of cohort member, the ethnicity category of ethnicity not reported, number of children older than child, persons per room ratio, premarital conception, mother's age at delivery, and breastfeeding between 0-3 months of age and 3+ months. Sex of cohort member $(\operatorname{Exp}(\mathrm{B})=1.367, \mathrm{p}<.001)$ had a highly significant impact that indicated being male increased the likelihood of having allergy, skin and joint issues by 1.37 times. A disparity may exist in the influence of biological sex on the likelihood of developing allergy, skin, and joint issues such that males in this birth cohort are more likely to develop these type of health issues. For the variable of ethnicity, ethnicity not reported $(\operatorname{Exp}(B)=1.151$, 
$\mathrm{p}=.020$ ) had a significant impact that indicated that, compared to those who reported having an ethnicity of United Kingdom, the likelihood of having allergy, skin and joint issues increased by 1.15 times for those who did not report their ethnicity. Since it is unknown why some cohort members did not report their ethnicity, it is difficult to determine the potential link between those who did not report their ethnicity and their increased risk of developing allergy, skin, and joint issues. For number of children older than child $(\operatorname{Exp}(B)=.906, p<.001)$, this variable had a significant impact, indicating that, for every additional older sibling a cohort member had, the likelihood of having allergy, skin, or joint issues decreased by .91 times. This was contrary to expectations since a greater number of older siblings represents a greater parental resource distribution across siblings, a potential for access to a lower quality diet, and an increased likelihood of exposure to pathogens and disease risk (Downey 1995; Hart and Smith 2003). For persons per room ratio $(\operatorname{Exp}(B)=.783, p=.005)$, this variable had a significant impact such that, for every unit increase in persons per room ratio, the likelihood of having allergy, joint, or skin issues decreased by .78 times. Since persons per room ratio is an indicator of socioeconomic status, a higher persons per room ratio, indicating lower socioeconomic status, was expected to correlate with a greater likelihood of developing allergy, skin, and joint issues. However, this was not the case and, instead, this result appears to be consistent with the hygiene hypothesis. According to the hygiene hypothesis, the absence of early exposure to infections and childhood diseases increases one's susceptibility to allergic diseases by suppressing the development of a healthy immune system (Delli and Lernmark 2016). Therefore, since high socioeconomic status is often associated with a decrease in exposure to infections and childhood diseases, this would be expected to lead 
to an increase in the development of allergic diseases, which is consistent with my findings for the relationship between persons per room ratio and the likelihood of developing allergy, skin, and joint issues. Another potential explanation is that an underlying connection may exist between socioeconomic status and the location in which cohort members grew up. As previously discussed in the Methods section in regards to the cultural context of the 1970 British Cohort, air quality was a major concern in 1970 in the United Kingdom due to high emissions from major air pollutants (National Statistics 2016). Since there is a greater dependence on energy in population dense areas such as large cities, different areas in the United Kingdom experienced varying degrees of poor air quality conditions in the 1970s (Department for Environment, Food \& Rural Affairs N.d.; Pearce 2016). Thus, the location in which a cohort member grew up could potentially influence whether a cohort member is more likely to develop allergy, skin, and joint issues due to air quality conditions. The variable of premarital conception $(\operatorname{Exp}(B)=.726, p<.001)$ was also highly significant, indicating that being conceived when parents were unmarried decreased the likelihood of developing allergy, skin, or joint issues by .73 times. This was also contrary to expectations as premarital conception was included to account for the influence of potential parental investment. Since the variable marital status was not also significant, this leads me to presume that premarital conception was not a good indicator for potential parental investment. The impacts of premarital conception and parental marital status in the subsequent outcome, Outcome 1C, also provided support for this speculation that premarital conception was not a good indicator for potential parental investment, and these variables might be more associated with wealth. For mother's age at delivery $(\operatorname{Exp}(\mathrm{B})=1.009, \mathrm{p}=.069)$, this variable had a 
negative correlation indicating that, for each year older a cohort member's mother was at their delivery, the likelihood of developing allergy, skin, or joint issues increased slightly. This slight increased risk of developing these health issues is likely related to genetic factors that are associated with advanced maternal risk of negative pregnancy and perinatal outcomes (Blomberg, Tyrberg, and Kjølhede 2014). For breastfeeding, compared to those who were never breastfed, breastfeeding between 0-3 months $(\operatorname{Exp}(\mathrm{B})=1.137, \mathrm{p}=.012)$ and breastfeeding at least 3 months or more $(\operatorname{Exp}(\mathrm{B})=1.491$, $\mathrm{p}<.001$ ) increased the likelihood of having allergy, skin, and joint issues by 1.1 times and 1.5 times, respectively. This was contrary to expectations as research indicates that breastfeeding contributes to a reduction in morbidity and mortality in childhood (Horta and Victora 2013), and early infant diet has been shown to have an important role in the colonization of the infant gut microbiota and child health (Rodríguez et al. 2015). However, there may be a potential underlying link with length of breastfeeding and another variable, such as socioeconomic status, that could help to explain this deviation from expectation. These variables demonstrated a significant impact on the likelihood of a cohort member developing allergy, skin, or joint issues and thus were included as controls in this model.

\section{Independent Variables}

For Outcome 1B with the dependent variable of allergies, skin and joint issues, I predicted that, if modern technological birthing conditions are a form early life stress, then I would find a correlation between technological birthing conditions and a higher rate of allergies, skin, and joint issues. Since no independent variables were significant at $\mathrm{p}<.10$ in Outcome 1B, no independent variables predicted the likelihood of developing 
allergies, skin, and joint issues in this birth cohort. Therefore, this led me to reject my prediction for Outcome 1B.

\section{Outcome 1C - Respiratory Issues}

\section{Control Variables}

For Outcome $1 \mathrm{C}$, the control variables that had a significant impact included sex of cohort member, number of children older than child, mother's age at completion of education, persons per room ratio, parent marital status, premarital conception, and smoking during pregnancy. Sex of cohort member $(\beta=-.022, \mathrm{p}<.001)$ had a highly significant impact such that being female was correlated with an increased risk of having respiratory issues during one's lifetime. There may be a genetic factor or bias that potentially explains the disparity in the influence of biological sex on the likelihood of developing respiratory issues such that females in this birth cohort were more likely to develop issues related to their respiratory health or were more susceptible to respiratory issues related to air quality. Further investigation is required in order to determine the basis for this disparity. For number of children older than child $(\beta=.008, p=.020)$, the number of older siblings a cohort member had had a significant impact, with a greater number of older siblings correlated to an increased likelihood of developing respiratory issues. As expected, since a greater number of older siblings represents a greater parental resource distribution, there is a potential for lower quality living conditions and, subsequently, an increased likelihood of exposure to pathogens and disease risk (Downey 1995; Hart and Smith 2003). Against expectation, mother's age at completion of education $(\beta=.003, \mathrm{p}=.006)$ had a slight but significant impact with a positive correlation between higher maternal educational achievement and a greater likelihood of a cohort 
member developing respiratory issues. Maternal educational achievement is an indicator of socioeconomic status so, as maternal age of completion of education increases, it is expected that socioeconomic status also increases, with an expected decrease in the likelihood of developing respiratory issues; however, this was not the observed result. There may be a confounding variable influencing the relationship between maternal age at completion of education and risk of child developing respiratory issues. Concerns of a confounding variable were also raised by the following variable of persons per room ratio. Persons per room ratio $(\beta=-.050, \mathrm{p}<.001)$ had a highly significant impact with a correlation between a higher persons per room ratio and a lower likelihood of developing respiratory issues. This indicates that a cohort member who grew up in more crowded living conditions had a lower likelihood of developing respiratory issues. This impact was contrary to expectation since persons per room ratio is an indicator of socioeconomic status and greater wealth is often associated with improved child health outcomes. As discussed in the previous outcome, Outcome 1B, there may be an underlying connection with higher socioeconomic status and the location where cohort members grew up. With different areas in the United Kingdom experiencing varying degrees of poor air quality conditions prevalent during the 1970s, location of residence may, therefore, account for the confounding factor. While I attempted to control for confounding factors in my experimental design, I did not control for the potential confounding impact of urban versus rural settlement differences. This factor may account for a link between a slightly higher level of maternal educational achievement and a lower persons per room ratio, both of which could represent greater wealth, to urban locations with more air pollution that could potentially account for the higher likelihood of a cohort member developing 
respiratory issues. To account for the influence of potential parental investment on child health, parental marital status at the time of the cohort member's birth $(\beta=-.034, p=.037)$ was included and had a significant impact such that those cohort members born to parents who were married were less likely to develop respiratory issues. Since greater parental investment is associated with improved child health (Lawson et al. 2017), this impact was therefore expected since those cohort members whose parents were married were less likely to develop respiratory issues. In contrast, premarital conception $(\beta=-.019, p=.072)$ was also significant but indicated that cohort members who were conceived before their parents were married were less likely to develop respiratory issues. This was contrary to expectation as premarital conception was included to account for the influence of potential parental investment. Since the variable of parent marital status was also significant but with the opposite impact, this leads me to presume that premarital conception was not a good indicator for potential parental investment, as also previously discussed earlier in this chapter regarding Outcome 1B, and this variable might be associated with wealth. To control for the impacts of maternal smoking, smoking during pregnancy of cohort member $(\beta=.016, \mathrm{p}=.011)$ was included and had a significant impact indicating that, compared to those who were non-smokers, a cohort member born to a mother who smoked during her pregnancy had a higher likelihood of having respiratory issues. This was as expected since, as previously discussed in Outcome 1A, the evidence of smoking during pregnancy has been well-established to have significant negative impacts on development in-utero through the introduction of toxins and by decreasing oxygen supply that adversely affects fetal development (CDC 2017). Those cohort members whose mothers smoked during pregnancy also likely grew up in homes with a 
smoker increasing the likelihood of respiratory issues. Since these variables had a significant impact on the likelihood of a cohort member having respiratory issues, they were controlled for in this model.

\section{Independent Variables}

For Outcome $1 \mathrm{C}$ with the dependent variable of respiratory issues, I predicted that, if modern technological birthing conditions are a form of early life stress, then I would find a correlation between technological birthing conditions and a higher rate of respiratory issues. The independent variables that were significant in Outcome 1C included place of delivery, method of delivery, and pain relief during labor. Similar to the results for Outcome 1A, as expected, place of delivery $(\beta=.022, p=.008)$ had a significant positive correlation between being born in a medical facility and the occurrence of developing respiratory issues. Since there is a greater likelihood of being exposed to pathogens in a medical facility, this exposure could have had an adverse effect on the development of the cohort members' gut microbiota as a neonate, thus representing an early life stress for the cohort member and potentially resulting in a higher occurrence of respiratory issues.

In addition to the impact of place of delivery on the likelihood of developing respiratory issues, method of delivery also had a significant impact. Compared to those born through a vaginal unassisted delivery, delivery that started and ended as a cesarean delivery $(\beta=-.074, \mathrm{p}=.004)$, also known as an elective cesarean delivery, had a significant impact that indicated being born by elective cesarean delivery was correlated with a lower likelihood of developing respiratory issues. This was contrary to expectation since numerous studies indicate that babies born by cesarean delivery have a higher likelihood 
of developing respiratory issues, and these studies emphasize elective cesarean delivery and its link with increased risk of respiratory issues (Levine et al. 2001; Dehdashtian, Riazi, and Aletayeb 2008).

According to a study conducted by the United Kingdom's Department of Health in 2001, while elective cesarean deliveries accounted for $21 \%$ of all cesarean births in the United Kingdom, the rate of elective cesareans ranged from $10 \%$ to $30 \%$ between hospitals (Parliament Postnote 2002). Since these figures are on a national level, they can therefore mask local variation, and, according to findings from Barley et al. (2004), the odds of having an elective cesarean in England are lowest for a fifth of the population living in the most deprived areas. From this, the impacts of elective cesarean which result in a lower likelihood of respiratory issues may be linked with socioeconomic status, where lower socioeconomic status is associated with less respiratory issues. However, the researchers did not discover a connection between higher rates of elective cesarean deliveries with increasing affluence. Barley notes that, rather than "too posh to push", a more likely circumstance may be "too proletarian for a cesarean" (Barley et al. 2004, 1399). More research is needed to understand these dynamics. Going back to the results for the control variables of persons per room ratio and maternal educational achievement, which indicated that those cohort members of lower socioeconomic status were less likely to have respiratory issues, these results contradict the finding of elective cesarean delivery resulting in a lower likelihood of developing respiratory issues. Additionally, out of 17,000 births, elective cesarean delivery accounted for a minute fraction, or $1.5 \%$, of all births. Ultimately, these results are not as predicted and appear to contradict one another within the model, and it is unclear what may explain this discrepancy in my 
findings for the outcome of respiratory issues. Future research is needed to explain this in more detail along with controlling for urban versus rural-based differences.

In addition to delivery that started and ended as a cesarean delivery, compared to unassisted vaginal delivery, vaginal assisted delivery $(\beta=-.018, \mathrm{p}=.056)$ also had a significant impact and indicated being born by an assisted vaginal delivery was correlated with a lower occurrence of developing respiratory issues. This result was as expected since research indicates that being born by vaginal delivery is associated with a decrease in the incidence of respiratory issues (Dehdashtian, Riazi, and Aletayeb 2008; Petrou and Khan 2013). However, contrary to expectations, the use of interventions was expected to represent a form of early life stress and have some degree of impact on the likelihood of delivering respiratory issues between that of unassisted vaginal delivery and cesarean delivery, with the expectation that both emergency and elective cesarean deliveries would result in a greater likelihood of developing respiratory issues. This was not the case, though, and suggests that the use of interventions during an assisted vaginal delivery does not pose a significant early life stress on a neonate that would influence the development of respiratory issues.

Another birthing condition that had an impact on the likelihood of developing respiratory issues is the use of maternal pain relief during labor. The impact of pain relief during labor $(\beta=-.030, p=.015)$ was contrary to expectation and had an inverse relationship, where a cohort member's mother receiving pain relief during labor is associated with a decreased likelihood of the cohort member developing respiratory issues. This finding was also similar to the results for Outcome 1A. There is a potential correlation between stress, in the form of pain, experienced during labor by the birthing 
mother and corresponding fetal stress, such that a decrease in stress for a birthing mother could result in a decrease in stress for the cohort member at birth. With a decrease in early life stress at birth, this could lead to a decrease in an infant's susceptibility to respiratory issues.

These results both demonstrate support for and contradict my prediction for Outcome 1C. Similar to my findings in Outcome 1A, place of delivery and pain relief both support and do not support my prediction, respectively, that, if modern technological birthing conditions are a form of early life stress, then I would find a correlation between technological birthing conditions and a higher rate of respiratory issues. As discussed in Outcome 1A, while the use of pain relief during labor is considered a technological birthing condition, maternal pain and stress experienced during childbirth could be considered a form of early life stress for a child. Therefore, if use of pain relief results in a reduction of stress during labor for the birthing mother and, subsequently, early life stress for the child, then the impact of pain relief may, in a way, provide a form of indirect support for my prediction that those birthing conditions which are a form of early life stress would result in a greater occurrence of respiratory issues. The impact of assisted vaginal delivery supports my prediction for Outcome $1 \mathrm{C}$ since the use of interventions during vaginal delivery did not represent a form of early life stress. However, the impact of elective cesarean delivery contradicted my prediction for Outcome 1C since those cohort members who were delivered by elective cesarean also had a lower likelihood of developing respiratory issues. This result was not as predicted, and it is unclear what could account for this discrepancy in my results. Future research is needed to explore this finding in more detail. As previously discussed, there may also be 
a confounding variable of urban versus rural location potentially influencing the likelihood of developing respiratory issues, given differences in air quality, which merits exploration in future research.

\section{$\underline{\text { Outcome 1D - Digestive Issues }}$}

\section{Control Variables}

For Outcome 1D, the control variables that had a significant impact included sex of cohort member, the category of ethnicity not reported, number of children older than child, and breastfeeding for at least three months or more. Sex of cohort member $(\operatorname{Exp}(B)=.699, \mathrm{p}<.001)$ was highly significant and indicated that being male decreased the likelihood of having digestive issues by .70 times. A genetic factor may exist that potentially explains the disparity in the influence of biological sex on the likelihood of developing digestive issues such that males in this birth cohort were more likely to develop issues related to their digestive health. For the variable of ethnicity, the category of ethnicity not reported $(\operatorname{Exp}(B)=1.428, \mathrm{p}<.001)$ was highly significant and indicated that, compared to those who reported having an ethnicity of United Kingdom, the likelihood of having digestive issues increased by 1.4 times for those who did not report their ethnicity. As discussed in Outcome 1B, since it is unknown why some cohort members did not report their ethnicity, it is difficult to deduce a potential link between likelihood of developing digestive issues and those cohort members who did not report their ethnicity. The number of older siblings a cohort member had was significant $(\operatorname{Exp}(\mathrm{B})=1.123, \mathrm{p}=.006)$ and indicated that, for each additional older sibling a cohort member had, the likelihood of digestive issues increased by 1.1 times. As expected, since an increasingly greater number of older siblings for a cohort member represents a greater 
parental resource distribution, there is a potential for lower quality living conditions, access to a lower quality diet, and an increased likelihood of exposure to pathogens and disease risk (Downey 1995; Hart and Smith 2003). This exposure would likely impact digestive health leading to a greater number of digestive issues. For breastfeeding, compared to those who were never breastfeed, breastfeeding for a duration of at least three months or more $(\operatorname{Exp}(B)=.690, \mathrm{p}=.006)$ was significant and, as expected, indicated that the likelihood of developing digestive issues decreased by .69 times for cohort members who were breastfed for a longer duration. As discussed at length in the introduction chapter, the benefits of breastfeeding have been well-documented to provide significant benefits for both digestive health and the development of the gut microbiota. The World Health Organization $(2002 ; 2011)$ confirms this and asserts, as a global public health recommendation for optimal health and development, that infants should be exclusively breastfeed during the first six months of life. Because these variables had a significant impact on the likelihood of a cohort member developing digestive issues, they were controlled for in this model.

\section{Independent Variables}

For Outcome 1D with the dependent variable of digestive issues, I predicted that, if modern technological birthing conditions are a form of early life stress, then I would find a correlation between technological birthing conditions and a higher rate of digestive issues. The independent variable that was significant in Outcome 1D included maternal anesthetic use. The impact of anesthetic use during labor $(\operatorname{Exp}(B)=1.160, \mathrm{p}=.079)$ was an unexpected finding that indicated maternal anesthetic use during the birth of a cohort member increased the likelihood of that cohort member developing digestive issues by 
1.2 times. While I did not find conclusive evidence in the literature regarding the impact of maternal anesthetic use on neonatal outcomes, the results for Outcome 1D suggest that use of maternal anesthetics, which range from local to general anesthesia, poses an early life stress that slightly increases the likelihood of a cohort member developing digestive issues; however, this result is only marginally significant. Based on speculation, some amount of maternal anesthetics could get transferred to the fetus prior to delivery, potentially impacting the functioning of the digestive system of the neonate. If so, this has the potential for detrimental impacts on the development of the gut microbiota if it allowed for the opportunistic colonization of pathogens or bacteria early on in life which could lead to future digestive health issues. If other studies were to uncover similar results, this could be an interesting area of future research meriting further investigation.

\section{Overall Health Outcome Conclusion}

The results of the overall health outcome provide partial support for Hypothesis 1. Hypothesis 1 proposed that, if the technological birthing conditions influence the development of the immune system via the gut microbiota, then I expected to see a greater occurrence of immune dysfunction. While the results for Outcome 1B allergy, skin, and joint issues did not support Hypothesis 1 since no independent variables were significant, the results of Outcome 1D digestive issues provide support for Hypothesis 1. As well, the results for Outcomes 1A infections and childhood diseases and Outcome 1C respiratory issues provided partial support for Hypothesis 1. The independent variables for Outcome 1A that predicted an impact on the likelihood of having infections and childhood diseases were place of delivery and pain relief during labor which support and do not support Hypothesis 1, respectively. While pain relief during labor would be 
considered a technological birthing condition, the finding that the use of pain relief during labor resulted in a lower occurrence of infections and childhood diseases for a cohort member may provide indirect support for my prediction such that a reduction of stress for the birthing mother could present a reduction in early life stress for a fetus, leading to a lower occurrence of immune dysfunction. This outcome, therefore, provides partial support for Hypothesis 1. The use of maternal anesthetics during labor in Outcome 1D predicted the likelihood of developing digestive issues. With anesthetic use during labor potentially posing an early life stress for a child and disrupting the colonization of the infant gut microbiota, this finding also supports Hypothesis 1. For Outcome $1 \mathrm{C}$, the independent variables that predicted an impact on the likelihood of having respiratory issues were place of delivery, assisted vaginal delivery, elective cesarean delivery, and use of pain relief during labor. Similar to Outcome 1A, place of delivery and pain relief both supported and did not support Hypothesis 1, respectively, for Outcome 1C. However, the results for pain relief in Outcome 1C may provide a form of indirect support for Hypothesis 1 if a reduction of stress for the birthing mother could present a reduction in early life stress for a fetus, leading to a lower occurrence of respiratory issues. Compared to unassisted vaginal delivery, elective cesarean delivery predicted a lower likelihood of developing respiratory issues which is contrary to the expected impact and requires future research to explore this result in more detail. Therefore, the impact of elective cesarean delivery did not support Hypothesis 1. For Outcome 1B, since no birthing conditions predicted the likelihood of having allergies, skin, and joint issues in this birth cohort, this result did not support Hypothesis 1. From this, it is evident that 
the findings of the overall health outcome do provide partial support for my Hypothesis 1.

Results from the overall health outcome, namely Outcome 1A infections and childhood diseases and Outcome 1B allergy, skin, and joint issues, appear to be consistent with the hygiene hypothesis. As previously discussed in Outcome 1B, according to the hygiene hypothesis, absence of early exposure to infections and childhood diseases suppresses the development of a healthy immune system, thereby increasing one's susceptibility to allergic diseases (Delli and Lernmark 2016). Therefore, with increased exposure to infections and childhood diseases, this could lead to a decrease in the development of allergic diseases since exposure to infections and childhood diseases supports the natural development of a competent immune system. While the results for Outcome 1A support the idea that exposure to bacteria and pathogens in a medical facility at birth may lead to a slightly greater likelihood of developing infections and childhood diseases, since no independent variables were significant predictors in developing allergy, skin, or joint issues in Outcome 1B in this birth cohort, my results do not provide conclusive support for the hygiene hypothesis but are consistent with expectations such that those who had a greater likelihood of developing infections and childhood diseases did not also have a greater likelihood of developing allergic diseases.

While there are a number of interesting findings from the results of the overall health outcomes, what is even more interesting is the lack of significant results found in regard to method of delivery. Method of delivery is known to be one of the key factors that shape the early development of the gut microbiota and, with the continued rise of 
elective cesarean delivery worldwide, a wealth of research has been amassed demonstrating significant negative impacts of cesarean delivery on health outcomes through its disruption of the gut microbiota (Jandhyala, Talukdar, and Subramanyam 2015; Azad et al. 2013). As previously discussed in the Introduction, research indicates that the birthing condition of cesarean delivery is known to be a significant disruptor to the initial inoculation and development of the infant gut microbiota (Jandhyala, Talukdar, and Subramanyam 2015). Therefore, against expectation, I was surprised to find this birthing condition was not a significant predictor of negative health outcomes in this birth cohort.

To understand why we might be seeing this deviation from expectation, we have to look at the trends in birthing conditions at the time these cohort members were born. While the 1970 British Cohort was born at a time when we see a marked transition from giving birth at home to giving birth in a medical facility, with home births dropping from $30 \%$ in 1963 to $4.2 \%$ in 1974 , this birth cohort was born prior to the substantial rise in cesarean delivery (Nove, Berrington, and Matthews 2008). In 1970, the rate of cesarean delivery in the United Kingdom was a mere 4\% (Dobson 2001). In contrast, in 2001, more than 1 in 5 births in the United Kingdom were delivered by cesarean delivery, resulting in an increased rate of cesarean delivery to $21.5 \%$. So, while this birth cohort was born right at the cusp of when we see the transition to a more medicalized approach to childbirth in the United Kingdom, we are not yet seeing the negative impacts of cesarean delivery on health outcomes since cesarean delivery accounts for a total of $4.5 \%$ of births in this cohort, with elective cesarean only accounting for $1.5 \%$ of those births. This also begs the question of whether there could be another underlying trend that 
occurred simultaneously with the rise of cesarean delivery that is contributing to the negative impact of this method of delivery on health outcomes. If prophylactic antibiotic use was on a similar rise, this factor could contribute to the increase in negative health outcomes for cesarean delivery numerous other studies have observed but may not be captured in the 1970 British Cohort.

Additionally, another possibility may be that the lack of correlation seen in this birth cohort could be indicative that the relationship between method of delivery, particularly cesarean delivery, and negative health outcomes may not be as clear as it appears to be. Perhaps, it is not cesarean delivery that is solely responsible for these negative health outcomes other studies are finding but rather a combination of birthing conditions that are influencing the development of the gut microbiota and contributing to the negative health outcomes commonly associated with those born by cesarean delivery. Approaching future studies looking at health outcomes and their relationship with birthing conditions holistically may provide us with a more comprehensive understanding of the role birthing conditions have on the development of the gut microbiota and subsequent health outcomes.

\section{Reproduction Outcome - Hypothesis 2}

In this section, I discuss the results from the best reduced models for the reproduction outcome in relation to Hypothesis 2 . Hypothesis 2 stated that, if there is a relationship between birthing conditions and future reproduction, then, in the presence of adequate nutrition, with increased detriments on health, I expected to see life history speed up, such that there is $(2 \mathrm{~A})$ an earlier age of menarche and (2B) an increase in total number of offspring. In determining whether expectations for Hypothesis 2 were met, I 
address each reproductive outcome and their results below. For this discussion, I begin by discussing Outcome 2B, followed by a discussion of Outcome 2A. I conclude this section with a discussion of the results from the reproductive outcome and their relation to Hypothesis 2.

Outcome 2B-Total Number of Offspring

\section{Control Variables}

For Outcome $2 \mathrm{~B}$, the control variables that had a significant impact included sex of cohort member, persons per room ratio, number of children older than child, mother's age at delivery, smoking during pregnancy of cohort member, breastfeeding for at least three months or more, and working status of cohort member's mother at the time of delivery. Sex of cohort member $(\beta=.172, \mathrm{p}<.001)$ was highly significant and indicated that, compared to male cohort members, female cohort members had a greater number of offspring. Since the last available survey year included in this analysis is from 2004 , when cohort members are 42 years of age, the data does not capture the full reproduction of cohort members and may skew the data, particularly if male cohort members are reproducing at later ages than their female counterparts. For persons per room ratio $(\beta=.316, \mathrm{p}<.001)$, this variable was highly significant and indicated that there is a correlation between being born into a lower socioeconomic status, represented by a higher persons per room ratio, and having a greater number of offspring. The trade-off between offspring quantity and quality due to ecological variation in resources is a central prediction to life history theory (Hackman and Hruschka 2013). Somewhat counterintuitively, having more offspring with a lower parental investment of resources per child in the face of limited resources is proposed to be an adaptive reproductive 
strategy (Belsky, Steinberg, and Draper 1991). Additionally, number of children older than child $(\beta=.106, \mathrm{p}<.001)$ was also highly significant and indicated that those cohort members who had a greater number of older siblings were more likely to have a greater number of children themselves. The relative size of a family and the number of siblings a cohort member has may impact the size of family they themselves will have as an adult. For mother's age at delivery $(\beta=-.028, \mathrm{p}<.001)$, this variable was highly significant, indicating that the younger a cohort member's mother was at their delivery the greater number of total offspring a cohort member was likely to have themselves. This correlation may be getting at age of first reproduction, such that a cohort member may be more likely to begin their reproductive career at an earlier age if their mother gave birth to them at a younger age herself. Regarding maternal smoking, smoking during pregnancy of a cohort member $(\beta=.076, \mathrm{p}=.035)$ was significant and indicated that, compared to those cohort members whose mothers were non-smokers, a cohort member born to a mother who smoked throughout her pregnancy was more likely to have a greater number of offspring. Maternal smoking during pregnancy of a cohort member could represent an early life stress and extrinsic risk for the cohort member which would theoretically influence a cohort member's life history strategy (Hackman and Hruschka 2013). With higher levels of extrinsic risk influencing mortality, a faster life history trajectory could be adaptive with an earlier age of menarche and the potential for a greater number of total offspring due to the trade-off between offspring quantity-quality and parental investment (Lawson 2011). For breastfeeding, breastfeeding for at least three months or more $(\beta=.089, \mathrm{p}=.087)$ was significant and indicated that, compared to those who were never breastfed, cohort members who were breastfed for a duration 
longer than three months had a greater likelihood of having more offspring. Those born into a lower socioeconomic status whose parents may not have been able to afford the cost of formula would have likely been breastfed for a longer duration. This may be reflecting a potential connection between socioeconomic status and total number of offspring such that, as previously noted in persons per room ratio, being born into a lower socioeconomic status may be related to having a greater number of total offspring. For the variable of maternal working status, the working status of the cohort member's mother at the time of delivery $(\beta=.091, p=.022)$ was significant and indicated that those cohort members whose mothers worked had a great number of offspring themselves. Cohort member's whose mothers worked at the time of their delivery potentially worked out of necessity and so would have been of a lower socioeconomic status. So, this result may be, once again, reflecting the connection between socioeconomic status and total number of offspring. These variables had a significant impact on the total number of offspring a cohort member had and thus were controlled for in this model.

\section{Independent Variables}

For Outcome 2B with the dependent variable of total number of offspring, I predicted that, if there is a relationship between birthing conditions and future reproduction, then, in the presence of adequate nutrition, with increased detriments on health, I expected to find an increase in total number of offspring. The independent variable that was significant in Outcome 2B included place of delivery. Place of delivery $(\beta=-.0146, p=.003)$ was significant and indicated a correlation between being born at home and the likelihood of a cohort member having more offspring themselves. Since the results of the overall health outcome indicated that being born in a medical facility was 
shown to be associated with having a greater likelihood of respiratory issues and infections and childhood diseases, I expected being born in a medical facility would represent a form of early life stress. This early life stress via extrinsic risk could therefore influence a cohort member's life history trajectory with a faster life history potentially resulting in a greater number of total offspring. However, in this outcome, it is not being born in a medical facility that is significantly correlated with the greater likelihood of a cohort member having more offspring; rather, it is being born at home that is significantly correlated with having a greater number of offspring.

In addition to the correlation between being born at home and having a greater number of offspring, a higher persons per room ratio, as previously noted, is also significantly correlated with having a greater number of offspring. According to the United Kingdom's Department for Environment, Food, and Rural Affairs (2012), lower annual income in the United Kingdom tends to be associated with living in rural areas. While the National Healthcare Service provides free healthcare to all residents in the United Kingdom, hospitals in rural areas are likely to be more dispersed and could lead to a higher number of home births for cohort members born in rural areas due to accessibility and an increase in relative distance to the nearest hospital. Being born at home thus has a greater potential to be associated with lower socioeconomic status as well as rural residency.

From these results, it appears that the correlation between a cohort member being born at home and a cohort member having a greater number of offspring is likely related to relative wealth with the potential for an additional correlation with location of residence. However, future research is needed to investigate this relationship looking 
specifically at differences in urban versus rural residential patterns in this birth cohort. While there does appear to be a relationship between place of delivery of a cohort member and future reproduction, those cohort members with a greater total number of offspring had a likelihood of better health outcomes, which contradicts my expectation for Outcome 2B.

\section{Outcome 2A-Age of Menarche}

\section{Control Variables}

For Outcome 2A, the control variable that had a significant impact included the ethnicity category of ethnicity other than United Kingdom. Other ethnicity $(\beta=-.290$, $\mathrm{p}=.071$ ) had a significant impact that indicated a correlation between having an ethnicity other than United Kingdom and an earlier age of onset of menarche. Categories of "other ethnicity' were grouped together due to low survey responses and include Irish, other European, West Indian/Guyana, Indian, Pakistani, Bangladeshi, and mixed/other. Ethnicity was included to control for the potential influence of associated genetic and cultural variation on the outcome variables. Therefore, a potential genetic or cultural factor may account for the difference observed in age of onset of menarche with those of a United Kingdom ethnicity being more likely to have a slightly later age of menarche compared to other ethnicities. There is a potential for a confounding variable of socioeconomic status influencing the relationship between ethnicity and age of menarche in the United Kingdom, however further research will need to be conducted to explore whether ethnicity is correlated with socioeconomic status in this cohort. Since this variable had a significant impact on the age of menarche of a cohort member, it was controlled for in this model. 


\section{Independent Variables}

For Outcome 2A with the dependent variable of age of menarche, I predicted that, if there is a relationship between birthing conditions and future reproduction, then, in the presence of adequate nutrition, with increased detriments on health, I expected to find an earlier age of menarche. For the independent variable of place and attendant at delivery, the categories that were significant in Outcome $2 \mathrm{~A}$ included being born at home with a medical practitioner and being born in a medical facility with a medical practitioner. For the variable place and attendant at delivery of the cohort member, having been delivered at home with a medical practitioner $(\beta=-.605, \mathrm{p}=.014)$ was significant and indicated that, compared to those cohort members who were delivered at a medical facility with a midwife, these cohort members were more likely to have an earlier age of menarche. As well, being born at a medical facility with a medical practitioner $(\beta=-.102, p=.071)$ was also significant and indicated that, compared to those who were delivered at a medical facility with a midwife, these cohort members had an earlier age of onset of menarche, although this result was not as significant as the previous result for those born at home with a medical practitioner.

As previously discussed in the overall health outcome, I found that those cohort members who were born at a medical facility had worse health outcomes for both respiratory issues and infections and childhood diseases. In the present reproductive outcome, being born in a medical facility is also associated with an earlier age of menarche. This makes sense because, as previously discussed in Outcome 2B, the increase in negative health outcomes that are correlated with being born in a medical facility could represent a form of early life stress with a higher level of extrinsic risk. 
This higher level of extrinsic risk early on in life has the potential to influence life history trajectory and the trade-off between somatic and reproductive investment that could result in an earlier age of menarche (Hackman and Hruschka 2013). As well, being born in a medical facility with a medical practitioner is correlated with a lower persons per room ratio and a higher socioeconomic status, as illustrated in Figure 1 in the Results. With greater wealth, cohort members likely had better access to higher quality nutrition which could also facilitate the adaptive strategy of earlier investment in current reproduction via an earlier age of menarche associated with higher extrinsic risk.

Additionally, the results for Outcome 2A also indicate that being born at home with a medical practitioner is likewise associated with an earlier age of menarche. However, the results from the overall health outcome indicate being born at home is associated with improved health outcomes. While being born at home results in a decrease in the negative health outcomes included in this study, being born at home with a medical practitioner could, itself, be indicative of a stressful childbirth. In comparing the beta values for each of the categories of location and attendant at birth, having a medical practitioner at home has a larger beta value indicating a stronger effect of the location and attendant at birth on age of menarche. In this birth cohort, the most common location and attendant at birth was being born at a medical facility attended by a midwife. With a midwife being the most common birthing attendant, it is likely that a medical practitioner would attend to a birth for one of two reasons. First, if a birth is particularly stressful, it would likely be attended by a medical practitioner rather than a midwife. Secondly, if a family is wealthy and able to afford a medical practitioner, we may see a correlation between higher socioeconomic status and having a medical practitioner as the 
birthing attendant. According to Figure 1 in the Results, having a medical practitioner in a medical facility attend the birth of a cohort member is, in fact, correlated with a lower persons per room ratio, representing higher socioeconomic status, and this correlation is also statistically significantly different from the other three categories of location and attendant at birth. Figure 1 also indicates that being born in a medical facility, regardless of who attends the birth, tends to be associated with a mid to lower persons per room ratio. While being born at home covers a wider range of values for persons per room ratio, we do not see those cohort members represented in the lower end of persons per room ratio, and therefore of greater wealth, also represented in the category of being born at home. So, being born at home has a greater potential to be associated with lower socioeconomic status than being born in a medical facility, as also discussed in Outcome 2B. Along with the lower annual income in the United Kingdom tending to be associated with living in rural areas (Department for Environment, Food \& Rural Affairs 2012), since hospitals in rural areas are likely to be more dispersed and could lead to a higher number of home births, a medical practitioner attending a home birth under these circumstances is likely due to a complicated birth. Having a complicated birth could then pose an increase in extrinsic risk for the cohort member that was not accounted for by variables in this study. If having a medial practitioner at home is indicative of a stressful birth, then, according to life history theory, we would expect having a medical practitioner at home to result in an earlier age of menarche, and this does appear to be the case.

In looking at the variable of place and attendant at delivery and its impact on age of menarche, these results both support and do not support my prediction for Outcome 
2A, such that, with increased detriments on health, there is a relationship between birthing conditions and age of menarche. Interestingly, the results of the two categories of place and attendant at delivery predicted similar outcomes for age of menarche but for different reasons. While both groups of cohort members had a medical practitioner attend their birth, these cohort members likely had different extrinsic risk factors that stemmed from their birthing attendant and differing locations at birth and how these circumstances played a role in influencing an earlier onset of menarche. Since being born in a medical facility was associated with worse overall health outcomes, as indicated by the results of Outcome $1 \mathrm{~A}$ and $1 \mathrm{C}$, being born in a medical facility with a medical practitioner was associated with a higher degree of extrinsic risk from negative health outcomes that then resulted in an earlier age of menarche. Thus, the category of being born in a medical facility with a medical practitioner supports my prediction for Outcome 2A. In contrast, while being born at home was associated with improved overall health outcomes, as again indicated by Outcome $1 \mathrm{~A}$ and $1 \mathrm{C}$, a home birth attended by a medical practitioner could represent a more difficult birth and therefore a source of greater extrinsic risk that also resulted in an earlier age of menarche. If that is the case, the category of being born at home with a medical practitioner may provide some indirect support for my prediction for Outcome 2A. Therefore, while attendant and location of birth predict age of menarche in this cohort, this variable likely captures various extrinsic risk factors that confound this relationship and influence the age of onset of menarche.

\section{$\underline{\text { Reproduction Outcome Conclusion }}$}

At first it appeared that the two outcomes of the reproductive outcome provided only partial support for Hypothesis 2, however, upon combining my findings from 
Outcome $2 \mathrm{~A}$ and $2 \mathrm{~B}$, these outcomes do provide support for Hypothesis 2. Hypothesis 2 proposes that, if a relationship exists between birthing conditions and future reproduction, in the presence of adequate nutrition, with increased detriments on health, I would see evidence for life history speed up, resulting in an earlier age of menarche and an increase in total number of offspring. The results for Outcome 2B did not at first appear to support my expectation since being born at home was associated with better health outcomes, per the overall health outcome, yet resulted in a greater number of offspring. With being born in a medical facility associated with worse health outcomes, I expected this location of birth to represent a form of early life stress since it increased a cohort member's exposure to extrinsic risk. This would then, theoretically, influence a cohort member's life history trajectory, with a faster life history potentially resulting in a greater number of total offspring. However, per the discussion from Outcome 2A, being born at home with a medical practitioner could be representative of a more difficult childbirth, and thus an increase in extrinsic risk, that could influence life history trajectory and result in both an earlier age of menarche and an increase in total number of offspring. Therefore, while my results for Outcome $2 \mathrm{~B}$ and $2 \mathrm{~A}$ contradicted expectations, in regard to being born at home with a medical practitioner, the results may provide a form of indirect support for Hypothesis 2. The results for Outcome 2A, in regard to being born in a medical facility with a medical practitioner, provide some support for Hypothesis 2 since being born in a medical facility with a medical practitioner was correlated with worse overall health outcomes and an earlier age of menarche. 


\section{Mental Health Outcome - Hypothesis 3}

In this section, I discuss the results from the best reduced model for the mental health outcome in relation to Hypothesis 3 . Hypothesis 3 stated that, if birthing conditions are linked to the development of the gut microbiota and there is a connection between digestive health and mental health, then I expected to see digestive health mediate the relationship between birthing conditions and depression. Specifically, I expected to see a correlation between birthing conditions that resulted in a greater number of digestive issues and an increase in the occurrence of depression. In determining whether the expectation for Hypothesis 3 was met, I address the results for the outcome of depression below. I conclude this section with a discussion of the results from the mental health outcome and their relation to Hypothesis 3.

$\underline{\text { Outcome 3A - Depression }}$

\section{Control Variables}

For Outcome 3A, the control variables that had a significant impact included sex of cohort member, parent marital status at birth, premarital conception, and the smoking status of the cohort member's mother during pregnancy including both those who ceased smoking prior to pregnancy and those who smoked during pregnancy. Sex of cohort member $(\operatorname{Exp}(B)=2.176, p<.001)$ was highly significant and indicated that being male significantly increased the likelihood of having depression by 2.2 times. A genetic factor, or perhaps a cultural factor, may exist that could explain the disparity in the influence of biological sex on the likelihood of having depression such that males in this birth cohort were significantly more likely to develop depression at some point in their lives. Parent marital status at birth $(\operatorname{Exp}(B)=.761, p=.083)$ was also significant and indicated that 
cohort members whose parents were married before they were born were less likely to develop depression by .76 times. As discussed in Outcome 1D, since greater parental investment is associated with improved child health (Lawson et al. 2017), parent marital status was included to account for the influence of potential parental investment on child health outcomes. The impact of parent marital status was expected since cohort members who were born to parents who were married were less likely to develop depression, however this result is marginally significant. Additionally, premarital conception $(\operatorname{Exp}(B)=1.122, p=.072)$ was also significant, indicating that being conceived before parents were married increased the likelihood of developing depression by 1.1 times. This impact was expected since $74 \%$ of cohort member who were conceived premaritally were also born to unwed parents and these individuals were slightly more likely to develop depression in both cases. However, this result is marginally significant, and, as previously discussed, premarital conception may not be a good indicator of potential parental investment since this control variable had an impact contrary to expectation in both Outcome 1B and 1C. Regarding smoking, compared to those whose mothers never smoked, for those cohort members whose mothers stopped smoking prior to pregnancy $(\operatorname{Exp}(B)=1.247, p=.016)$ or smoking during their pregnancy $(\operatorname{Exp}(B)=1.205, p=.004)$, this increased the likelihood of a cohort member developing depression by 1.2 times. The adverse health impacts of smoking are well-known both for maternal and offspring health, however researchers have also discovered that maternal smoking during pregnancy is associated with higher odds of offspring developing depression (Taylor et al. 2017). The impact of maternal smoking in-utero related to an increased likelihood of a cohort member developing depression was therefore expected. In an effort to understand 
how smoking in-utero impacts offspring health, researchers have found that the mechanisms through which maternal tobacco use affects neonatal health and development are epigenetic (Knopik et al. 2012). Since the impact of maternal smoking is epigenetic in nature, it was not surprising to discover a similar increased likelihood of a cohort member developing depression if their mother stopped smoking prior to pregnancy. However, reverse causation is also a possibility if people who are depressed are more likely to smoke and more likely to have children who also report having depression. Regardless, these variables had a significant impact on the likelihood of a cohort member having depression and thus were controlled for in this model.

\section{Independent Variables}

For Outcome 3A with the dependent variable of depression, I predicted that, if birthing conditions are linked to the development of the gut microbiota and there is a connection between digestive health and mental health, then I expected to see digestive health mediate the relationship between birthing conditions and depression. Since no independent variables were significant at $\mathrm{p}<.10$ in Outcome $3 \mathrm{~A}$, no birthing conditions predicted the likelihood of having depression.

\section{$\underline{\text { Mental Health Outcome Conclusion }}$}

Since I did not find a correlation between birthing conditions and a greater likelihood of a cohort member having depression, the results for the mental health outcome did not support my prediction for Outcome 3A. As previously discussed in the Introduction, while prior studies have provided support for the impact of method of delivery on the initial inoculation and development of the gut microbiota, as well as support for a link between dysregulation of the gut microbiota and mental health 
disorders, the conditions surrounding the birth of a cohort member did not predict the likelihood of a cohort member developing depression. Therefore, my results for the mental health outcome did not support Hypothesis 3. The lack of a correlation between method of delivery and the development of depression demonstrates the adaptive and resilient nature of the human body even when pressed with a significant disturbance to the initial inoculation and development process of the gut microbiota via cesarean delivery. While I did not find support for this hypothesis, an important finding in Outcome $3 \mathrm{~A}$ is the impact observed for maternal smoking both prior to and during pregnancy associated with their offspring developing depression. This finding not only reinforces existing knowledge about the impacts of smoking in-utero but also contributes information regarding developmental factors to the etiology of depression.

\section{Conclusion}

A wealth of research has been amassed and continues to grow through efforts to understand the complex nature of the relationship between the colonization and development of the human gut microbiota and its role in both health and disease. Since early life influences can impact both the colonization of the gut microbiota and the development of a competent immune system, understanding the role birthing conditions play and their impact on long-term outcomes is of crucial importance. In considering a broader perspective on the relationship between birthing conditions and the long-term outcomes of overall health, mental health, and reproduction, one thing is clear: these relationships are multi-faceted. Rather than asking what birthing conditions have implications for long-term outcomes, it is more prudent to ask what birthing conditions and their surrounding circumstances present conditions of increased extrinsic risk and 
early life stress during a critical period in our development. This is because there appears to be a connection between conditions that present an early life stress and the likelihood of developing negative health outcomes in this birth cohort including digestive issues, respiratory issues, and infections and childhood diseases. A similar connection was also found in the mental health outcome. The relationship between maternal smoking both prior to and during pregnancy on the increased likelihood of an offspring developing depression at some point during their life represents a condition of early life stress that affects adverse mental health outcomes. As well, this connection between early life stress and its impact on long-term outcomes is also evident in the reproduction outcome. Instead of discovering a direct relationship between the reproduction measures and place and attendant at delivery, it appears that the encompassing circumstances surrounding the location and attendant at delivery are more representative of extrinsic risk, whether that risk be exposure to pathogens or due to a more difficult birth, than of the influence of attendant and location of delivery itself on the reproduction measures. These examples are demonstrating the multi-faceted relationship that must be considered in order to tease apart these relationships and understand not just what but also how conditions during early life can have lasting impacts on long-term outcomes.

An additional discovery during my analysis is that cesarean delivery was not a significant predictor of negative health outcomes in this birth cohort. This finding is wholly against expectation and suggests that, perhaps, the direct causal role of cesarean delivery in negative health outcomes suggested by current research is overestimated and rather it is a combination of birthing conditions that contribute to the negative health outcomes commonly associated with this method of delivery. By approaching future 
studies looking at birthing conditions and their relationship with long-term outcomes from a holistic perspective, a more comprehensive understanding of the role birthing conditions and surrounding circumstances have on overall health, mental health, and reproduction outcomes can be achieved.

$\underline{\text { Limitations \& Future Research }}$

Several limitations and suggestions for future research were exposed during my analysis. As discussed earlier in this chapter, persons per room ratio does not appear to be the best indicator for socioeconomic status, and this may be particularly true for the United Kingdom. This is due to a greater potential for a skew in the measure itself such that urban versus rural residential location may also be contributing to the persons per room ratio. Future research is needed to control for urban versus rural residential differences in the overall health outcome as well as controlling for the impact of location of residency on the location of delivery and birthing attendant. In addition to controlling for differences in urban and rural residential locations, it would be advantageous to determine a measure to take into account implications of environmental conditions, such as a measure of air pollution based on residential location, since this can have notable impacts on health outcomes. While one may expect this variable to be controlled for by the socioeconomic variables, that isn't always the case. This appears to be the case in my study as, according to the Office for National Statistics (2011), rural residents reported having better health on average than urban residents in both English regions and Wales. While rural residents may have a lower annual income than their urban counterparts, they also generally reported having better health. Taking into account confounding factors, such as urban versus rural and influential environmental conditions, allows for the ability 
to more clearly tease apart causal relationships between the independent and dependent variables.

While the reproduction outcome presented some interesting findings, since the last survey sweep available for my analysis is from 2012, the data encompasses most but not all of the 1970 birth cohort's reproductive years; thus, total reproduction is not captured in this analysis. It would be interesting for future research to reanalyze the data on total reproduction once reproduction is completed and surveyed. In addition, due to the unclear nature of capturing the total number of pregnancies for cohort members from the data, total number of genetic offspring was used as a proxy therefore presents a limitation in this study. Another limitation is the lack of available information on antibiotic use, which is known to have a significant impact on the early development of the infant gut microbiota, and thus resulted in its exclusion as a variable in my analysis.

Lastly, the control variables of maternal alcohol consumption during pregnancy, cohort member's alcohol consumption and tobacco usage, and father presence were excluded from the models due to significant limitations on the number of valid cases included in the analysis. Therefore, sensitivity analyses should be performed on these control variables to assess their impact and the robustness of the results. The limitations and suggestions for future research outlined have the potential for enabling a more comprehensive understanding of the birthing conditions and surrounding circumstances influencing early life stress that could have lasting impacts on overall health, mental health, and reproduction outcomes. 


\section{REFERENCES}

Albenberg, L. G., and G. D. Wu. 2014. Diet and the Intestinal Microbiome: Associations, Functions, and Implications for Health and Disease. Gastroenterology 146(6). Elsevier, Inc: 1564-1572.

Azad, M., T. Konya, H. Maughan, D. Guttman, C. Field, R. Chari, M. Sears, A. Becker, J. Scott, A. Kozyrskyj. 2013. Gut Microbiota of Healthy Canadian Infants: Profiles by Mode of Delivery and Infant Diet at 4 Months. Canadian Medical Association Journal 185(5): 385-394.

Bailey, M. T., S. E. Dowd, J. D. Galley, A. R. Hufnagle, R. G. Allen, and M. Lyte. 2011. Exposure to a Social Stressor Alters the Structure of the Intestinal Microbiota: Implications for Stressor-Induced Immunomodulation. Brain, Behavior, and Immunity 25(3): 397-407.

Bailey, M. T., G. R. Lubach, and C. L. Coe. 2004. Prenatal Stress Alters Bacterial Colonization of the Gut in Infant Monkeys. Journal of Pediatric Gastroenterology and Nutrition 38(4): 414-421.

Balasch, J., E. Gratacós. 2011. Delayed Childbearing: Effects on Fertility and the Outcome of Pregnancy, Mini-Review. Fetal Diagnosis and Therapy 29(4): 263273.

Barley, P., A. Aylin, B. Bottle, K. Jarman. 2004. Social Class and Elective Caesareans in the English NHS. British Medical Journal 328(7453): 1399.

Belsky, J., L. Steinberg, P. Draper. 1991. Childhood Experience, Interpersonal Development, and Reproductive Strategy: An Evolutionary Theory of Socialization. Child Development 62(4): 647-670.

Blomberg, M., R. B. Tyrberg, and P. Kjølhede. 2014. Impact of Maternal Age on Obstetric and Neonatal Outcome with Emphasis on Primiparous Adolescents and 
Older Women: A Swedish Medical Birth Register Study. British Medical Journal Open 4(11): 1-10.

Blondel, B., M. D. Kogan, G. R. Alexander, et al. 2002. The Impact of the Increasing Number of Multiple Births on the Rates of Preterm Birth and Low Birthweight: An International Study. American Journal of Public Health 92(8). American Public Health Association: 1323-30.

Bradley, R., and R. Corwyn. 2002. Socioeconomic Status and Child Development. Annual Review of Psychology 53(1): 371-400.

British Heart Foundation. 2017. BHF CVD Statistics. https://www.bhf.org.uk/research/heart-statistics.

CDC. 2017. Tobacco Use and Pregnancy. Centers for Disease Control and Prevention: Reproductive Health. https://www.cdc.gov/reproductivehealth/maternalinfanthealth/tobaccousepregnan cy/index.htm.

Central Intelligence Agency. 2017. The World Factbook, Europe: United Kingdom. The World Factbook. https://www.cia.gov/library/publications/the-worldfactbook/geos/uk.html.

Chamberlain, R., G. Chamberlain, University of London, and Institute of Education Centre for Longitudinal Studies. 2016. 1970 British Cohort Study, 1970-2012. UK Data Service.

Chantrill, C. 2016. UK Public Spending Since 1900. http://www.ukpublicspending.co.uk/past_spending.

Conrad, R., and A. V. Vlassov. 2015. The Human Microbiota: Composition, Functions, and Therapeutic Potential. Medical Science Review 2: 92-105.

Dehdashtian, M., E. Riazi, and M. H. Aletayeb. 2008. Influence of Mode of Delivery at Term on the Neonatal Respiratory Morbidity. Pakistan Journal of Medical Sciences 24(4): 556-9. 
Delli, A. J., and A. Lernmark. 2016. "Chapter 39 - Type 1 (Insulin-Dependent) Diabetes Mellitus: Etiology, Pathogenesis, Prediction, and Prevention." In Endocrinology: Adult and Pediatric (Seventh Edition), edited by J. Larry Jameson, 672-690. Philadelphia: Elsevier Saunders.

Demirci, O., E. Yılmaz, Ö. Tosun, P. Kumru, A. Arınkan, D. Mahmutoğlu, S. Selçuk, Z. N. Dolgun, R. Arısoy, E. Erdoğdu, and N. Tarhan. 2016. Effect of Young Maternal Age on Obstetric and Perinatal Outcomes: Results from the Tertiary Center in Turkey. Balkan Medical Journal 33(3): 344-349.

Department for Business, Energy, \& Industrial Strategy. 2013. Historical Coal Data: Coal Production, Availability and Consumption 1853 to 2015. https://www.gov.uk/government/statistical-data-sets/historical-coal-data-coalproduction-availability-and-consumption-1853-to-2011.

Department for Environment, Food \& Rural Affairs. 2012. Official Statistics: Rural Earnings Statistics. GOV.UK. https://www.gov.uk/government/statistics/ruralearnings.

Department for Environment, Food \& Rural Affairs. N.d. DAQI Regional Data. UK Air. https://uk-air.defra.gov.uk/data/DAQI-regional-data.

Dethlefsen, L., D. A. Relman. 2011. Incomplete Recovery and Individualized Responses of the Human Distal Gut Microbiota to Repeated Antibiotic Perturbation. Proceedings of the National Academy of Sciences of the United States of America 108(Suppl 1): 4554-4561.

Dinan, T. G., and J. F. Cryan. 2012. Regulation of the Stress Response by the Gut Microbiota: Implications for Psychoneuroendocrinology. Psychoneuroendocrinology 37(9): 1369-1378.

Dinan, T. G., and J. F. Cryan. 2013. Melancholic Microbes: A Link between Gut Microbiota and Depression? Neurogastroenterology \& Motility 25: 713-719.

Dobson, R. 2001. Caesarean Section Rate in England and Wales Hits 21. British Medical Journal 323(7319). BMJ Publishing Group: 951. 
Dominguez-Bello, M. G., E. K. Costello, M. Contreras, et al. 2010. Delivery Mode Shapes the Acquisition and Structure of the Initial Microbiota across Multiple Body Habitats in Newborns. PNAS 107(26): 11971-11975.

Downey, D. B. 1995. When Bigger Is Not Better: Family Size, Parental Resources, and Children's Educational Performance. American Sociological Review 60(5). American Sociological Association: 746.

Education System in the UK. 2017. GOV.UK. https://www.gov.uk/government/uploads/system/uploads/attachment_data/file/21 9167/v01-2012ukes.pdf.

Ellis, B. J., A. J. Figueredo, B. H. Brumbach, and G. L. Schlomer. 2009. Fundamental Dimensions of Environmental Risk: The Impact of Harsh versus Unpredictable Environments on the Evolution and Development of Life History Strategies. Human Nature 20: 204-268.

Foster, L., J. Rinaman, J. Cryan. 2017. Stress \& the Gut-Brain Axis: Regulation by the Microbiome. Neurobiology of Stress 7: 124-136.

Francino, M. P. 2015. Antibiotics and the Human Gut Microbiome: Dysbioses and Accumulation of Resistances. Frontiers in Microbiology 6(1543): 1-11.

Fujimura, K., N. A. Slusher, M. D. Cabana, and S. V. Lynch. 2010. Role of the Gut Microbiota in Defining Human Health. Expert Review of Anti-Infective Therapy 8(4): 434-454.

Gakidou, E., K. Cowling, R. Lozano, and C. Murray. 2010. Increased Educational Attainment and Its Effect on Child Mortality in 175 Countries between 1970 and 2009: A Systematic Analysis. The Lancet 376(9745): 959-974.

Gibson, M., T. S. Crofts, and G. Dantas. 2015. Antibiotics and the Developing Infant Gut Microbiota and Resistome. Current Opinion in Microbiology(27): 51-56.

Guarner, F., and J-R. Malagelada. 2003. Gut Flora in Health and Disease. The Lancet 361: 512-519. 
Hackman, J., and D. Hruschka. 2013. Fast Life Histories, Not Pathogens, Account for State-Level Variation in Homicide, Child Maltreatment, and Family Ties in the U.S. Evolution and Human Behavior 34(2): 118-124.

Hart, C. L., and G. D. Smith. 2003. Relation between Number of Siblings and Adult Mortality and Stroke Risk: 25 Year Follow up of Men in the Collaborative Study. Journal of Epidemiology and Community Health 57(5). BMJ: 385-391.

History of Air Pollution in the UK. 2000. http://www.air-quality.org.uk/02.php.

Hong, R. 2006. Effect of Multiple Birth on Infant Mortality in Bangladesh. Journal of Paediatrics and Child Health 42(10). Wiley Online Library: 630-635.

Horta, B., and C. Victora. 2013. Long-Term Effects of Breastfeeding: A Systematic Review. Geneva.

Jandhyala, S., R. Talukdar, C. Subramanyam, et al. 2015. Role of the Normal Gut Microbiota. World Journal of Gastroenterology 21(29): 8787-8803.

Kåhrström, C. T., N. Pariente, U. Weiss. 2016. Intestinal Microbiota in Health and Disease. Nature 535: 47.

Kamada, N., G. Y. Chen, N. Inohara, and G. Núñez. 2013. Control of Pathogens and Pathobionts by the Gut Microbiota. Nature Immunology 14(7): 685-690.

Kang, Ga., J. Y. Lim, A. S. Kale, and L. Y. Lee. 2015. Adverse Effects of Young Maternal Age on Neonatal Outcomes. Singapore Medical Journal 56(3): 157-163.

Kent-Smith, R. 2017. Gross Domestic Product: Chained Volume Measures: Seasonally Adjusted £m. Office for National Statistics. https://www.ons.gov.uk/economy/grossdomesticproductgdp/timeseries/abmi/pn2.

Knopik, V. S., M. A. Maccani, S. Francazio, and J. E. McGeary. 2012. The Epigenetics of Maternal Cigarette Smoking During Pregnancy and Effects on Child Development. Development and Psychopathology 24(4): 1377-1390.

Kozyrskyj, A. 2015. Can We Predict Future Allergies from Our Infant Gut Microbiota? Expert Review of Respiratory Medicine 9(6): 1-4. 
Lach, G., H. Schellekens, T. G. Dinan, and J. F. Cryan. 2018. Anxiety, Depression, and the Microbiome: A Role for Gut Peptides. Neurotherapeutics 15: 36-59.

Lawson, D. W. 2011. Life history theory and human reproductive behavior. In V. Swami (Ed). Evolutionary Psychology: A Critical Introduction. Oxford: BPS Blackwell.

Lawson, D. W., S. B. Schaffnit, A. Hassan, et al. 2017. Father Absence but Not Fosterage Predicts Food Insecurity, Relative Poverty, and Poor Child Health in Northern Tanzania. American Journal of Human Biology 29(3).

Levine, E. M., V. Ghai, J. J. Barton, and C. M. Strom. 2001. Mode of Delivery and Risk of Respiratory Diseases in Newborns. Obstetrics \& Gynecology 97(3): 439-42.

Lopez, A. D., and C. Murray. 1998. The Global Burden of Disease. Nature Medicine 4(11): 1241-1243.

Lozupone, C. A., J. I. Stombaugh, J.I. Gordon, J.K. Jansson, and R. Knight. 2012. Diversity, Stability and Resilience of the Human Gut Microbiota. Nature(489): 220-230.

McDade, T. W. 2003. Life History Theory and the Immune System: Steps Toward a Human Ecological Immunology. American Journal of Physical Anthropology 46: $100-125$.

McKean, K. A., C. P. Yourth, B. P. Lazzaro, and A. G. Clark. 2008. The Evolutionary Costs of Immunological Maintenance and Deployment. BMC Evolutionary Biology 8: 76.

Melli, L. C., M. S. do Carmo-Rodrigues, H. B. Araujo-Filho, D. Sole, and M. B. de Morais. 2015. Intestinal Microbiota and Allergic Diseases: A Systematic Review. Allergologia et Immunopathologia: 1-12.

Mental Health Foundation. 2016. Fundamental Facts About Mental Health 2016. London. https://www.mentalhealth.org.uk/file/2518/download?token=RU6lzcSK.

Miyake, S., S. Kim, W. Suda, et al. 2015. Dysbiosis in the Gut Microbiota of Patients with Multiple Sclerosis, with a Striking Depletion of Species Belonging to Clostridia XIVa and IV Clusters. PLOS ONE 10(9): 1-16. 
Moloney, R. D., L. Desbonnet, G. Clarke, T. G. Dinan, and J. R. Cryan. 2014. The Microbiome: Stress, Health, and Disease. Mammalian Genone 25: 49-74.

National Intitute of Health. 2015. Human Microbiome. NIH Human Microbiome Project. http://hmpdacc.org/overview/about.php.

National Statistics. 2016. DEFRA National Statistics Release: Emissions of Air Pollutants in the UK, 1970 to 2012. https://www.gov.uk/government/uploads/system/uploads/attachment_data/file/57 9200/Emissions_airpollutants_statisticalrelease_2016_final.pdf.

Nettle, D. 2014. What the Future Held: Childhood Psychosocial Adversity Is Associated with Health Deterioration through Adulthood in a Cohort of British Women. Evolution and Human Behavior 35(6): 519-525.

Nove, A., A. Berrington, and Z. Matthews. 2008. Population Trends: Home Births in the UK, 1955 to 2006. Office of National Statistics. https://www.ons.gov.uk/ons/rel/population-trends-rd/population-trends/no--133-autumn-2008/home-births-in-the-uk--1955-to-2006.pdf.

Office for National Statistics. 2013. An Overview of 40 Years of Data: General Lifestyle Survey Overview, a Report on the 2011 General Lifestyle Survey. Newport. http://webarchive.nationalarchives.gov.uk/20160105160709/http://www.ons.gov. uk/ons/dcp171776_302655.pdf.

Office for National Statistics. 2011. Census Analysis - Comparing Rural and Urban Areas of England and Wales. http://webarchive.nationalarchives.gov.uk/20160105224826/http://www.ons.gov. uk/ons/rel/census/2011-census-analysis/rural-urban-analysis/comparing-rural-andurban-areas-of-england-and-wales.html\#tab-Health--disability-and-unpaid-care.

Office for National Statistics. 2015. Health and Life Expectancies. Office for National Statistics. https://www.ons.gov.uk/peoplepopulationandcommunity/healthandsocialcare/heal thandlifeexpectancies. 
Parliament Postnote. 2002. Cesarean Sections. Parliamentary Office of Science and Technology. London. http://www.parliament.uk/documents/post/pn184.pdf.

Pearce, Fred. 2016. People Today are Still Dying Early from High 1970s Air Pollution. New Scientist, February 9, 2016. https://www.newscientist.com/article/2076728people-today-are-still-dying-early-from-high-1970s-air-pollution/amp/.

Petrou, S., and K. Khan. 2013. An Overview of the Health Economic Implications of Elective Caesarean Section. Applied Health Economics and Health Policy 11(6): $561-576$.

Randall, C. 2001. National Statistics: Environment. Newport. https://link.springer.com/content/pdf/10.1057\%2Fst.2011.16.pdf

Rautava, S., R. Luoto, S. Salminen, and E. Isolauri. 2012. Microbial Contact during Pregnancy, Intestinal Colonization and Human Disease. National Reviews Gastroenterology \& Hepatology 9: 565-576.

Roberts, A. 2016. How Does This Year's NHS Budget Compare Historically? The Health Foundation. http://www.health.org.uk/blog/how-does-year's-nhs-budgetcompare-historically.

Rodríguez, J. M., K. Murphy, C. Stanton, et al. 2015. The Composition of the Gut Microbiota throughout Life, with an Emphasis on Early Life. Microbial Ecology in Health and Disease 26: 26050.

Sullivan, A. 2017. 1970 British Cohort Study (BCS70). Center for Longitudinal Studies. http://www.cls.ioe.ac.uk/page.aspx?\&sitesectionid=795\&sitesectiontitle=Welcom e+to+the+1970+British+Cohort+Study.

Sweet, D. 2011. National Statistics: Health. Newport. https://slideheaven.com/health.html.

Taylor, A. E., D. Carslake, C. L. de Mola, et al. 2017. Maternal Smoking in Pregnancy and Offspring Depression: A Cross Cohort and Negative Control Study. Nature: Scientific Reports 7(1): 12579. 
The Equality Trust. 2017. Health. The Equality Trust UK. https://www.equalitytrust.org.uk/health.

de Vos, W. M., and E. de Vos. 2012. Role of the Intestinal Microbiome in Health and Disease: From Correlation to Causation. Nutrition Reviews 70(1): S45-S56.

Walker, R., M. Gurven, K. Hill, et al. 2006. Growth Rates and Life Histories in TwentyTwo Small-Sclae Socieities. American Journal of Human Biology 18: 295-311.

Wang, B., M. Yao, L. Lv, Z. Ling, and L. Li. 2017. The Human Microbiota in Health and Disease. Engineering 3: 71-82.

WHO. 2002. The World Health Organization's Infant Feeding Recommendation. World Health Organization.

http://www.who.int/nutrition/topics/infantfeeding_recommendation/en/.

WHO. 2011. Exclusive Breastfeeding for Six Months for Babies Everywhere. World Health Organization. http://www.who.int/mediacentre/news/statements/2011/breastfeeding_20110115/e $\mathrm{n} /$.

Wu, H-J., and E. Wu. 2012. The Role of Gut Microbiota in Immune Homeostasis and Autoimmunity. Gut Microbes 3(1): 4-14.

Zijlmans, M. A., K. Korpela, J. M. Riksen-Walraven, W. M. de Vos, and C. de Weerth. 2015. Maternal Prenatal Stress is Associated with the Infant Intestinal Microbiota. Psychoneuroendocrinology 53: 233-245. 
APPENDIX A 


\section{Assumptions}

Table A.1 Collinearity Statistics of Outcome 1A Infections and Childhood Diseases

\begin{tabular}{|l|c|c|}
\hline \multirow{2}{*}{} & \multicolumn{2}{|c|}{$\begin{array}{c}\text { Collinearity } \\
\text { Statistics }\end{array}$} \\
\cline { 2 - 3 } & Tolerance & VIF \\
\hline Single vs Twin & 0.971 & 1.030 \\
\hline Sex of the Baby & 0.997 & 1.003 \\
\hline UK vs. Other Ethnicity & 0.965 & 1.036 \\
\hline UK vs. Ethnicity Not Reported & 0.993 & 1.007 \\
\hline $\begin{array}{l}\text { Number of Children Older than } \\
\text { Child }\end{array}$ & 0.567 & 1.763 \\
\hline $\begin{array}{l}\text { Mother's Age at Completion of } \\
\text { Education }\end{array}$ & 0.958 & 1.044 \\
\hline Persons Per Room Ratio & 0.716 & 1.396 \\
\hline $\begin{array}{l}\text { Marital Status at Cohort Member's } \\
\text { Birth }\end{array}$ & 0.944 & 1.060 \\
\hline Premarital Conception & 0.854 & 1.171 \\
\hline Mother's Age at Delivery & 0.707 & 1.414 \\
\hline $\begin{array}{l}\text { Non-Smoker vs Stopped Smoking } \\
\text { Pre-Pregnancy }\end{array}$ & 0.878 & 1.139 \\
\hline $\begin{array}{l}\text { Non-Smoker vs Smoked During } \\
\text { Pregnancy }\end{array}$ & 0.843 & 1.186 \\
\hline $\begin{array}{l}\text { Never Breastfed vs. Breastfed <3 } \\
\text { month }\end{array}$ & 0.928 & 1.078 \\
\hline $\begin{array}{l}\text { Never Breastfed vs. Breastfed >= 3 } \\
\text { month }\end{array}$ & 0.903 & 1.107 \\
\hline Place of Delivery & 0.950 & 1.053 \\
\hline Pain Relief during Labor & 0.980 & 1.021 \\
\hline
\end{tabular}


Table A.2 Durbin-Watson for Independent Errors of Outcome 1A Infections and Childhood Diseases

\begin{tabular}{|l|l|}
\hline Model & Durbin-Watson \\
\hline
\end{tabular}

2.006 
Histogram

Dependent Variable: Infections \& Childhood Diseases (proportions, composite)

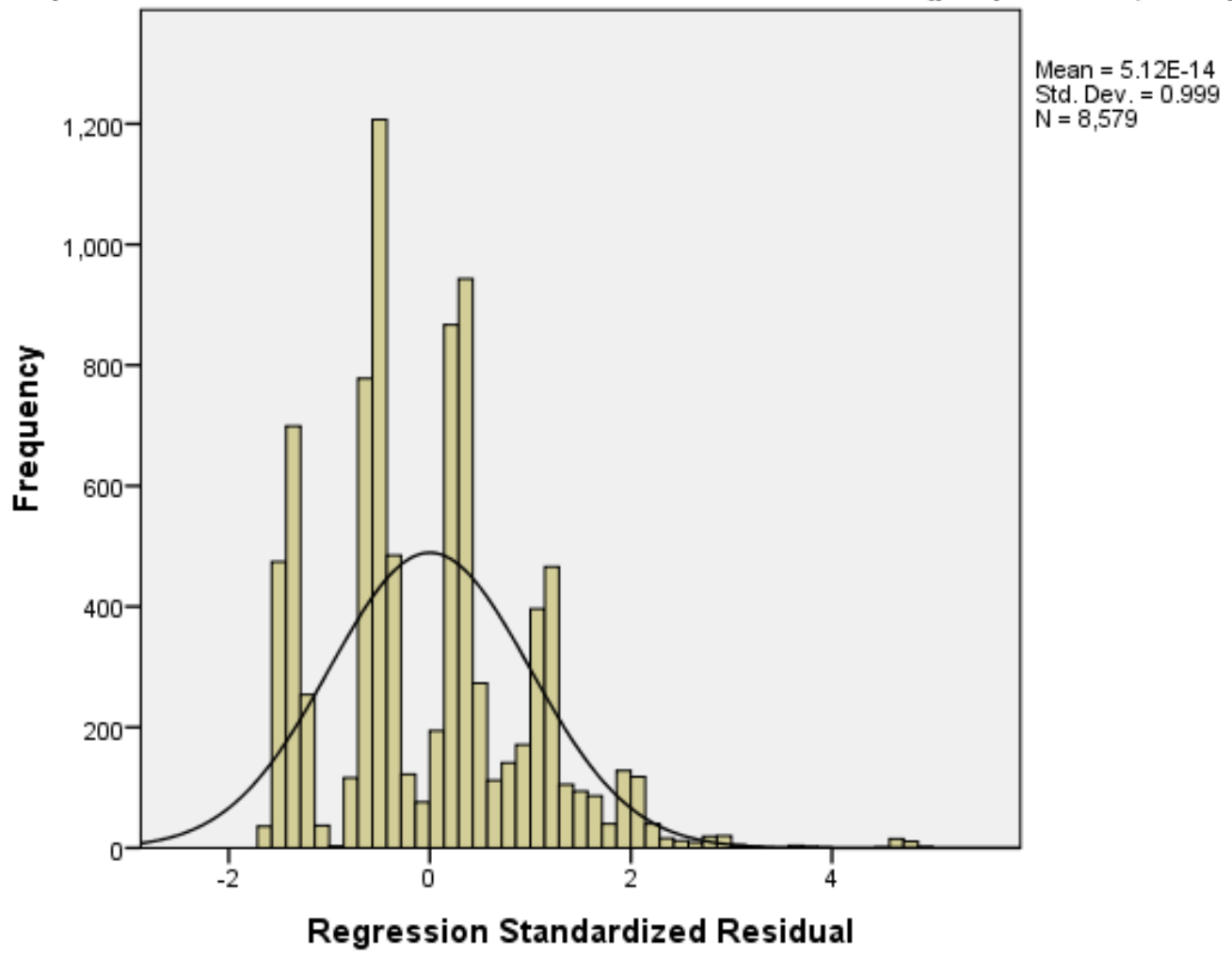

Figure A.1 Distribution of Residuals of Outcome 1A Infections and Childhood Diseases 
Normal P-P Plot of Regression Standardized Residual Dependent Variable: Infections \& Childhood Diseases (proportions, composite)

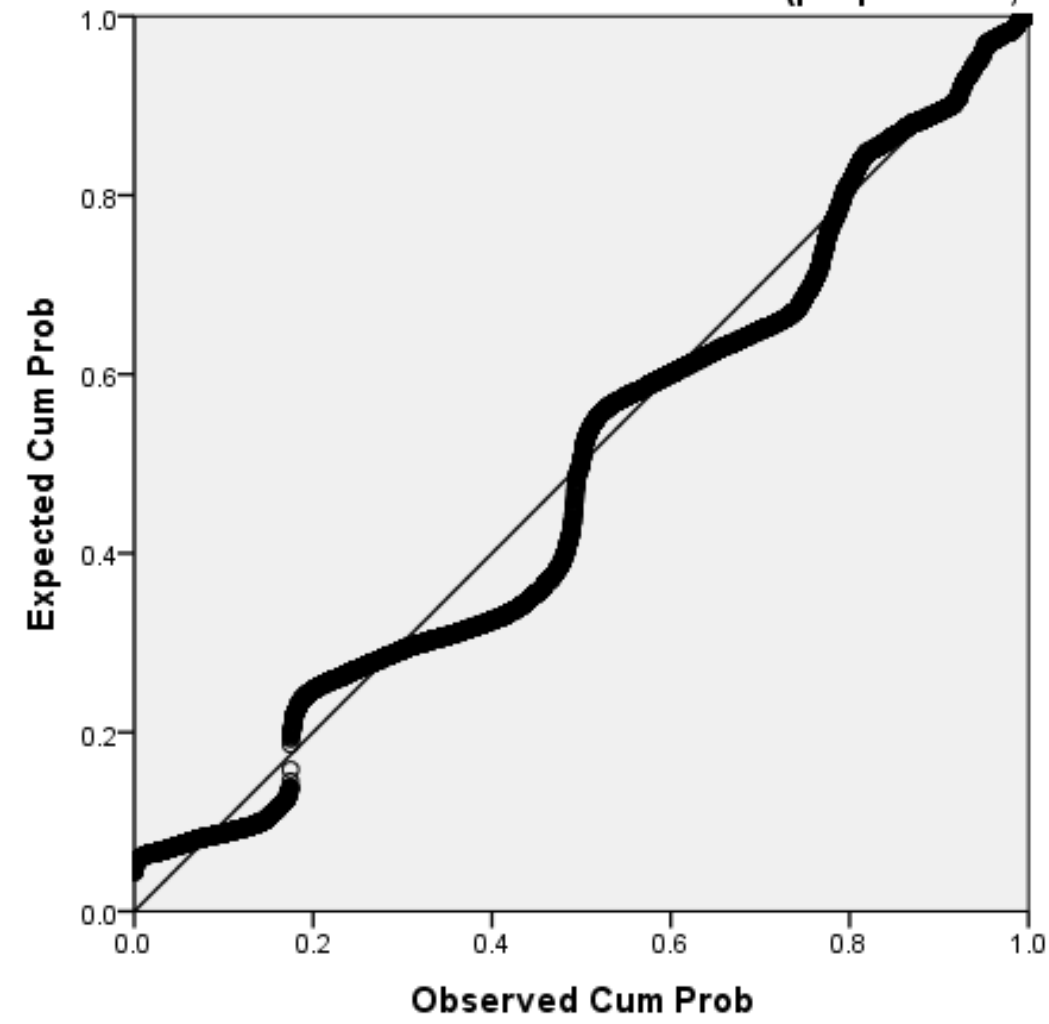

Figure A.2 P-P Plot of Outcome 1A Infections and Childhood Diseases 


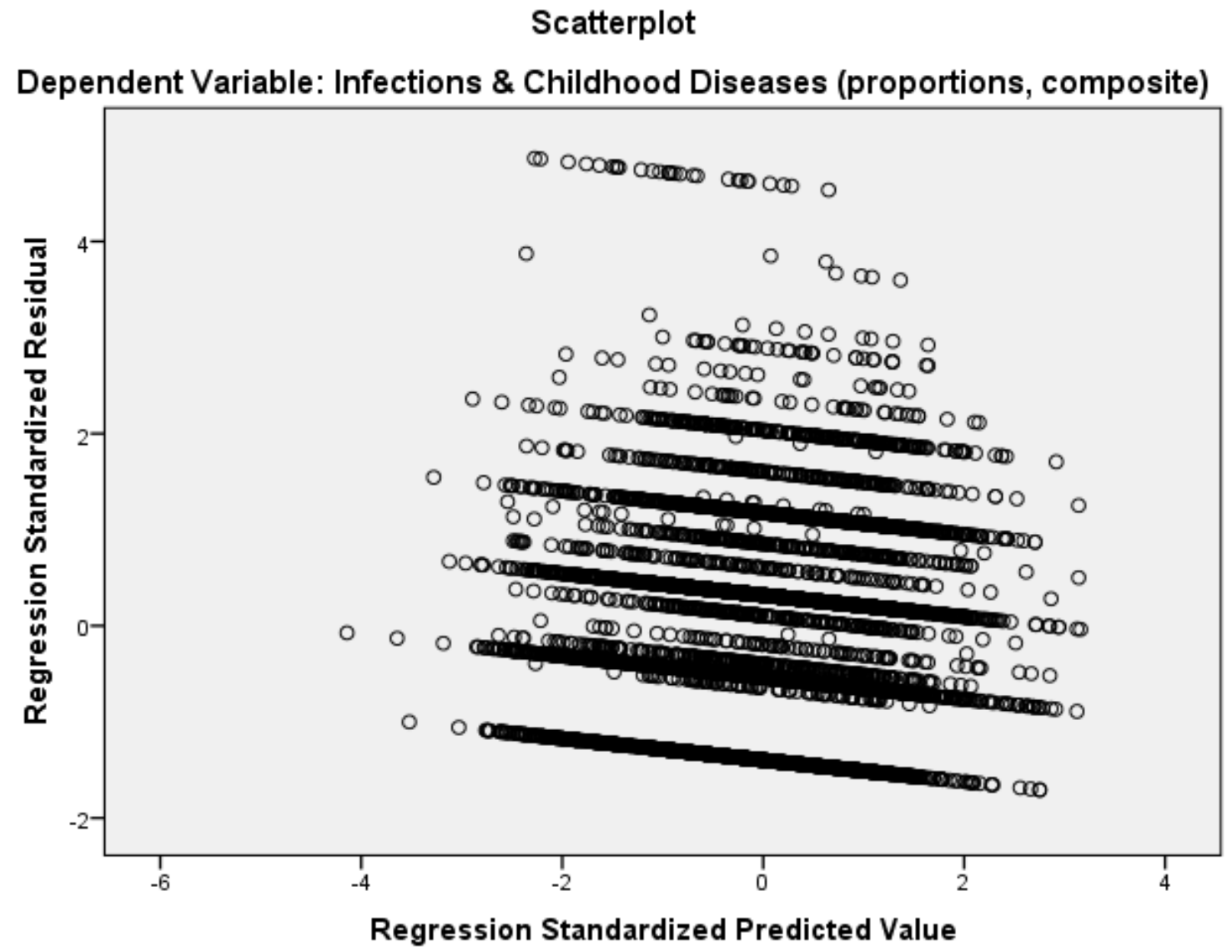

Figure A.3 Plot of Outcome 1A Infections and Childhood Diseases 
Table A.3 Linearity of the logit of Outcome 1B Allergy, Skin, and Joint Issues

\begin{tabular}{|l|c|c|c|c|c|c|}
\hline & B & S.E. & Wald & df & Sig. & Exp(B) \\
\hline $\begin{array}{l}\text { Number Of Children Older than } \\
\text { Child }\end{array}$ & -0.146 & 0.076 & 3.669 & 1 & 0.055 & 0.864 \\
\hline $\begin{array}{l}\text { Mother's Age at Completion of } \\
\text { Education }\end{array}$ & 0.170 & 0.069 & 6.007 & 1 & 0.014 & 1.185 \\
\hline Persons Per Room Ratio & -0.063 & 0.415 & 0.023 & 1 & 0.879 & 0.939 \\
\hline Mother's Age at Delivery & 0.272 & 0.157 & 3.012 & 1 & 0.083 & 1.312 \\
\hline $\begin{array}{l}\text { Ln_Number of Children Older } \\
\text { than Child by Number of Children } \\
\text { Older than Child }\end{array}$ & 0.028 & 0.048 & 0.338 & 1 & 0.561 & 1.028 \\
\hline $\begin{array}{l}\text { Ln_Mother's Age Completion } \\
\text { Education by Mother's Age at } \\
\text { Completion of Education }\end{array}$ & -0.034 & 0.015 & 5.343 & 1 & 0.021 & 0.966 \\
\hline $\begin{array}{l}\text { Ln_Persons Per Room Ratio by } \\
\text { Persons Per Room Ratio }\end{array}$ & -0.109 & 0.313 & 0.121 & 1 & 0.728 & 0.897 \\
\hline $\begin{array}{l}\text { Ln_Mother's Age Delivery by } \\
\text { Mother's age at Delivery }\end{array}$ & -0.061 & 0.036 & 2.824 & 1 & 0.093 & 0.941 \\
\hline Constant & -2.823 & 1.022 & 7.637 & 1 & 0.006 & 0.059 \\
\hline
\end{tabular}


Table A.4 Collinearity Statistics of Outcome 1B Allergy, Skin, and Joint Issues

\begin{tabular}{|l|c|c|}
\hline \multirow{2}{*}{} & \multicolumn{2}{|c|}{$\begin{array}{c}\text { Collinearity } \\
\text { Statistics }\end{array}$} \\
\cline { 2 - 3 } & Tolerance & VIF \\
\hline Single vs Twin & 0.975 & 1.026 \\
\hline Sex of the Baby & 0.998 & 1.002 \\
\hline UK vs. Other ethnicity & 0.963 & 1.039 \\
\hline UK vs. Ethnicity Not Reported & 0.994 & 1.006 \\
\hline Number of Children Older than Child & 0.592 & 1.689 \\
\hline Mother's Age at Completion of Education & 0.957 & 1.045 \\
\hline Persons Per Room Ratio & 0.716 & 1.397 \\
\hline Marital Status at Cohort Member's Birth & 0.944 & 1.059 \\
\hline Premarital Conception & 0.859 & 1.164 \\
\hline Mother's Age at Delivery & 0.718 & 1.392 \\
\hline Non-Smoker vs Stopped Smoking Pre-Pregnancy & 0.878 & 1.139 \\
\hline Non-Smoker vs Smoked During Pregnancy & 0.844 & 1.184 \\
\hline Never Breastfed vs. Breastfed < 3 month & 0.929 & 1.077 \\
\hline Never Breastfed vs. Breastfed >= 3 month & 0.904 & 1.107 \\
\hline
\end{tabular}


Table A.5 Collinearity Statistics of Outcome 1C Respiratory Issues

\begin{tabular}{|l|c|c|}
\hline \multirow{2}{*}{} & \multicolumn{2}{|c|}{$\begin{array}{c}\text { Collinearity } \\
\text { Statistics }\end{array}$} \\
\cline { 2 - 3 } & Tolerance & VIF \\
\hline Single vs Twin & 0.946 & 1.057 \\
\hline Sex of the Baby & 0.995 & 1.005 \\
\hline UK vs. Other Ethnicity & 0.965 & 1.036 \\
\hline UK vs. Ethnicity Not Reported & 0.993 & 1.007 \\
\hline Number of Children Older than Child & 0.540 & 1.850 \\
\hline Mother's Age at Completion of Education & 0.958 & 1.044 \\
\hline Persons Per Room Ratio & 0.715 & 1.398 \\
\hline Marital Status at CM birth & 0.944 & 1.059 \\
\hline Premarital Conception & 0.854 & 1.171 \\
\hline Mothers Age at Delivery & 0.697 & 1.434 \\
\hline $\begin{array}{l}\text { Non-Smoker vs Stopped Smoking } \\
\text { Pre-Pregnancy }\end{array}$ & 0.881 & 1.135 \\
\hline Non-Smoker vs Smoked during Pregnancy & 0.848 & 1.179 \\
\hline Never Breastfed vs. Breastfed < 3 month & 0.924 & 1.083 \\
\hline Never Breastfed vs. Breastfed >=3 month & 0.902 & 1.109 \\
\hline Place of Delivery & 0.929 & 1.076 \\
\hline $\begin{array}{l}\text { Vaginal Unassisted vs. Vaginal Assisted } \\
\text { Delivery }\end{array}$ & 0.919 & 1.089 \\
\hline $\begin{array}{l}\text { Vaginal unassisted vs. Cesarean delivery - } \\
\text { spontaneous }\end{array}$ & 0.910 & 1.099 \\
\hline $\begin{array}{l}\text { Vaginal Unassisted vs. Cesarean Delivery - } \\
\text { Started as }\end{array}$ & 0.791 & 1.264 \\
\hline Pain Relief during Labor & 0.752 & 1.330 \\
\hline
\end{tabular}


Table A.6 Durbin-Watson for Independent Errors of Outcome 1C Respiratory Issues

\begin{tabular}{|l|c|}
\hline Model & Durbin-Watson \\
\hline & 1.963 \\
\hline
\end{tabular}




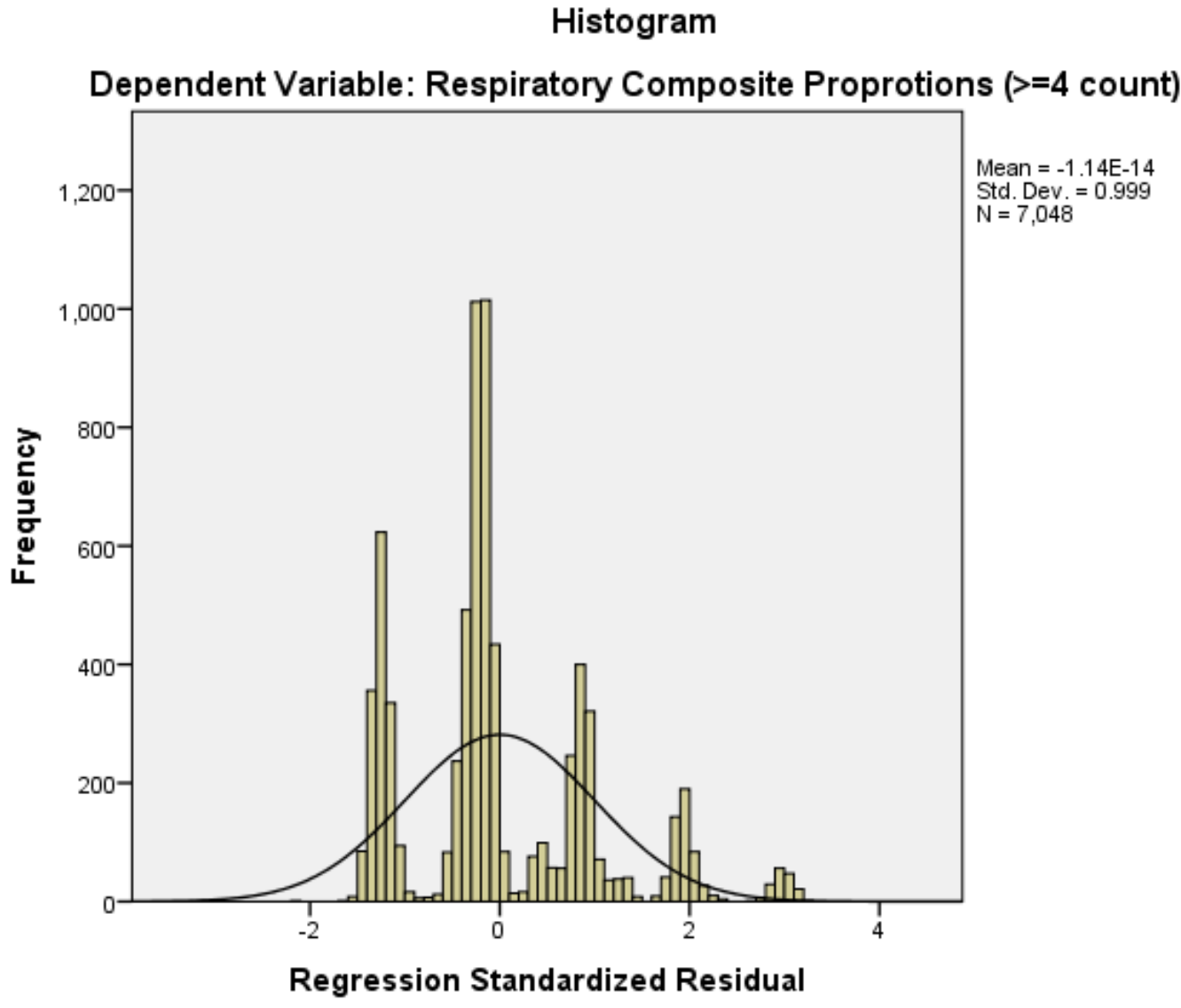

Figure A.4 Distribution of Residuals of Outcome 1C Respiratory Issues 


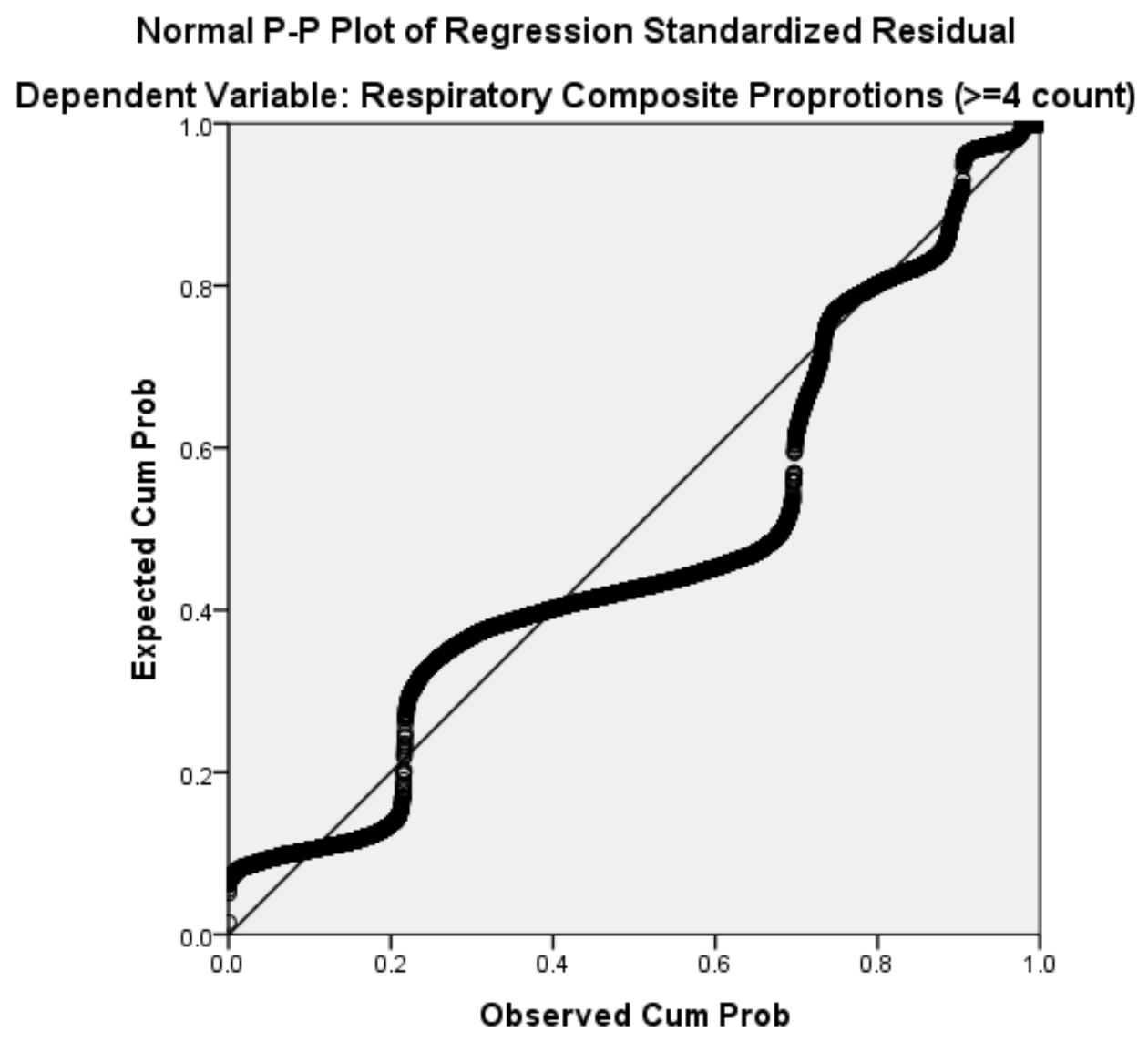

Figure A.5 P-P Plot of Outcome 1C Respiratory Issues 


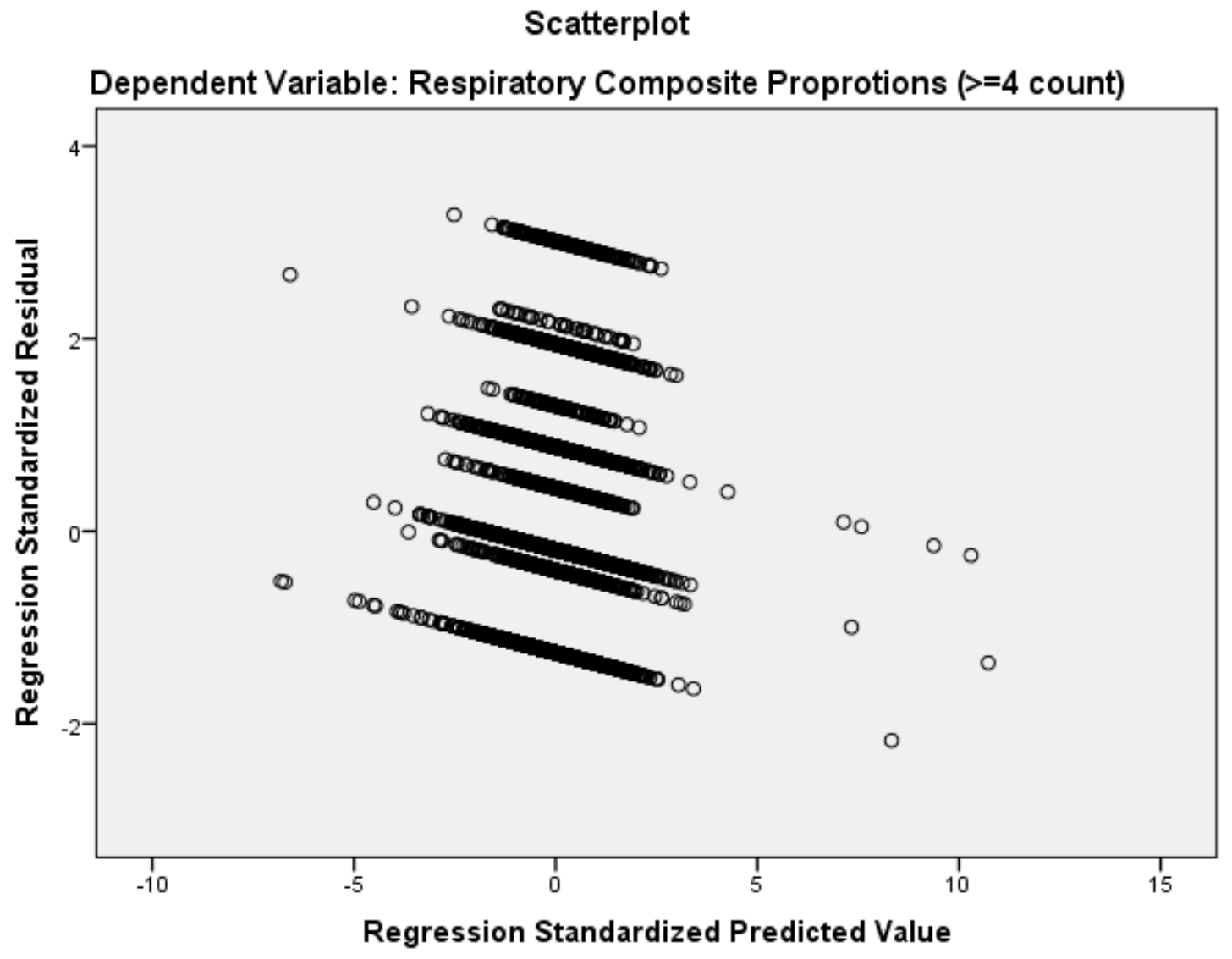

Figure A.6 Plot of Outcome 1C Respiratory Issues 
Table A.7 Linearity of the logit of Outcome 1D Digestive Issues

\begin{tabular}{|l|c|c|c|c|c|c|}
\hline & B & S.E. & Wald & df & Sig. & Exp(B) \\
\hline $\begin{array}{l}\text { Number Of Children Older than } \\
\text { Child }\end{array}$ & 0.402 & 0.131 & 9.412 & 1 & 0.002 & 1.494 \\
\hline $\begin{array}{l}\text { Mother's Age at Completion of } \\
\text { Education }\end{array}$ & -0.034 & 0.118 & 0.081 & 1 & 0.775 & 0.967 \\
\hline Persons Per Room Ratio & -0.402 & 0.645 & 0.388 & 1 & 0.533 & 0.669 \\
\hline Mother's Age at Delivery & 0.039 & 0.059 & 0.429 & 1 & 0.512 & 1.040 \\
\hline $\begin{array}{l}\text { Ln_Number of Children Older } \\
\text { than Child by Number of Children } \\
\text { Older than Child }\end{array}$ & -0.181 & 0.080 & 5.084 & 1 & 0.024 & 0.835 \\
\hline $\begin{array}{l}\text { Ln_Mother's Age Completion } \\
\text { Education by Mother's Age at } \\
\text { Completion of Education }\end{array}$ & 0.004 & 0.027 & 0.018 & 1 & 0.893 & 1.004 \\
\hline $\begin{array}{l}\text { Ln_Persons Per Room Ratio by } \\
\text { Persons Per Room Ratio }\end{array}$ & 0.283 & 0.474 & 0.357 & 1 & 0.550 & 1.327 \\
\hline Ln_Mother's Age Delivery & -1.558 & 1.689 & 0.851 & 1 & 0.356 & 0.211 \\
\hline Constant & 2.281 & 3.977 & 0.329 & 1 & 0.566 & 9.783 \\
\hline
\end{tabular}


Table A.8 Collinearity Statistics of Outcome 1D Digestive Issues

\begin{tabular}{|l|c|c|}
\hline \multirow{2}{*}{} & \multicolumn{2}{|c|}{$\begin{array}{c}\text { Collinearity } \\
\text { Statistics }\end{array}$} \\
\cline { 2 - 3 } & Tolerance & VIF \\
\hline Single vs Twin & 0.958 & 1.044 \\
\hline Sex of the Baby & 0.997 & 1.003 \\
\hline UK vs. Other ethnicity & 0.963 & 1.039 \\
\hline UK vs. Ethnicity Not Reported & 0.993 & 1.007 \\
\hline Number of Children Older than Child & 0.551 & 1.816 \\
\hline Mother's Age at Completion of Education & 0.956 & 1.046 \\
\hline Persons Per Room Ratio & 0.713 & 1.403 \\
\hline Marital Status at Cohort Member's Birth & 0.944 & 1.060 \\
\hline Premarital Conception & 0.859 & 1.164 \\
\hline Mother's Age at Delivery & 0.714 & 1.401 \\
\hline $\begin{array}{l}\text { Non-Smoker vs Stopped Smoking } \\
\text { Pre-Pregnancy }\end{array}$ & 0.878 & 1.139 \\
\hline $\begin{array}{l}\text { Non-Smoker vs Smoked During } \\
\text { Pregnancy }\end{array}$ & 0.844 & 1.185 \\
\hline Never Breastfed vs. Breastfed <3 month & 0.929 & 1.076 \\
\hline Never Breastfed vs. Breastfed >= 3 month & 0.904 & 1.106 \\
\hline Anesthetics during Labor & 0.903 & 1.107 \\
\hline
\end{tabular}


Table A.9 Collinearity Statistics of Outcome 2A Age of Menarche

\begin{tabular}{|l|c|c|}
\hline \multirow{2}{*}{} & \multicolumn{2}{|c|}{$\begin{array}{c}\text { Collinearity } \\
\text { Statistics }\end{array}$} \\
\cline { 2 - 3 } & Tolerance & VIF \\
\hline Single vs Twin & 0.949 & 1.054 \\
\hline UK vs. Other Ethnicity & 0.957 & 1.045 \\
\hline UK vs. Ethnicity Not Reported & 0.994 & 1.006 \\
\hline Number of Children Older than Child & 0.561 & 1.782 \\
\hline Mother's Age at Completion of Education & 0.965 & 1.036 \\
\hline Persons Per Room Ratio & 0.728 & 1.373 \\
\hline Marital Status at Cohort Member's Birth & 0.929 & 1.076 \\
\hline Premarital Conception & 0.858 & 1.165 \\
\hline Mother's Age at Delivery & 0.685 & 1.460 \\
\hline $\begin{array}{l}\text { Non-Smoker vs Stopped Smoking } \\
\text { Pre-Pregnancy }\end{array}$ & 0.882 & 1.133 \\
\hline $\begin{array}{l}\text { Non-Smoker vs Smoked During } \\
\text { Pregnancy }\end{array}$ & 0.846 & 1.181 \\
\hline Never Breastfed vs. Breastfed <3 month & 0.919 & 1.088 \\
\hline Never Breastfed vs. Breastfed >= 3 month & 0.896 & 1.116 \\
\hline $\begin{array}{l}\text { Midwife in Medical Facility vs. Medical } \\
\text { Practitioner at Home }\end{array}$ & 0.987 & 1.013 \\
\hline $\begin{array}{l}\text { Midwife in Medical Facility vs. Midwife at } \\
\text { Home }\end{array}$ & 0.913 & 1.096 \\
\hline $\begin{array}{l}\text { Midwife in Medical Facility vs. Medical } \\
\text { Practitioner at Medical Facility }\end{array}$ & 0.902 & 1.109 \\
\hline
\end{tabular}


Table A.10 Durbin-Watson for Independent Errors of Outcome 2A Age of Menarche

\begin{tabular}{|l|l|}
\hline Model & Durbin-Watson \\
\hline
\end{tabular} 1.967 


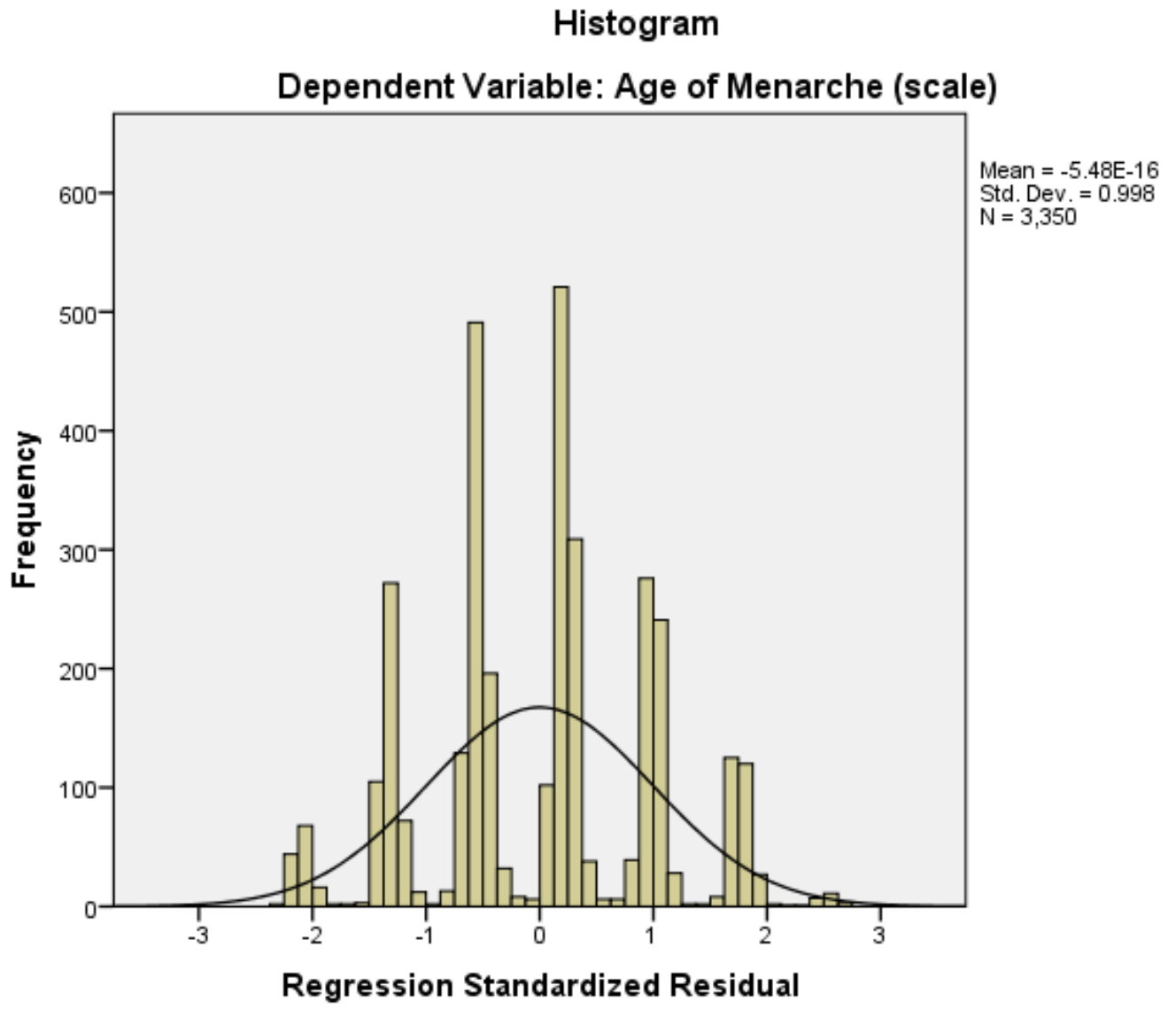

Figure A.7 Distribution of Residuals of Outcome 2A Age of Menarche 


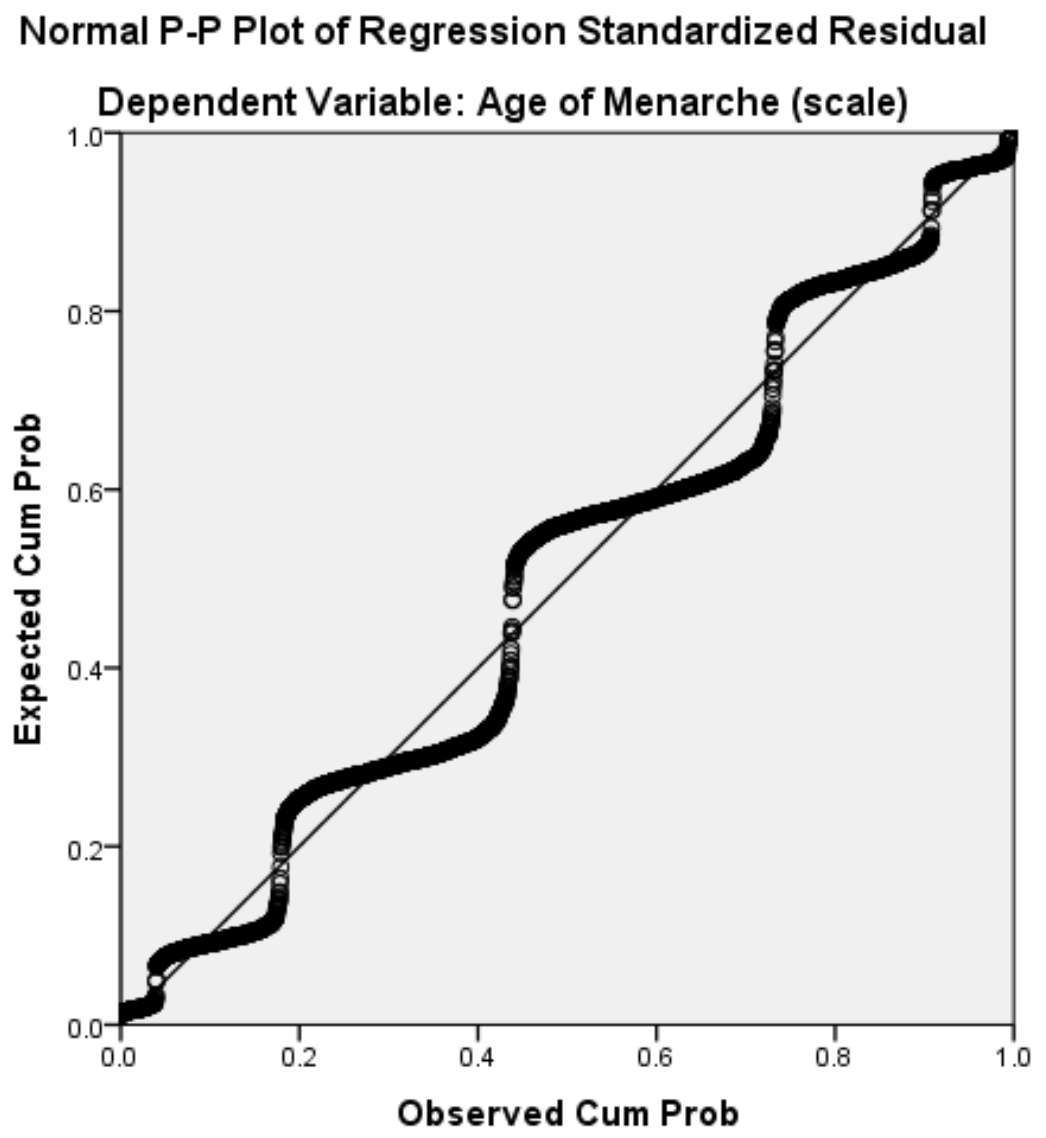

Figure A.8 P-P Plot of Outcome 2A Age of Menarche 


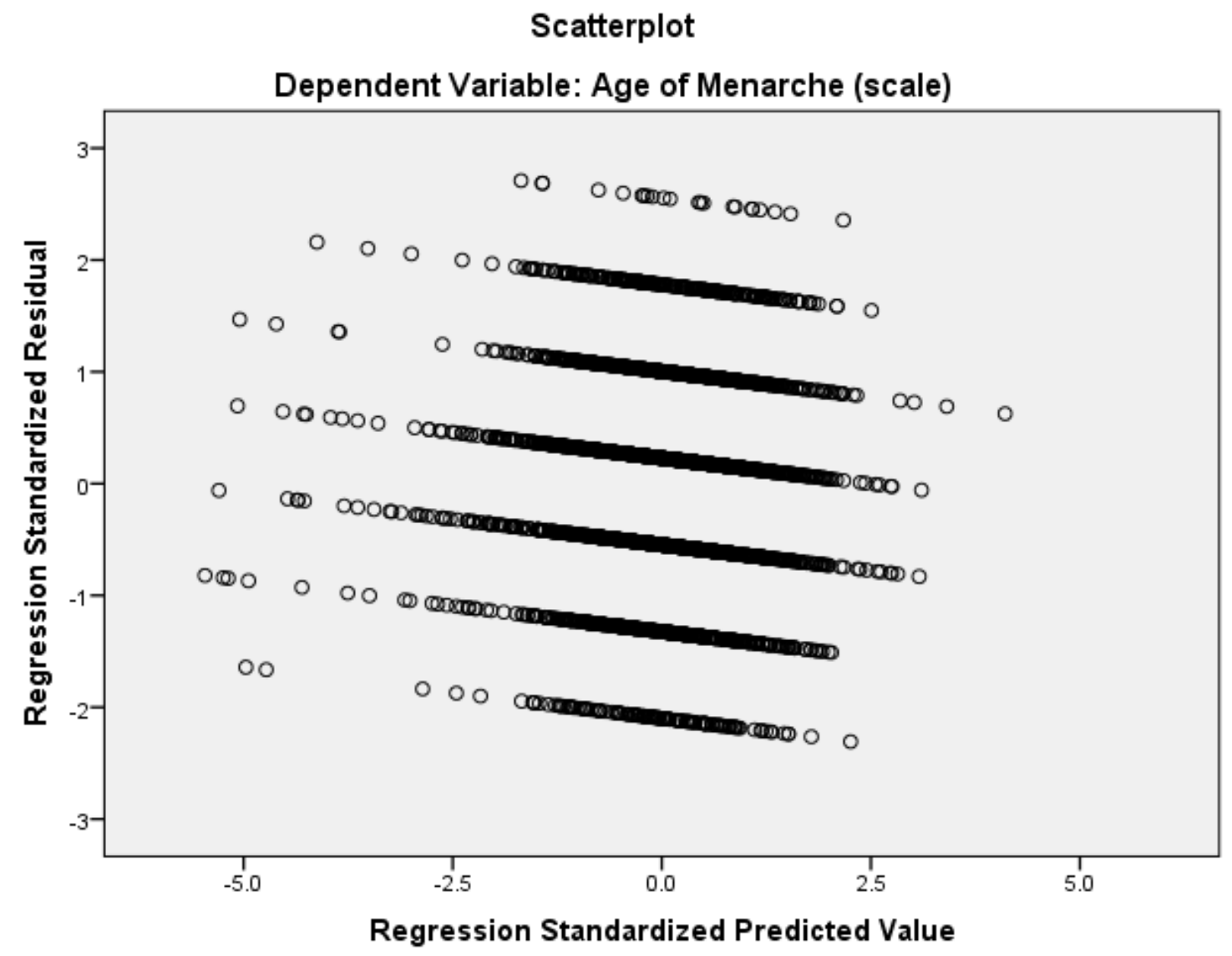

Figure A.9 Plot of Outcome 2A Age of Menarche 
Table A.11 Collinearity Statistics of Outcome 2B Total Number of Offspring

\begin{tabular}{|l|c|c|}
\hline \multirow{2}{*}{} & \multicolumn{2}{|c|}{$\begin{array}{c}\text { Collinearity } \\
\text { Statistics }\end{array}$} \\
\cline { 2 - 3 } & Tolerance & VIF \\
\hline Single vs Twin & 0.959 & 1.043 \\
\hline Sex of the Baby & 0.996 & 1.004 \\
\hline UK vs. Other Ethnicity & 0.960 & 1.041 \\
\hline UK vs. Ethnicity Not Reported & 0.993 & 1.007 \\
\hline Number of Children Older than Child & 0.588 & 1.700 \\
\hline Mother's Age at Completion of Education & 0.959 & 1.043 \\
\hline Persons Per Room Ratio & 0.735 & 1.361 \\
\hline Marital Status at Cohort Member's Birth & 0.930 & 1.075 \\
\hline Premarital Conception & 0.862 & 1.160 \\
\hline Mother's Age at Delivery & 0.719 & 1.391 \\
\hline $\begin{array}{l}\text { Non-Smoker vs Stopped Smoking } \\
\text { Pre-Pregnancy }\end{array}$ & 0.883 & 1.133 \\
\hline Non-Smoker vs Smoked During Pregnancy & 0.848 & 1.179 \\
\hline Never Breastfed vs. Breastfed < 3 month & 0.918 & 1.090 \\
\hline Never Breastfed vs. Breastfed >= 3 month & 0.896 & 1.116 \\
\hline Place of Delivery & 0.941 & 1.062 \\
\hline
\end{tabular}


Table A.12 Durbin-Watson for Independent Errors of Outcome 2B Total Number of Offspring

\author{
\begin{tabular}{|l|l|}
\hline Model & Durbin-Watson \\
\hline
\end{tabular}
}

1.976 


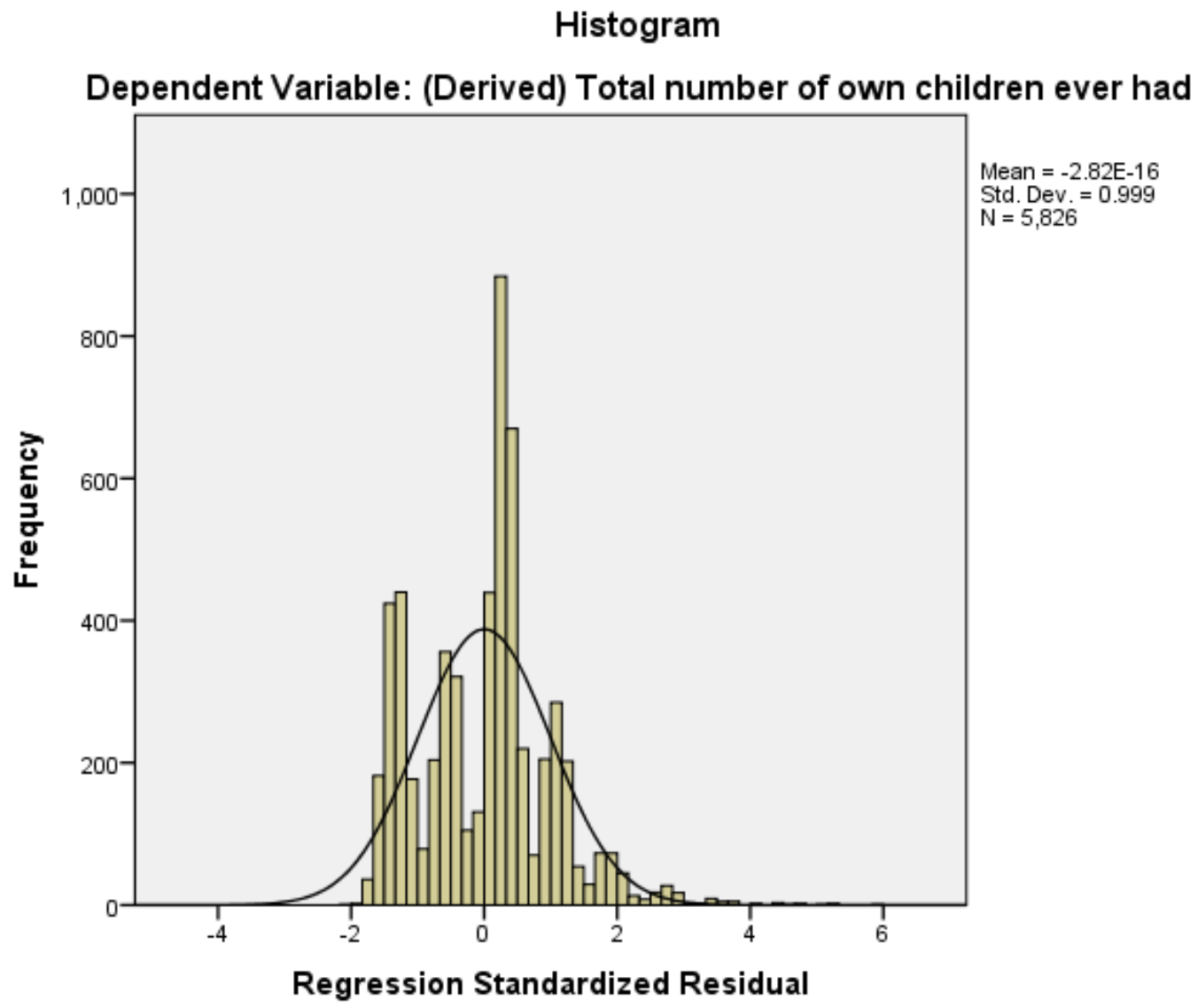

Figure A.10 Normal Distribution of Outcome 2B Total Number of Offspring 


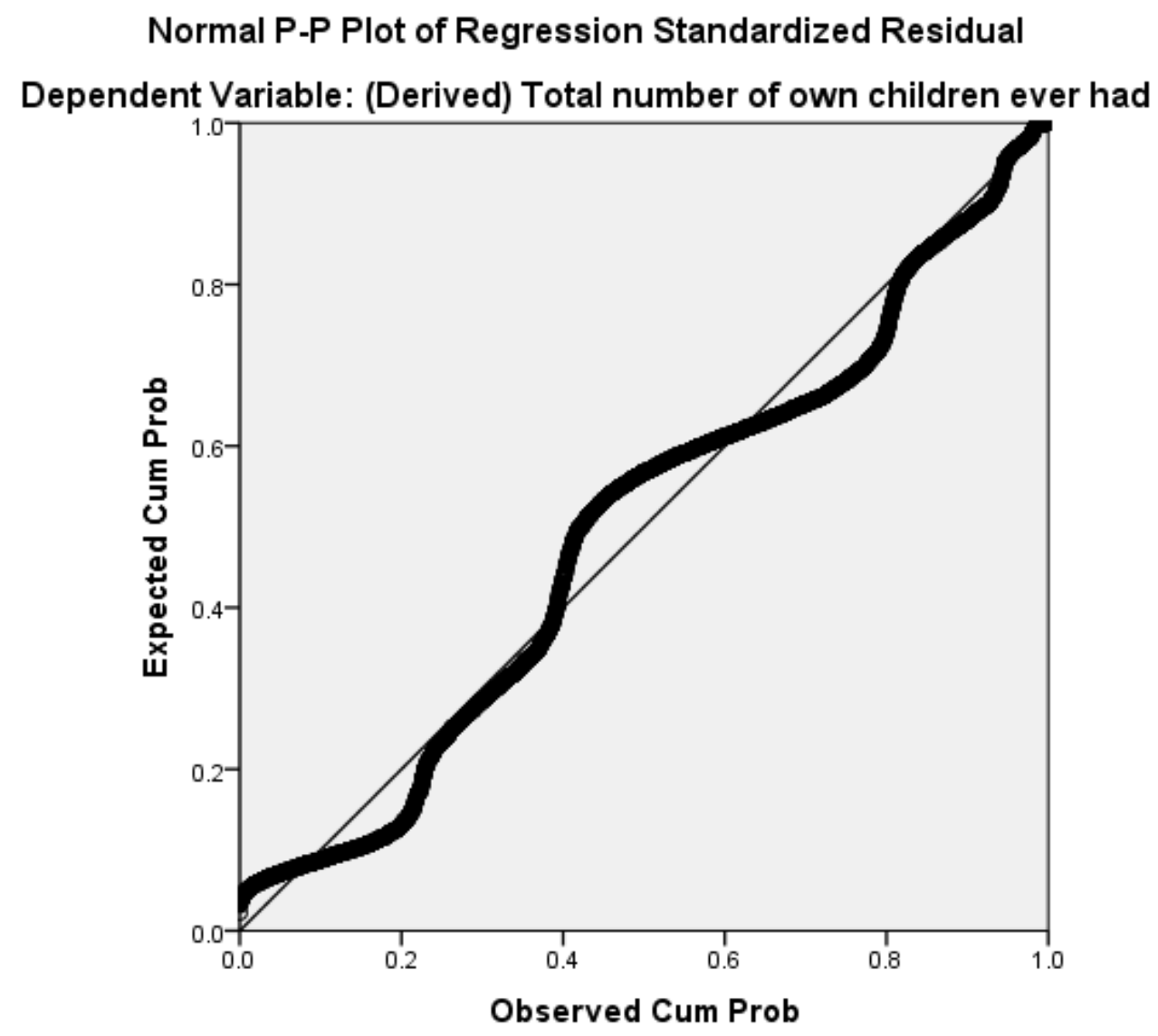

Figure A.11 P-P Plot of 2B Total Number of Offspring 


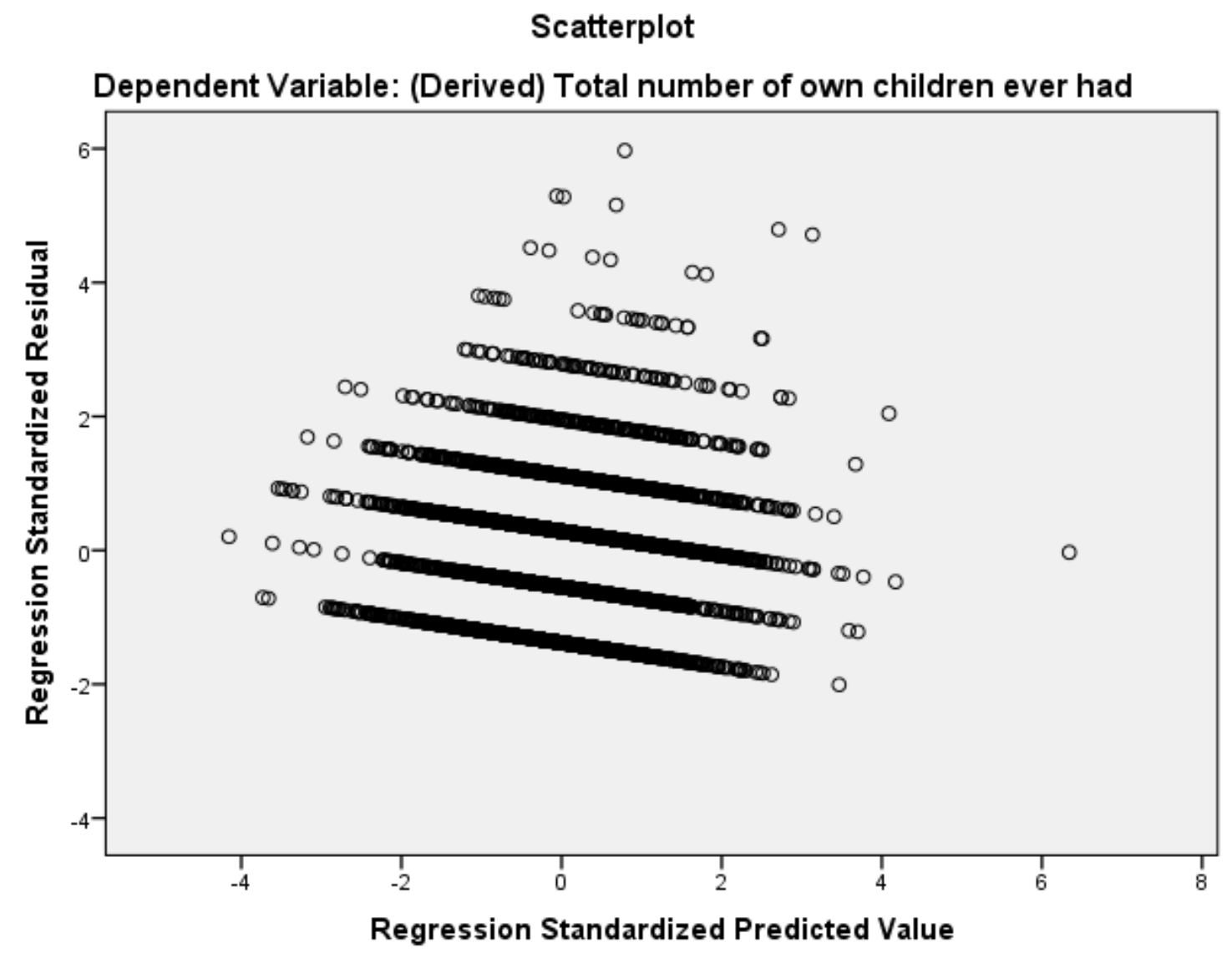

Figure A.12 Plot of Outcome 2B Total Number of Offspring 
Table A.13 Linearity of the Logit of Outcome 3A Depression

\begin{tabular}{|l|c|c|c|c|c|c|}
\hline & & & & & & \\
& B & S.E. & Wald & df & Sig. & Exp(B) \\
\hline $\begin{array}{l}\text { Number Of Children Older Than } \\
\text { Child }\end{array}$ & 0.047 & 0.102 & 0.216 & 1 & 0.642 & 1.048 \\
\hline $\begin{array}{l}\text { Mother's Age at Completion of } \\
\text { Education }\end{array}$ & 0.114 & 0.162 & 0.498 & 1 & 0.480 & 1.121 \\
\hline Persons Per Room Ratio & 0.102 & 0.554 & 0.034 & 1 & 0.855 & 1.107 \\
\hline Mother's Age at Delivery & 0.048 & 0.049 & 0.987 & 1 & 0.320 & 1.050 \\
\hline $\begin{array}{l}\text { Ln_Number of Children Older } \\
\text { than Child by Number of } \\
\text { Children Older than Child }\end{array}$ & -0.002 & 0.063 & 0.001 & 1 & 0.974 & 0.998 \\
\hline $\begin{array}{l}\text { Ln_Mother's Age Completion } \\
\text { Education by Mother's Age at } \\
\text { Completion of Education }\end{array}$ & -0.032 & 0.040 & 0.614 & 1 & 0.433 & 0.969 \\
\hline $\begin{array}{l}\text { Ln_Persons Per Room Ratio by } \\
\text { Persons Per Room Ratio }\end{array}$ & -0.029 & 0.418 & 0.005 & 1 & 0.944 & 0.971 \\
\hline $\begin{array}{l}\text { Ln_Mother's Age Delivery } \\
\text { Constant }\end{array}$ & -1.221 & 1.396 & 0.765 & 1 & 0.382 & 0.295 \\
\hline
\end{tabular}


Table A.14 Collinearity Statistics of Outcome 3A Depression

\begin{tabular}{|l|c|c|}
\hline \multirow{2}{*}{} & \multicolumn{2}{|c|}{$\begin{array}{c}\text { Collinearity } \\
\text { Statistics }\end{array}$} \\
\cline { 2 - 3 } & Tolerance & VIF \\
\hline Single vs Twin & 0.973 & 1.028 \\
\hline Sex of the Baby & 0.998 & 1.002 \\
\hline UK vs. Other Ethnicity & 0.958 & 1.044 \\
\hline UK vs. Ethnicity Not Reported & 0.994 & 1.006 \\
\hline Number Of Children Older Than Child & 0.592 & 1.689 \\
\hline Mother's Age at Completion of Education & 0.957 & 1.045 \\
\hline Persons Per Room Ratio & 0.710 & 1.408 \\
\hline Marital Status at Cohort Member Birth & 0.945 & 1.058 \\
\hline Premarital Conception & 0.861 & 1.162 \\
\hline Mother's Age at Delivery & 0.720 & 1.388 \\
\hline Non-Smoker vs Stopped Smoking & 0.881 & 1.135 \\
Pre-Pregnancy & & \\
\hline Non-Smoker vs Smoked During Pregnancy & 0.846 & 1.182 \\
\hline Never Breastfed vs. Breastfed <3 month & 0.925 & 1.082 \\
\hline Never Breastfed vs. Breastfed > = 3 month & 0.903 & 1.108 \\
\hline
\end{tabular}

